\title{
Revisiting Ionic Liquid Structure-Property Relationship: A Critical Analysis
}

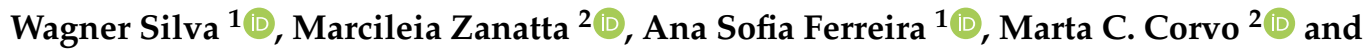 \\ Eurico J. Cabrita $1, *(D)$ \\ 1 UCIBIO, Chemistry Department, School of Science and Technology, NOVA University Lisbon, \\ 2829-516 Caparica, Portugal; wm.silva@campus.fct.unl.pt (W.S.); asd.ferreira@fct.unl.pt (A.S.F.) \\ 2 i3N|Cenimat, Materials Science Department, School of Science and Technology, NOVA University Lisbon, \\ 2829-516 Caparica, Portugal; m.zanatta@fct.unl.pt (M.Z.); marta.corvo@fct.unl.pt (M.C.C.) \\ * Correspondence: ejc@fct.unl.pt
}

Received: 2 October 2020; Accepted: 16 October 2020; Published: 19 October 2020

check for updates

\begin{abstract}
In the last few years, ionic liquids (ILs) have been the focus of extensive studies concerning the relationship between structure and properties and how this impacts their application. Despite a large number of studies, several topics remain controversial or not fully answered, such as: the existence of ion pairs, the concept of free volume and the effect of water and its implications in the modulation of ILs physicochemical properties. In this paper, we present a critical review of state-of-the-art literature regarding structure-property relationship of ILs, we re-examine analytical theories on the structure-property correlations and present new perspectives based on the existing data. The interrelation between transport properties (viscosity, diffusion, conductivity) of IL structure and free volume are analysed and discussed at a molecular level. In addition, we demonstrate how the analysis of microscopic features (particularly using NMR-derived data) can be used to explain and predict macroscopic properties, reaching new perspectives on the properties and application of ILs.
\end{abstract}

Keywords: ionic liquid; supramolecular organization; free volume; water; ion pair; physicochemical properties; transport properties

\section{Introduction}

Ionic Liquids (ILs) are organic salts that melt commonly below $100^{\circ} \mathrm{C}$, therefore they are constituted entirely by charged species, usually an organic cation and an organic or inorganic anion. The extensive amount of possible combinations of known cations and anions $\left(10^{6}-10^{18}\right)$ [1], results in different and unique physicochemical properties such as high thermal stability, large electrochemical window and low vapor pressure. Because of these attractive properties, ILs have garnered industrial and scientific interest, see Figure 1 [2,3].

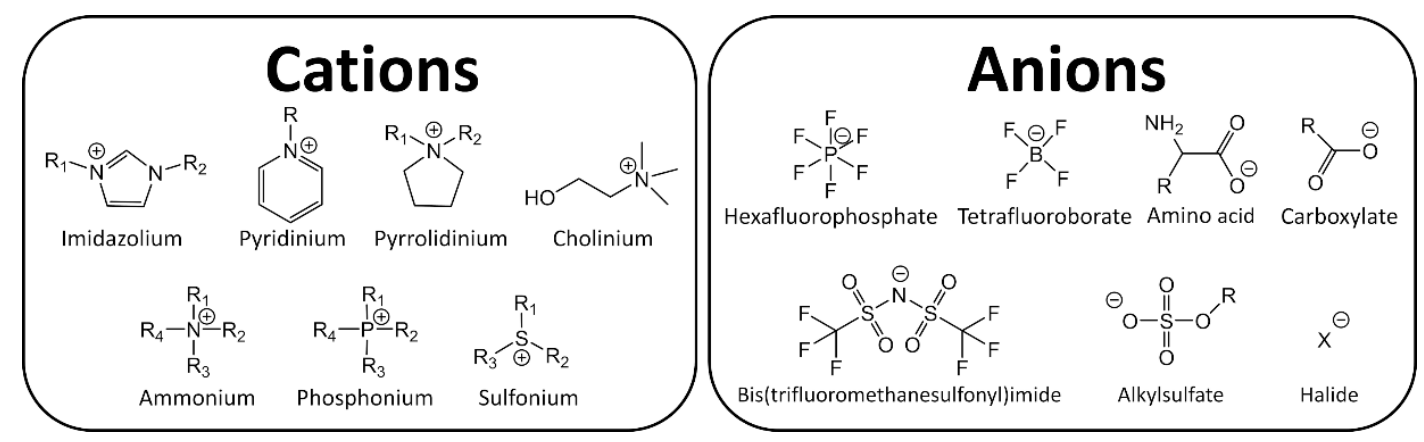

Figure 1. Typical ions in ionic liquids (ILs). 
The tunability and versatility of ILs have given rise to several applications such as solvents for synthesis and catalysis $[4,5] \mathrm{CO}_{2}$ capture and storage [6-8] energy generation and storage [9], extraction/dissolution of biomass [10,11], and active pharmaceutical ingredients [12,13].

ILs are normally divided into two classes: aprotic ionic liquids (APILs) and protic ionic liquids (PILs). PILs are formed by the transfer of protons from Brønsted acid to Brønsted base, this proton transfer does not take place in AILS due to the nature of the ions constituting the salt. PILs are generally prepared through a neutralization reaction and APILs by a quaternization reaction followed by anion exchange, Figure $2[14,15]$.

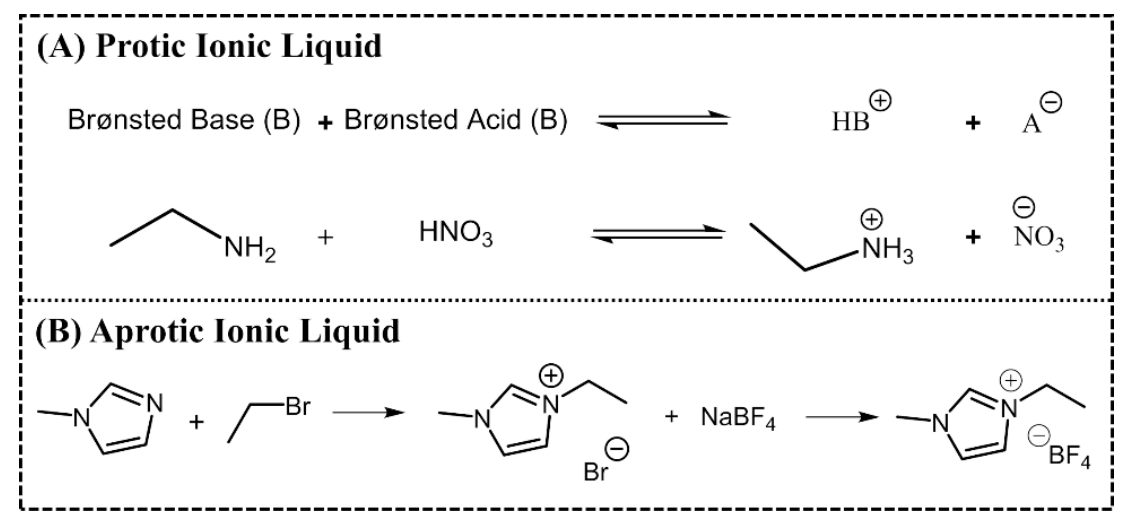

Figure 2. Typical synthetic route of a protic ionic liquid (PIL) (A) ethylammonium nitrate and an APIL

(B) 1-ethyl-3-methylimidazolium tetrafluoroborate.

The first IL reported in the literature is a controversial matter. Most authors state that the history starts with Paul Walden's discovery in 1914 with the report of ethylammonium nitrate ([EtNH 3$\left.]\left[\mathrm{NO}_{3}\right]\right)$ synthesis, see Figure 3 [16]; however, some authors attribute the first IL to Gabriel and Weiner in 1888 [17], with the synthesis of ethanolammonium nitrate. This confusion arises from the reported melting point, while Walden's compound was characterized with a melting point of $13-14{ }^{\circ} \mathrm{C}$, Gabriel's compound exhibited a melting point of $50^{\circ} \mathrm{C}$, substantially higher than room temperature. These works marked the beginning of the First Generation of ILs. Cations of the first generation of ILs are characterized by large volumes, such as 1,3-dialkyl-imidazolium or 1-alkylpyridinium and anions based mostly on halogen aluminate $\left(\mathrm{Al}^{+3}\right)[1,18]$. The disadvantage of this generation was the instability in relation to air and water.

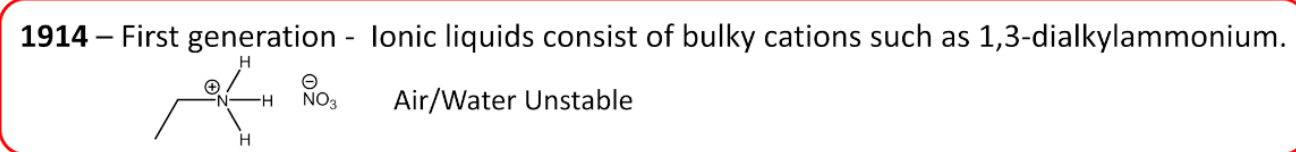

1992 - Second Generation - Air and water stable 1-ethyl-3-methylimidazolium based ILs.

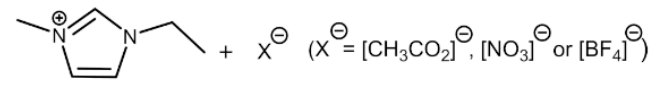

2000 - Third-generation - "Task-specific" ILs. Targeted biological properties combined with chosen physical chemical properties.

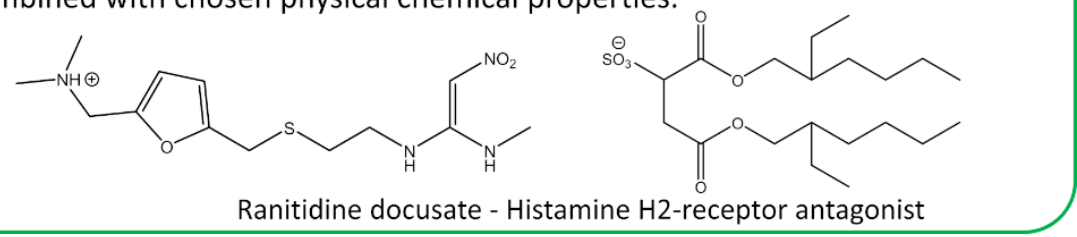

Figure 3. Generations of ILs through time. 
The introduction of the Second Generation of ILs comes with the preparation of air and water stable ILs, reported in 1992 by Wilkes and Zaworotko [19], based on the 1-ethyl-3-methylimidazolium cation and alternative anions, $\left[\mathrm{CH}_{3} \mathrm{CO}_{2}\right]^{-},\left[\mathrm{NO}_{3}\right]^{-}$and $\left[\mathrm{BF}_{4}\right]^{-}$, see Figure 3. ILs from the second generation are much easier to handle than those of the first generation. It was due to this fact and their particular properties, that IL-based research has become one of the major scientific topics over the last 25 years [20].

During the first decade after the publication of Wilkes and Zaworotko [19], solid scientific background was built on the subject of ILs and specific applications started to be targeted. In Ann Visser's paper, a series of functionalized imidazolium-based ILs was synthesized to extract heavy metals, $\mathrm{Hg}^{+2}$ and $\mathrm{Cd}^{+2}$ from aqueous solutions [21,22], and the terminology "Task-Specific" was introduced in connection to IL applications. Tuneable physical and chemical properties according to the desired application are what defines the Third Generation of ILs, see Figure 3. Among these properties, rationally selected biological action is already a reality, as evidenced by Hough's review [23] where several ILs candidates were used as Active Pharmaceutical Ingredients (API) or precursors.

As ILs applications matured, a detailed understanding and predictive capabilities towards their thermophysical properties have become progressively more important.

Since the introduction of the second generation of ILs, this class of compounds was brought to trend topics in the scientific world, and several works correlating structure and properties have been published. However, many issues are still the subject of intensive investigation, such as the existence of ion pairs, the definition of ionicity, the structuring of water inside the ILs and the mechanism of diffusion, and mainly the relationship between the free volume and transport properties. Therefore, this review presents a rationalization of IL properties starting from the classical chemical structure-property relationship generally described in the literature, followed by a detailed discussion analysing the reasons for their properties, starting from the smaller scale towards higher degrees of complexity, i.e., going from the microstructures to higher organized aggregates and solvent effect. The physicochemical properties of the second generation of ILs are revised and correlated to free volume theory for the first time. In addition, the application of NMR to determine these properties is highlighted.

\section{Structure-Property Relationships}

The widespread application of ILs has motivated the need for a detailed understanding of these materials, to rationalize and predict their behaviour. Their tunability reinforces the necessity for a predictive capability towards their thermophysical properties and motivates the efforts to resolve the molecular-scale details of structure, dynamics, and interactions in ILs. Several reviews on structure-property relationships for ILs fundamental thermal and physicochemical bulk properties can be found in the literature [24-27]. The predictive methodologies generically consider either empirical or theoretical approaches for representing properties such as density, surface tension, sound velocity, heat capacity, melting points, and electrical conductivity [28-31].

Empirical approaches correlate IL properties with their respective structure. Among the transport properties of ILs, viscosity is one of the most studied because of its importance to electrochemical and separating applications. IL viscosities usually vary between 20 and 40,000 cP, which is 1 order of magnitude higher than that of conventional solvents, such as water, with a viscosity of $\sim 1 \mathrm{cP}$. A general trend is that the viscosity decreases with the increasing size of ions, with a greater dependence on the anion. For cations, the viscosity increases with the increasing length of the alkyl chains partially due to stronger van der Waals (VDW) interactions. A relationship between the viscosity and the symmetry of the cations was also disclosed, with asymmetric cations exhibiting linear correlations opposing the small and symmetric cations. Besides the size and shape of ions, viscosity is also closely related to intermolecular interactions. High interaction energy, due to electrostatic forces and VDW interactions between anion and cation, leads to higher viscosity. Additionally, viscosity also correlates with ion stacking caused by hydrogen bonding, with smaller interactions leading to lower viscosity, and with the delocalization of the charge on the anion that weakens the hydrogen bond, and consequently 
decreases the viscosity. Conductivity is also frequently studied and lays within the range of $0.1-30 \mathrm{~m} . \mathrm{S}$ $\mathrm{cm}^{-1}$. At low temperatures, the structures of cations and anions influence the conductivity of ILs. The conductivity usually decreases with the increasing length of alkyl chains of cations, and the anions have a more significant effect on the conductivity, with a higher influence of the charge distribution and the number of charge carriers [32].

The group led by Watanabe from Yokohama National University [33-36], published a series of articles with some of the first correlations between IL structure and properties. These publications highlighted the relationship between the ionic diffusivity, viscosity, and molar conductivity for different cationic and anionic structures. The first publication in 2004 [33] reports the study of the 1-butyl-3-methylimidazolium $\left(\left[\mathrm{C}_{4} \mathrm{mim}\right]^{+}\right)$cation with different fluorinated anions $\left(\left[\mathrm{NTF}_{2}\right]^{-},\left[\mathrm{OTF}^{-}\right.\right.$, $\left.\left[\mathrm{PF}_{6}\right]^{-},\left[\mathrm{CF}_{3} \mathrm{CO}_{2}\right]^{-},\left[\mathrm{BF}_{4}\right]^{-}\right)$. Through self-diffusion and conductivity experiments, it was found that the high rate of ions contributing to the ionic conductivity within the diffusion component is related to the poor interaction of the anion with the cation. The electronegative fluorine atoms and perfluorosulfonyl groups in the anion contribute to the distribution of the anionic charge in phosphate, borate and imide, respectively. This study concerned only anion effects. In this way, diffusive species in the IL that contribute to the ionic conduction depend only on the anion character. With these results, it is evident that the size, shape and geometry of the anion determine the strength of the electrostatic interaction between the cation and the anion (Figure 4). Moreover, the proximity between the ions also enables hydrogen bonds between the fluorine atoms of the anion and the cation protons. These factors justify the higher viscosity and lower conductivity observed for $\left[\mathrm{C}_{4} \mathrm{mim}\right]\left[\mathrm{PF}_{6}\right]$.
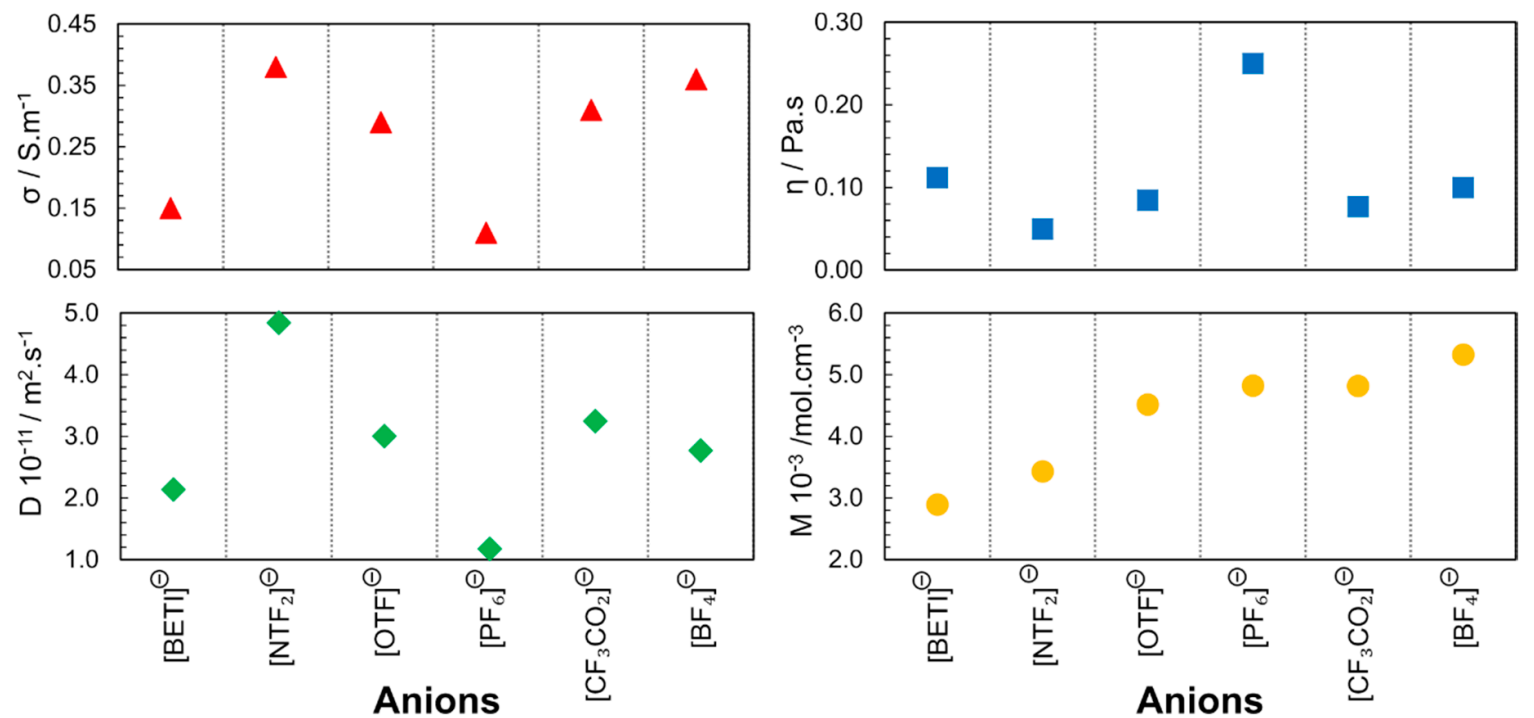

Figure 4. Anion dependence of electrical conductivity $(\sigma)$, viscosity $(\eta)$, self-diffusion $(D)$ and molar concentration $(M)$ for $\left[\mathrm{C}_{4} \mathrm{mim}\right][\mathrm{X}]$ at $298 \mathrm{~K}$ and $0.1 \mathrm{MPa}$. The diffusion coefficient presented is the result of the sum of cation and anion self-diffusion. Image created using data published in references $[33,36]$.

In 2005, another publication focused on the cation structure, where the alkyl chain length of 1-alkyl-3-methylimidazolium bis(trifluoromethane sulfonyl)imide $\left(\left[\mathrm{C}_{n} \operatorname{mim}\right]\left[\mathrm{NTF}_{2}\right]\right)$ was varied $(n=1$, $2,4,6,8)$ to study the ILs properties over a wide temperature range [34]. The increase in the alkyl chain length was found to cause changes in the interaction forces (VDW). The properties of the ILs were determined by the cumulative effect of the electrostatic interaction between the ionic species and the induction interactions between the ions, aggregates, and clusters (Figure 5). Among the studied ILs, $\left[\mathrm{C}_{2} \mathrm{mim}\right]\left[\mathrm{NTF}_{2}\right]$ had the highest diffusivity and electrical conductivity and also the lowest viscosity at $298 \mathrm{~K}$ and $0.1 \mathrm{MPa}$. 

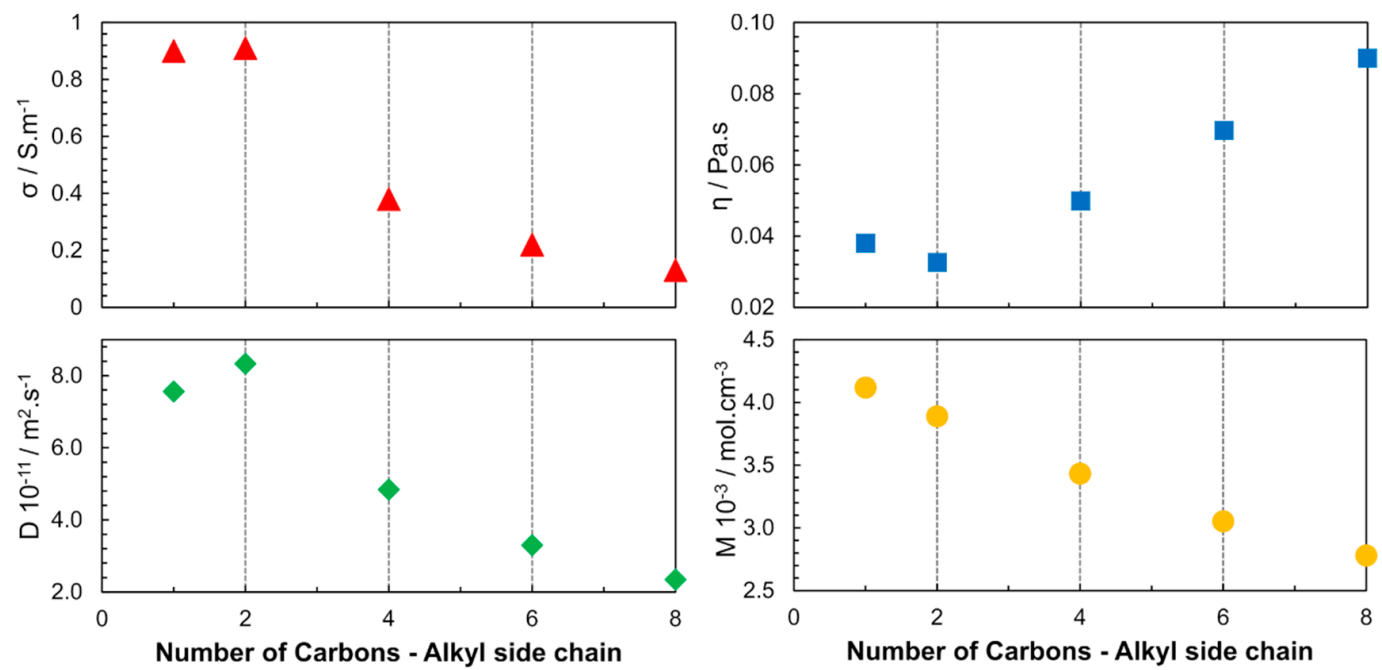

Figure 5. Alkyl-chain-length dependence of viscosity $(\eta)$, electrical conductivity $(\sigma)$, self-diffusion (D) and molar concentration (M) for $\left[\mathrm{C}_{\mathrm{n}} \mathrm{mim}\right]\left[\mathrm{NTF}_{2}\right]$ at $298 \mathrm{~K}$ and $0.1 \mathrm{MPa}$. The diffusion coefficient presented is the result of the sum of cation and anion self-diffusion. Image created using data published in references [34,36].

In 2006, different classes of cations were studied using 1-butyl-3-methylimidazolium $\left(\left[\mathrm{C}_{4}\right.\right.$ mim $\left.]\right), N$-butylpyridinium ([bpy]), N-butyl- $N$-methylpyrrolidinium $\left(\left[\mathrm{C}_{4} \mathrm{mpyr}\right]^{+}\right)$and $N$-butyl- $N, N, N$,-trimethylammonium $\left(\left[\mathrm{C}_{4} \mathrm{NMe}_{3}\right]^{+}\right)$combined with [ $\left.\mathrm{NTF}_{2}\right]^{-}$anions [35]. As depicted in Figure 6, the molar concentrations ( $\boldsymbol{M}$ in mol. $\mathrm{L}^{-1}$; in neat ILs, the molar concentration can be obtained by the ratio between density and molar mass of pure IL) of the studied ILs are close, leading to the conclusion that the steric hindrance is another factor that determines the properties of the ILs, not only due to the geometry but also due to the rotational dynamics of the substituents in the cationic families. Accessibility to the charged center (region with the higher charge density) determines the strength of the interaction between the cation and the anion. In these results, also implicit is the dependence of the physicochemical properties from the molecular dynamics; the speed of molecular rotation and the rotation of its functional groups is a factor that determines the proximity of the neighbouring species. The following order was found for the diffusion coefficient and conductivity: $\left[\mathrm{C}_{4} \mathrm{mim}\right]^{+}>[\mathrm{bpy}]^{+}>$ $\left[\mathrm{C}_{4} \mathrm{mpyr}\right]^{+}>\left[\mathrm{C}_{4} \mathrm{NMe}_{3}\right]^{+}$.
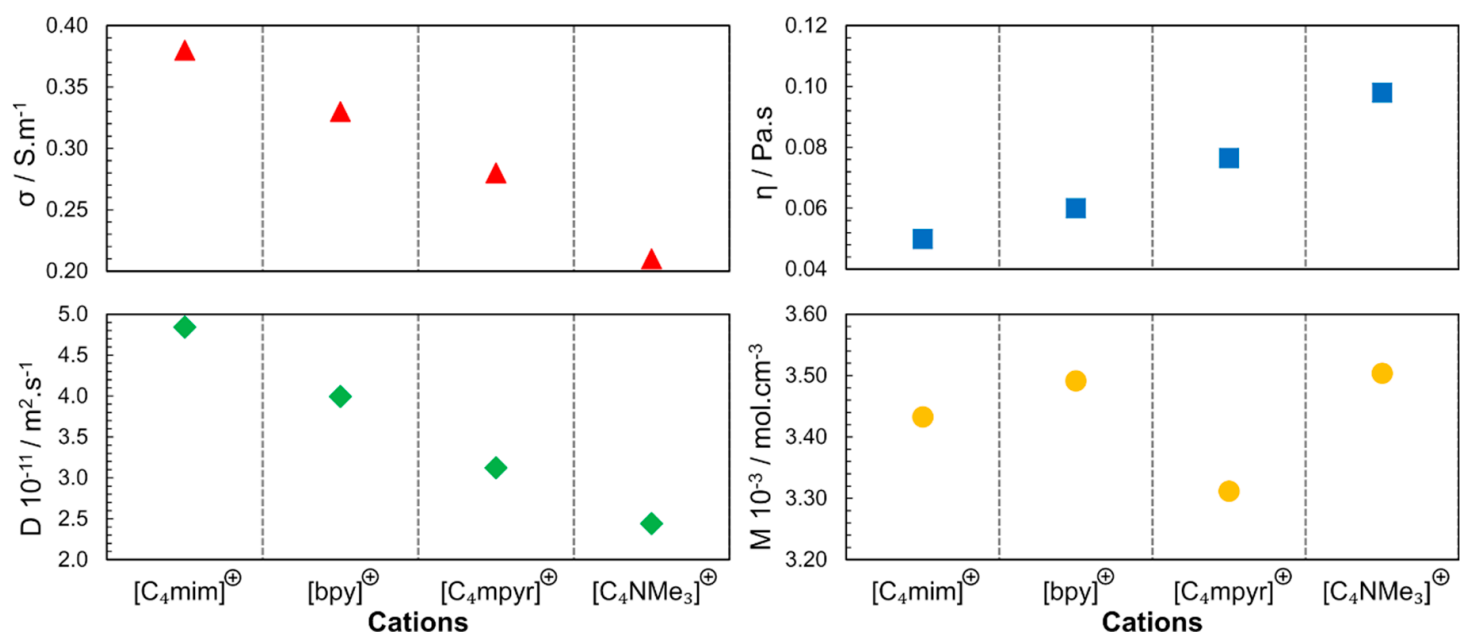

Figure 6. Cation dependence of viscosity $(\eta)$, electrical conductivity $(\sigma)$, self-diffusion $(D)$ and molar concentration $(M)$ for $\left[\mathrm{NTF}_{2}\right]^{-}$-based ILs at $298 \mathrm{~K}$ and $0.1 \mathrm{MPa}$. The diffusion coefficient presented is the result of the sum of cation and anion self-diffusion. Image created using data published in references [35-37]. 
The nature of the ionic species (size, shape, geometry, molecular dynamics and mass) and the interactions (cation-cation, cation-anion, anion-anion) that take place between them determine the macroscopic properties of the bulk ILs, that is, to understand the physical properties such as viscosity, density, electrical conductivity, surface tension, refractive index, melting point, among others it is necessary to look at the (sub) microscopic level.

\section{Structural Organization}

The local nanostructural organization and the physicochemical properties of ILs are directly related to intermolecular interactions present in the system. The non-directional (coulombic) interactions lead to a more isotropic distribution of ionic species and the directional interactions (Van der Waals and hydrogen bonding) to an anisotropic distribution. An intermolecular interaction study based on Density Functional Theory (DFT) using $\left[\mathrm{C}_{2} \mathrm{mim}\right]\left[\mathrm{BF}_{4}\right]$ and $\left[\mathrm{C}_{4} \mathrm{mim}\right]\left[\mathrm{PF}_{6}\right]$ ILs demonstrated that the Coulombic Force contributes with $70 \%$ of total energy, which indicates that the other interactions, like hydrogen bonding, $\pi-\pi$ stacking and dispersion interactions, should also affect significantly the physicochemical properties [38,39]. Recently, a thorough review focused on understanding heterogeneous microstructures and dynamics of ILs in bulk liquids, in mixtures with cosolvents, and in interfacial regions was published highlighting the importance of the interplay among the intra- and intermolecular interactions [40].

Cationic species based on imidazolium $\left(\left[\mathrm{C}_{\mathrm{n}} \mathrm{mim}\right]^{+}\right)$structures present polar (imidazole ring) and nonpolar (alkyl chain) domains. One of the first reports on the presence of nanosegregated domains in ILs associated the aggregation behaviour to the cation's side-chain length by multiscale coarse-graining method [41] a heterogeneity order parameter concept that quantifies the geometric heterogeneity in IL was later introduced [42-44]. Since then, molecular dynamics (MD) simulation and X-ray analysis of imidazolium ILs (ImIL) have been extensively used to observe the nanoscale IL structure, indicating a sophisticated special organization in the polar domain with a 3D network of ionic channels. This supramolecular organization remains practically unchanged in the solid and liquid phase [45-52]. Structural heterogeneity is observed with increased alkyl chain size as a consequence of the segregation of non-polar domains (Figure 7); the electrostatic interactions between charged sites assist the formation of polar domains and the uncharged groups are driven out of this region [25,45].

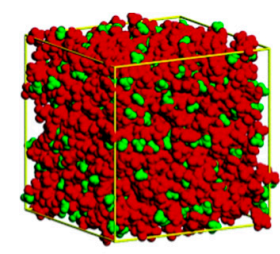

(a)

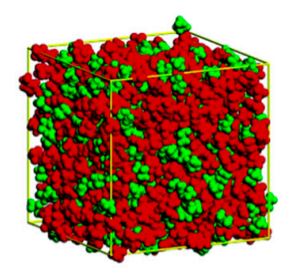

(b)

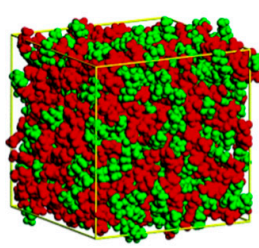

(c)

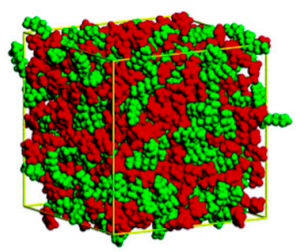

(d)

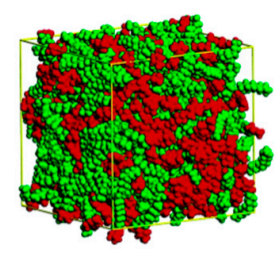

(e)

Figure 7. Snapshots of simulation boxes of $\left[\mathrm{C}_{n} \operatorname{mim}\right]\left[\mathrm{PF}_{6}\right]$. Red=polar and green $=$ nonpolar. (a) $\left[\mathrm{C}_{2} \mathrm{mim}\right]\left[\mathrm{PF}_{6}\right] ;(\mathbf{b})\left[\mathrm{C}_{4} \mathrm{mim}\right]\left[\mathrm{PF}_{6}\right] ;(\mathbf{c})\left[\mathrm{C}_{6} \mathrm{mim}\right]\left[\mathrm{PF}_{6}\right] ;(\mathbf{d})\left[\mathrm{C}_{8} \mathrm{mim}\right]\left[\mathrm{PF}_{6}\right]$ and $(\mathbf{e})\left[\mathrm{C}_{12} \mathrm{mim}\right]\left[\mathrm{PF}_{6}\right]$. Figure adapted from [45].

The main structure of ImILs can be described as a supramolecular polymeric network of intermolecular interactions that determine the interionic distances and consequently the existence of ion pairs and/or aggregates and free volume.

\subsection{Ion Pairs}

The concept of IP in ILs has been discussed and revised many times in the literature; for this reason, it will be only succinctly explored here.

The phenomenon of ion pair formation is of fundamental importance for different application fields, such as: (i) catalysis—due to its influence on reaction rates or transfer of chirality [53,54]; (ii) $\mathrm{CO}_{2}$ 
capture-being decisive on sorption mechanism [55,56]; (iii) ion pair chromatography or selective ion electrodes [57,58]. Since ILs are composed entirely of ions, a higher value of conductivity is expected. However, through experimental data, a smaller conductivity of the neat IL, when compared with diluted systems, has been reported [59-62]. This phenomenon has been interpreted as an indication of the existence of ion-pairing [63], transfer of charge [64] or the formation of small clusters of ions [65]. Marcus and Hefter defined ion pairing as:" ... (partial) association of oppositely charged ions in electrolyte solutions to form distinct chemical species called ion pairs" [63].

To evaluate the conductivity and understand how ionic an IL is, the concept of ionicity (I) was proposed by Watanabe and co-workers [33-36,66]. For this purpose, the molar conductivity ratio $\left(\frac{\Lambda_{i m p}}{\Lambda_{\text {NMR }}}\right)$ of an IL is used as a measure of the ionicity: $I=\frac{\Lambda_{i m p}}{\Lambda_{N M R}} . \Lambda_{i m p}$ is the ionic conductivity measured by the electrochemical impedance method and $\Lambda_{N M R}$ is calculated from the self-diffusion coefficients of cations $\left(\mathrm{D}^{+}\right)$and anions $\left(\mathrm{D}^{-}\right)$, determined from pulse-field-gradient spin-echo (PGSE) NMR, using the Nernst-Einstein Equation (1).

$$
\Lambda_{N M R}=\frac{N_{A} * e^{2}}{k T}\left(D^{+}+D^{-}\right)
$$

where $N_{A}$ is the Avogadro number, $e$ is the electric charge on each ionic carrier, $k$ is the Boltzmann constant, and $T$ is the absolute temperature.

The molar conductivity ratio indicates the proportion of ions that contributes to ionic conduction from all the diffusing species and therefore can be used as a quantitative measure of ionicity.

Another important feature of ILs to be considered for a tailored application is their polarity. However, due to the difficulty of establishing a polarity scale for ILs the hydrogen-bond basicity ( $\beta$ ) (a Kamlet-Taft parameter) has been studied. To estimate the hydrogen-bonding interaction energy in the equimolar cation-anion mixture $\left(E_{\mathrm{HB}}\left(\mathrm{kJ} \cdot \mathrm{mol}^{-1}\right)\right.$, the COnductor-like Screening MOdel for Real Solvents (COSMO-RS) has been used for several ILs [67].

From a qualitative perspective, ionicity and hydrogen-bonding interaction energy should be related, since it is expected that ILs with a lower $E_{\mathrm{HB}}$ (stronger hydrogen-bonding interaction) have a lower ionicity.

The values of ionicity of some ILs reported by Ueno et al. [66] and the $E_{\mathrm{HB}}$ reported by Cláudio et al. [67] were compiled and organized in Figure 8. The analysis of the data clearly shows two trends, one for ILs with the same cation $\left[\mathrm{C}_{4} \mathrm{mim}\right][\mathrm{X}]\left(\mathrm{R}^{2} 0.97\right)$ and another for ILs with the same anion $\left[\mathrm{C}_{\mathrm{n}} \mathrm{mim}\right]\left[\mathrm{NTF}_{2}\right]\left(\mathrm{R}^{2} 0.93\right)$. For the first group, ionicity and $E_{\mathrm{HB}}$ are strongly correlated and ionicity increases with the decrease in the strength of the hydrogen-bonding interaction (higher $E_{\mathrm{HB}}$ ) that is being controlled by the nature of the anion. For the second group, an increase in ionicity can be observed with the decrease in the size of the imidazolium side chain, but the interaction energy $E_{\mathrm{HB}}$ remains almost unchanged. These observations indicate that ionicity is influenced by other factors than the strength of the interaction between cation and anion by hydrogen bonding. For the first group the ionicity sequence for the ILs studied follows the reported basicity scale, $\left[\mathrm{CF}_{3} \mathrm{CO}_{2}\right]^{-}>[\mathrm{OTF}]^{-}>\left[\mathrm{BF}_{4}\right]^{-}>$ $\left[\mathrm{NTF}_{2}\right]^{-}>\left[\mathrm{PF}_{6}\right]^{-}[67,68]$. For the same cation, the stronger the interaction with the corresponding anion by hydrogen bonding, the lower the ionicity. In the second group, the behaviour observed for ILs with the same anion could be correlated to the structural heterogeneity of ILs, which increases according to the size of the cation side chain, as shown in the MD simulations (Figure 7) [45]. Segregation of non-polar domains leads to aggregate formation, which reduces the conductivity and ionicity of ILs. 


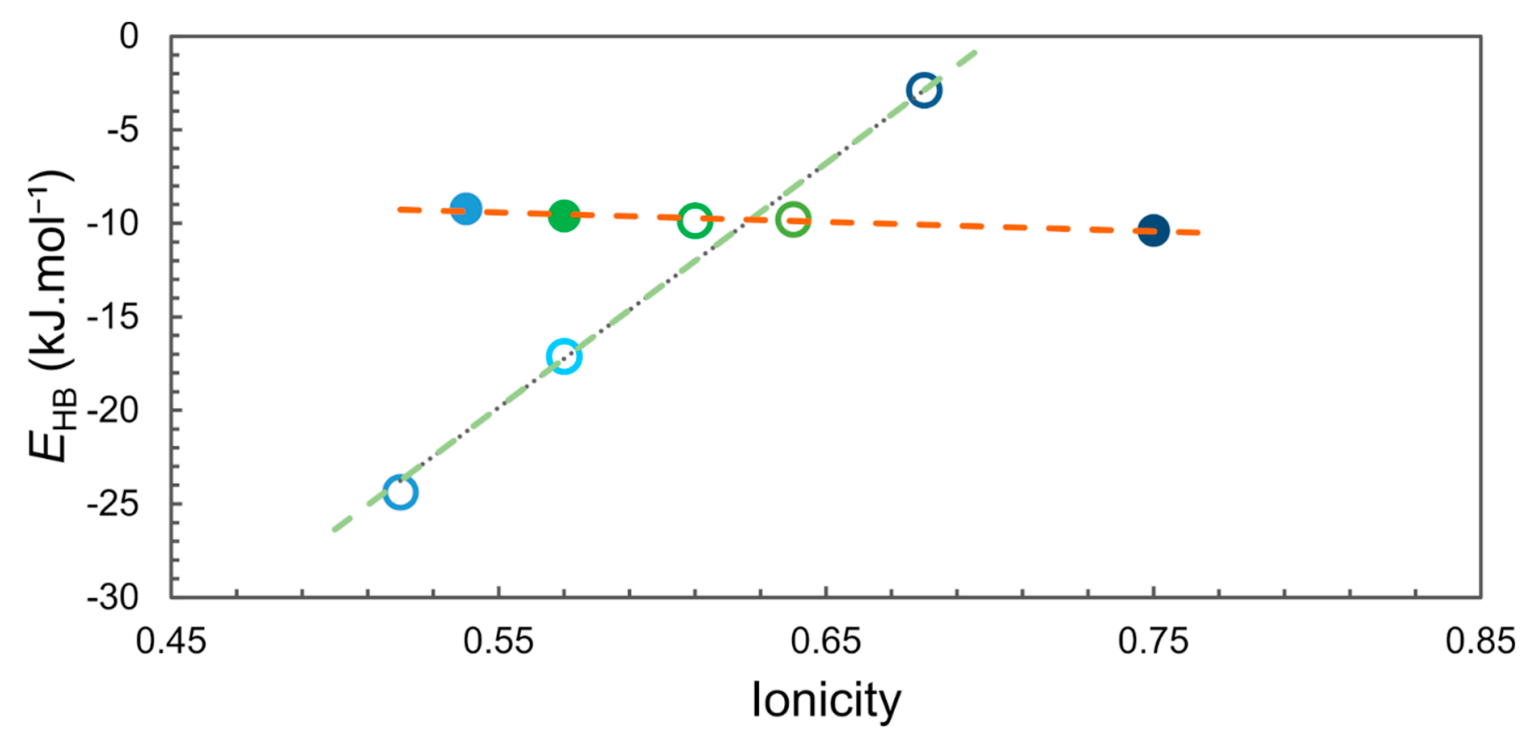

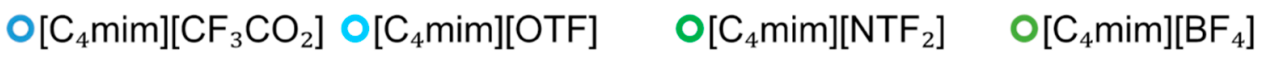

$$
\begin{aligned}
& O\left[\mathrm{C}_{4} \mathrm{mim}\right]\left[\mathrm{PF}_{6}\right] \quad \bullet\left[\mathrm { C } _ { 8 } \mathrm { mim } _ { [ } [ \mathrm { NTF } _ { 2 } ] \quad \bullet \left[\mathrm{C}_{6} \mathrm{mim}\left[\mathrm{NTF}_{2}\right] \quad \bullet\left[\mathrm{C}_{2} \mathrm{mim}\right]\left[\mathrm{NTF}_{2}\right]\right.\right.
\end{aligned}
$$

Figure 8. Ionicity $\left(\frac{\Lambda_{\text {imp }}}{\Lambda_{N M R}}\right)$ versus hydrogen-bonding interaction energy $\left(E_{\mathrm{HB}}\right)$. Ionicity data from Ueno et al. [66] and $E_{\mathrm{HB}}$ data from Cláudio et al. [67].

According to Equation (1), the ionicity data of Figure 8 show that not all the ions that are diffusing contribute to the conductivity, since generally, the values are non-integer and smaller than expected. To account for this the theory of ionicity in ILs was reformulated by Hollóczki et al. with the contribution of the Charge Transfer concept [64], closing a gap identified in the previous theory [66]. Considering that the value of the partial charge is a non-integer value, normally lower than expected due to the transfer of charges through hydrogen bonds, it has been estimated that the effective charge is reduced by a factor of \pm 0.8 , resulting in smaller conductivity $[64,66]$. Another possible explanation is that the concentration of "free" ions is reduced by the formation of ion pairs (neutral charge) or larger clusters leading to the reduction of conductivity [65].

For the existence of ion pairs to be responsible for changes in physicochemical properties, such as the conductivity, the ion pair must be long-lived enough to be detected, i.e., longer than the time required for thermal motion to cause the ions to move as separate species [63]. The lifetime of the ion pair can be determined through MD simulations and varies according to the choice of the reference distance used in the calculation, presenting values between nanoseconds to picoseconds [69-71]. Zhang and Maginn studied the lifetime of 29 ILs through MD [72]. They used a previously established definition of ion pair (IP) and ion cage (IC) $[63,65]$ (Figure 9), to quantify exchange between the counterions. IP can be defined as a partial association of oppositely charged ions to form distinct chemical species called IP (Figure 9a), whereas IC is formed by all the anions in the first solvation shell of a cation or vice versa, (Figure 9b). The authors also state that "the concept of a physical ion pair should not be taken too literally" [72]. From the figure it is possible to infer that: (a) At a given time $t_{0}$, an IP is defined by the anion (red) with the shortest distance from a central cation (blue) or vice versa. The dashed orange line represents the first IP contact. This IP remains formed at a later time $t_{1}$ until another counterion (purple) comes closer to the central ion at time $t_{2}$ as observed in Figure 9a. A similar observation can be made from Figure $9 \mathrm{~b}$ for IC structure: at a given time $t_{0}$, an IC is formed by all of the anions in the first solvation shell (dashed blue line) of a cation or vice versa. An IC remains formed later $\left(t_{1}\right)$ if no counterions leave or enter the first solvation shell. Otherwise, if either a counterion leaves (indicated in red) or a new counterion enters (indicated in purple), which happens at time $t_{2}$, the IC is considered broken. In addition, it is possible to punctuate that the $t_{1 I C}$ is larger than $t_{1 I P}$ [72]. 


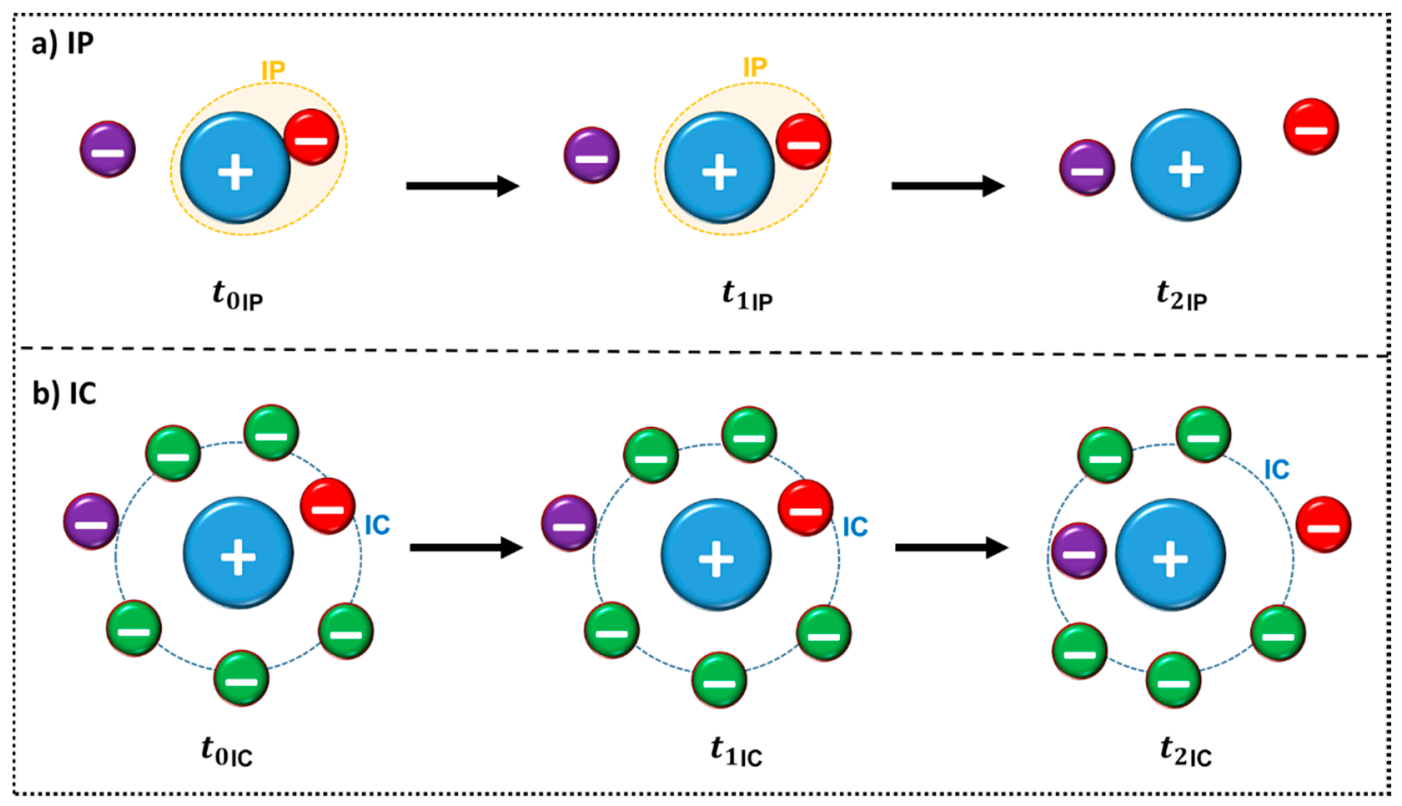

Figure 9. Schematic representation of the definition of an ion pair IP (a) and ion cage (IC) (b) adapted from reference [72]. The ion representations are merely illustrative, IL ions are not simple spheres, they have more complex shapes that assign directionality to specific regions of interaction.

Zhang et al. [72] reported a strong linear correlation that crosses the origin when plotting the average self-diffusivities $\left(D=\left(D^{+}+D^{-}\right) / 2\right)$ against the inverse of IP and IC lifetimes. Even more surprising, this correlation is independent of the temperature or nature of IL. In addition, the authors demonstrated that long lifetimes for a particular IL lead to low diffusivity and consequently high viscosity. This means that the transport properties are strongly influenced by the rate of formation/disruption of the IPs and ICs.

Kirchner and co-authors [69] defined that the existence of ion pairs should be considered only if the lifetime of the contact between the ions is long enough for the unit to travel (at least) the distance of its own size. Through MD simulations, no evidence of ion pair formation was found. The group explained that, since the contact between the ions occurs in a few picoseconds, this time is not enough for the unit to travel the distance of its own diameter. The authors pointed out that "ion pair" as a neutral entity is a misinterpretation. When the ions are close to each other, they used the terminology "ionic association" instead of "ion pair". Even with the discordance of ion-pair definition, a point of general accordance is that the structural organization and molecular dynamics of the ILs in solution depend on solution concentration and the nature of solvent [69]. The solvent can collaborate in the formation of ion pairs (or ionic association) or it can solvate the ions making it difficult for the ions to approach each other, Figure $10[73,74]$.

Despite the use of MD simulations, nuclear Overhauser effect (NOE) NMR spectroscopy has also been described as an alternative method for the systematic study of the interactions between ions in ILs systems. While the NOE correlation is normally used for studying local structure in liquids and solutions results from short-range effects $(d<5 \AA)$, Gabl et al. [75] have shown that in ILs this is not necessarily true. They have demonstrated that due to the high viscosity of IL systems, the experimental cross-relaxation rate giving rise to the NOE can give information on the mutual position of interacting species far beyond the first coordination shell. Therefore, the information provided by NOE analysis allows the observation of ion organization over longer distances rather than just the local structure [76,77]. 


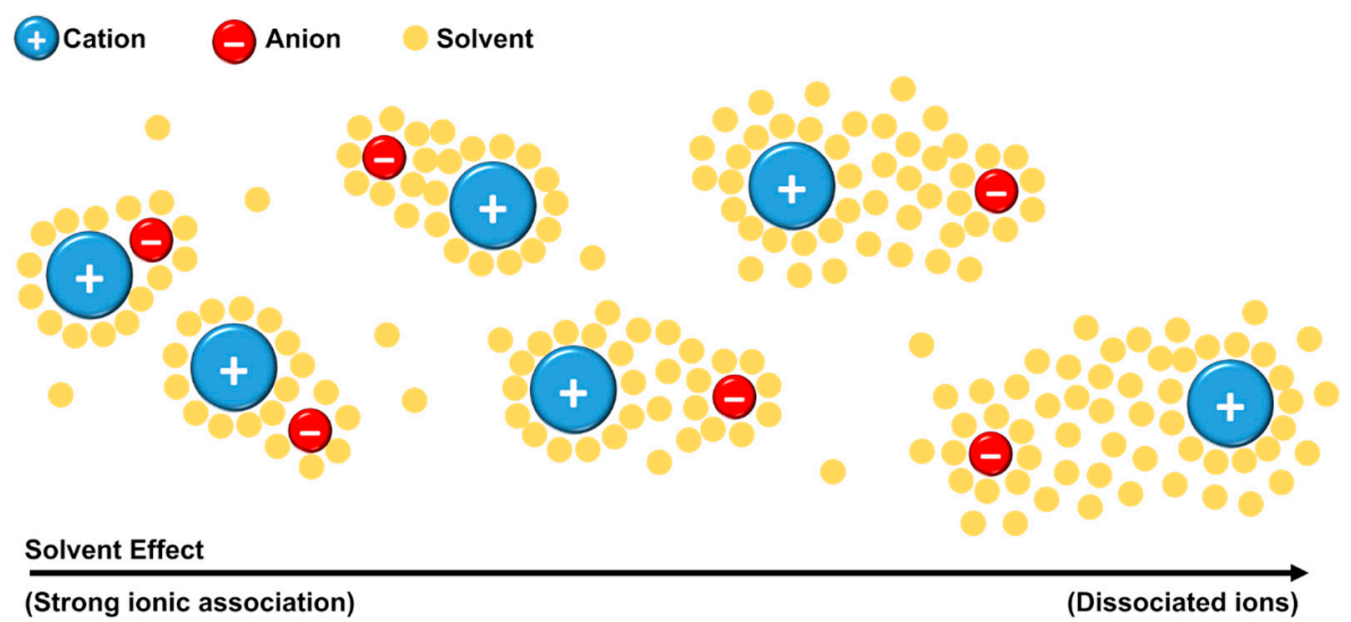

Figure 10. Schematic representation of a generic IL in solution-Effect of solvation shells on ionic association.

Hu et al. [78] have used DFT calculations with PCM (polarizable continuum model) to account for the effect of different solvents on the on the anion-cation and ion-solvent interactions. They found that the binding energies of the anion-cation obtained in solvents are quite different from that obtained in gas phase calculation, due to the remarkable solvation energy difference between the contacted ion pair and separated anion/cation. Their results give a theoretic reason why the anion-cation prefer to form contact ion pairs in solvents with low dielectric constant, whereas a high dielectric constant solvent has a great ability to separate the anion-cation.

In summary, ion-pairing in ILs, or more specifically, the lifetime of ion-pairing affects properties such as ionic conductivity and diffusivity, which will consequently affect the designed application.

\subsection{Free Volume}

\subsubsection{Free Volume Theory and Transport Properties}

The conductivity $(\sigma)$, viscosity $(\eta)$ and self-diffusion $(D)$ are the main transport properties of ILs (mass transport) and are critical aspects of the overall properties and applications. In ILs, the transport properties are determined by conditions such as temperature and pressure and the nature of its counterions, more precisely the calculated molecular volume of the ion pair $\left(V_{\text {IonPair }}\right)$ (Equation (2)), obtained by the sum of the molecular volume of each ion, cation $\left(V_{\text {ion }} C^{+}\right)$and anion $\left(V_{\text {ion }} A^{-}\right)$[79].

$$
V_{\text {IonPair }}=V_{\text {ion }}\left(C^{+}\right)+V_{\text {ion }}\left(A^{-}\right)
$$

Based on the free volume models of liquids, correlations between transport properties and molecular volume are qualitatively expected. In this context, Slattery et al. have shown a strong correlation of $V_{\text {IonPair }}($ Table 1) with viscosity and conductivity (Figure 11) [79]. The conductivity of these ILs decreases exponentially with increasing $V_{\text {IonPair }}(\mathrm{a})$ while the viscosity increases (b). The authors found three separated clusters in these correlations, according to the anion type: $\left[\mathrm{BF}_{4}\right]^{-}$and $\left[\mathrm{PF}_{6}\right]^{-}$; dicyanamide $[\mathrm{DCA}]^{-}$and $\left[\mathrm{NTF}_{2}\right]^{-}$, as observed in Figure 11 
Table 1. Molecular volume of ion pair ( $\left.\mathrm{V}_{\text {IonPair }}\right)$ of ILs separated by anionic group, data from Reference [79].

\begin{tabular}{|c|c|c|c|}
\hline Entry & [Anion] $]^{-}$Group & [Cation] $^{+}$ & $V_{\text {ionpair }}\left(\mathrm{nm}^{3}\right)^{[a]}$ \\
\hline 1 & \multirow{12}{*}[\mathrm{NTF}_{2}]{} & {$\left[\mathrm{C}_{2} \mathrm{mim}\right]$} & 0.388 \\
\hline 2 & & {$\left[\mathrm{C}_{3} \mathrm{mim}\right]$} & 0.410 \\
\hline 3 & & {$\left[\mathrm{C}_{4} \mathrm{mim}\right]$} & 0.428 \\
\hline 4 & & {$\left[\mathrm{C}_{5} \mathrm{mim}\right]$} & 0.451 \\
\hline 5 & & {$\left[\mathrm{C}_{4} \mathrm{mmim}\right]$} & 0.461 \\
\hline 6 & & {$\left[\mathrm{C}_{4} \mathrm{NMe}_{3}\right]$} & 0.430 \\
\hline 7 & & {$\left[\mathrm{C}_{4} \mathrm{mpyr}\right]$} & 0.453 \\
\hline 8 & & {$\left[\mathrm{C}_{5} \mathrm{mpyr}\right]$} & 0.470 \\
\hline 9 & & {$\left[\mathrm{C}_{5} \mathrm{NEt}_{3}\right]$} & 0.500 \\
\hline 10 & & {$\left[\mathrm{SEt}_{3}\right]$} & 0.409 \\
\hline 11 & & [bpy] & 0.430 \\
\hline 12 & & {$\left[\mathrm{MeSPh}_{2}\right]$} & 0.500 \\
\hline 13 & \multirow{3}{*}[\mathrm{BF}_{4}]{} & {$\left[\mathrm{C}_{4} \mathrm{mim}\right]$} & 0.269 \\
\hline 14 & & {$\left[\mathrm{C}_{6} \mathrm{mim}\right]$} & 0.315 \\
\hline 15 & & {$\left[\mathrm{C}_{8} \mathrm{mim}\right]$} & 0.361 \\
\hline 16 & \multirow{3}{*}[\mathrm{PF}_{6}]{} & {$\left[\mathrm{C}_{4} \mathrm{mim}\right]$} & 0.305 \\
\hline 17 & & {$\left[\mathrm{C}_{6} \mathrm{mim}\right]$} & 0.351 \\
\hline 18 & & {$\left[\mathrm{C}_{8} \mathrm{mim}\right]$} & 0.397 \\
\hline 19 & \multirow{3}{*}{ [DCA] } & {$\left[\mathrm{C}_{2} \mathrm{mim}\right]$} & 0.240 \\
\hline 20 & & {$\left[\mathrm{C}_{4} \mathrm{mim}\right]$} & 0.267 \\
\hline 21 & & {$\left[\mathrm{C}_{4} \mathrm{mpyr}\right]$} & 0.295 \\
\hline
\end{tabular}

[a] The ionic volume was determined from crystal structures containing the ion of interest in combination with a reference ion of known volume.
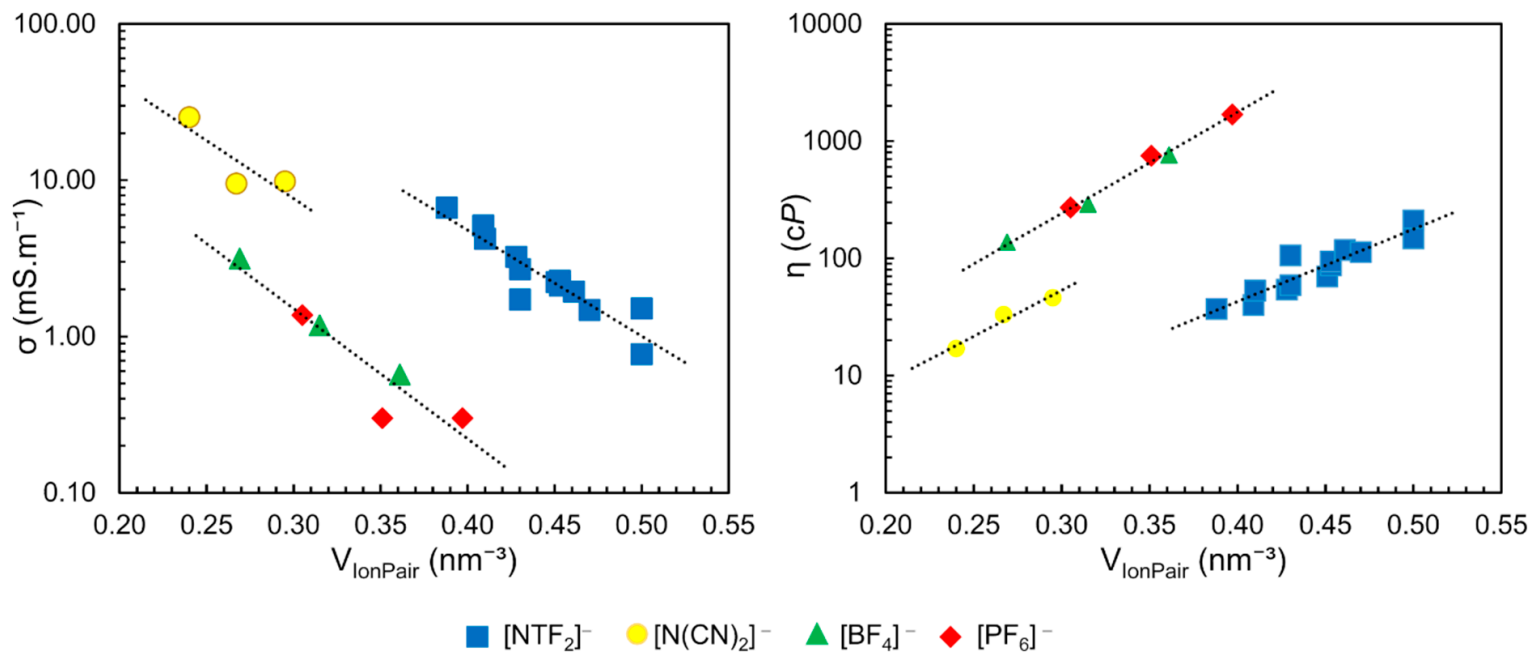

Figure 11. Conductivity and viscosity dependence of molecular volume of ion pairs for ILs present in Table 1 . Conductivity acquired at $295 \mathrm{~K}$ and viscosity at $294 \mathrm{~K}$. Each dotted line represents the correlation for a different group of IL with same anion nature. Figure adapted from reference [79].

Similar dependence was observed between the density $(\rho)$ and the nature of the anion. In the same work, the authors demonstrated a relationship between the molar concentration (M) of neat ILs, obtained by the ratio between density and molar mass of pure IL (in mol. $\mathrm{L}^{-1}$ ) as previously described, with the $V_{\text {IonPair }}$, resulting in an exponential correlation $\left(M=a \times V_{\text {IonPair }^{-b}}\right)$ with $\mathrm{R}^{2}=0.9889$. These results showed the possibility to predict the density, viscosity and conductivity as a function of the molar concentration $(\mathrm{M})$ and the anion type, with optimum correlation values $\left(\mathrm{R}^{2}\right.$ of $0.9889,0.9976$ and 0.9871 respectively), using the data in Figure 11 and Table $1[79,80]$. 
Taking into account that the transport properties demonstrated above, strongly depend on free volume, the study of this concept is of fundamental importance to design the properties of materials. The theory of the free volume effect can provide insight into gas solubility phenomena in IL and consequently resolve catalytic activity issues [81].

According to the free volume theory, the total volume of a liquid $\left(V_{l}\right)$ consists of two components: occupied $\left(V_{o c c}\right)$ and free volume $\left(V_{f}\right)$, Equation (3) [82].

$$
V_{l}=V_{o c c}+V_{f}
$$

The occupied volume is assumed to be incompressible while the $V_{f}$ is compressible. $V_{\text {occ }}$ can be defined as in Equation (4).

$$
V_{o c c}=V_{i}+V_{w}
$$

where $V_{i}$ means interstitial volume (a free volume existent even in the crystalline state), and $V_{w}$ represent the Van der Waals volume (related to the minimal volume occupied by molecules impenetrable for other molecules at ordinary temperatures). Based on temperature-dependent crystal structures, a radii-based methodology can be applied for the calculation of $V_{w}$ of organic salts. In this approach the atoms are assumed as fused spheres with Van der Waals radii and the space occupied by the hard spheres is calculated [83]. The schematic representation of the constitution of the volume of a liquid, glass or crystal according to temperature is illustrated in Figure 12 [3].

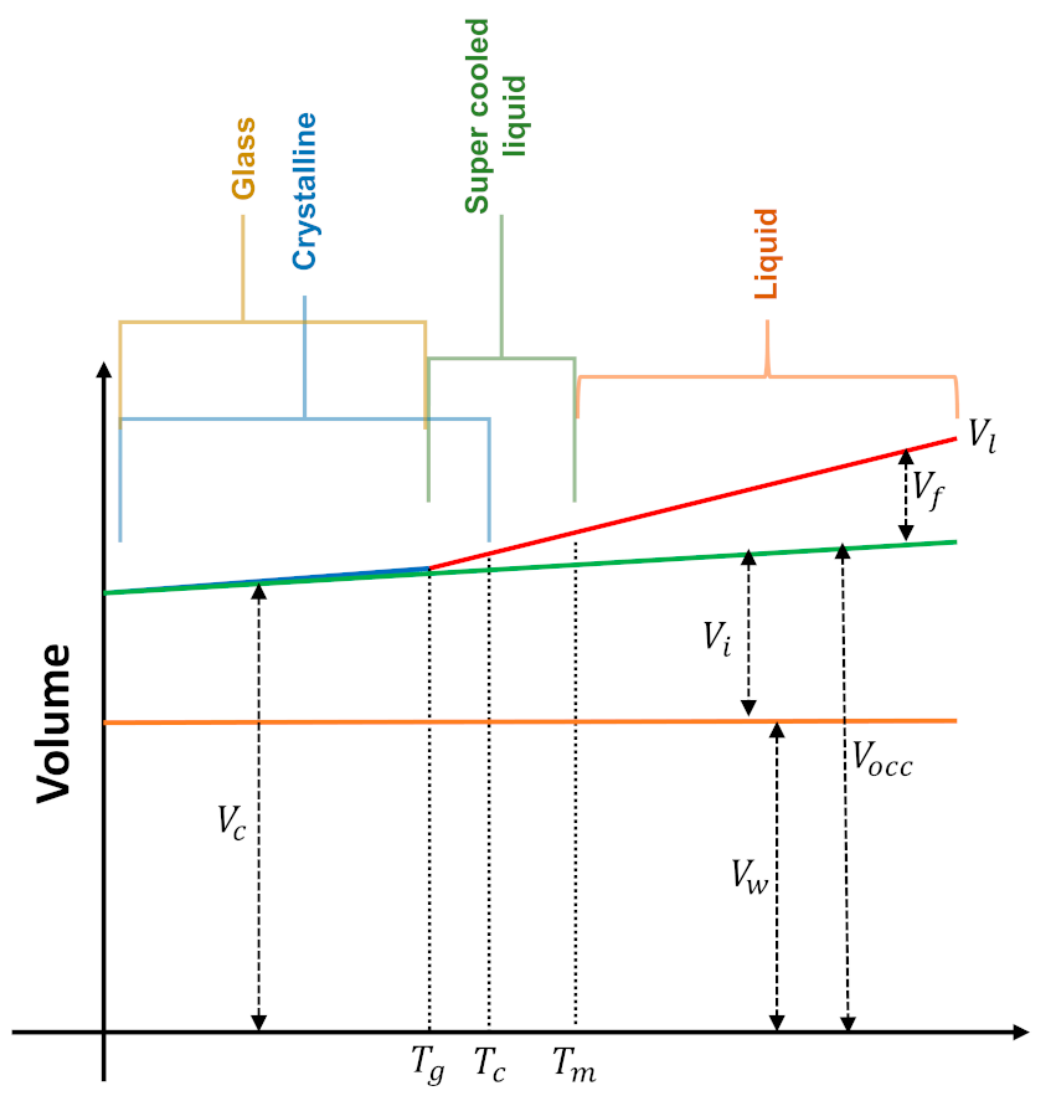

Temperature

Figure 12. Schematic representation of the constitution of the volume, at isobaric condition. $V_{i}$ interstitial volume; $V_{f}$ free volume; $V_{l}$ total volume of the liquid; $V_{c}$ volume of the crystal; $V_{W}$ Van der Walls volume; $V_{o c c}$ occupied volume; $T_{g}$ glass transition temperature; $T_{c}$-crystallization temperature; $T_{m}$ Melting temperature. Adapted from references $[3,82]$. 
From Figure 12 it follows that when a given IL at a temperature above its melting point $\left(T_{m}\right)$ is cooled, its volume $\left(V_{l}\right)$ decreases until it reaches the crystallization temperature $\left(T_{c}\right)$ (liquids with maximum density, like water, do not obey this behavior). $T_{c}$ may coincide with $T_{m}$, but normally the liquid remains in the supercooled condition and crystallizes. Some liquids do not crystallize, instead, they show a transition to the glass state at $T_{g}$. The decrease in $V_{l}$ can be almost entirely accounted for by a decrease in the free volume, $V_{f}$. A similar trend is observed for the volume of the crystal $\left(V_{c}\right)$, that also changes with temperature, although to a lesser extent, because $V_{i}$ has a smaller expansion coefficient than the $V_{f}$. Assuming that perfect single crystals are formed, $V_{c}$ is very well represented by the molecular volume (this is only valid for the single crystalline state).

The overall $V_{f}$ is distributed locally into cavities, voids or holes $\left(V_{h}\right)$. The local free volume, $V_{h}$, consists therefore of irregular shaped holes and cavities formed by a particular molecular distribution. The holes are formed by the coalescence of other free space regions and have random size, shape and location. These characteristics are constantly changing due to the displacement of the molecules into the bulk liquid. Given the relationship between free volume and transport properties such as viscosity and conductivity, the study of free volume in ILs and how it may influence its physicochemical properties provides a link between the structures of ILs and its effects for a particular application $[3,84]$.

The density dependence of pressure-temperature can be used to estimate $V_{f}$ using the Sanchez-Lacombe (SL) equation of state (EoS), Equation (5). SL theory introduces holes to explain variations on compressibility and density (isobaric expansivity $\left(\alpha_{p}\right)$ and isothermal compressibility $\left.\left(K_{T}\right)\right)[85,86]$.

$$
\begin{gathered}
\widetilde{\rho}^{2}+\widetilde{P}+\widetilde{T}\left[\ln (1-\widetilde{\rho})+\left(1-\frac{1}{r}\right) \widetilde{\rho}\right]=0 \\
\widetilde{T} \equiv \frac{T}{T^{*}} \widetilde{P} \equiv \frac{P}{P^{*}} \widetilde{\rho} \equiv \frac{\rho}{\rho^{*}} \\
\varepsilon^{*}=R T^{*} v^{*}=R T^{*} / P^{*} r=\frac{M_{w} P^{*}}{R T^{*} \rho^{*}}
\end{gathered}
$$

where $P^{*}, \rho^{*}$ and $T^{*}$ represent characteristic parameters of the SL equation; $M_{w}$ is the molecular weight; $R$ is the gas constant. A pure fluid is completely characterized by three molecular parameters in this EoS: $\varepsilon^{*}$ segment interaction energy, $r$ segment number of one molecule and $v^{*}$ segment volume. $v^{*} \times r$ is equal to the hard-core volume. The $V_{f}$ can be calculated as shown in Equation (6), where $V_{m}$ is the molar volume, $M_{w}$ is the respective IL molecular weight and $\rho$ is the density.

$$
V_{f}=V_{m}-\left(v^{*} \times r\right) ; V_{m}=\frac{M_{w}}{\rho}
$$

Analysing Equations (5) and (6), it is possible to observe that $V_{f}$ increases with temperature and decreases with pressure. When the temperature increases (at isobaric conditions), the kinetic energy of molecules and the total space between molecules increases; modifying the force between atoms and, consequently, the physicochemical properties [87-90].

Since the free volume and molar volume are correlated (Equation (6)), we performed an analytical treatment of literature data, plotting $V_{f}$ values (estimated by SL EoS) versus the inverse of $V_{m}$ for some ILs obtained at $313 \mathrm{~K}$ and $0.1 \mathrm{MPa}$, as shown in Figure 13. From this data treatment, it is possible to observe a strong exponential correlation between free volume and molar volume, represented by the equation $V_{f}=110.8 \times\left(e^{-572.9 / V_{m}}\right)+7.33$. This equation is very useful for predicting the free volume of pure ILs at studied conditions, being dependent only on density (or molar concentration), which in turn is dependent on temperature and pressure. The molar concentration at a given pressure and temperature is easily determined by reorganizing the Equation (6) $\left(M=\frac{\rho}{M_{W}}\right)$ if the density of an IL under such specific conditions is available, in other words, $1 / V_{m}$, is equal to molar concentration $(M)$. 


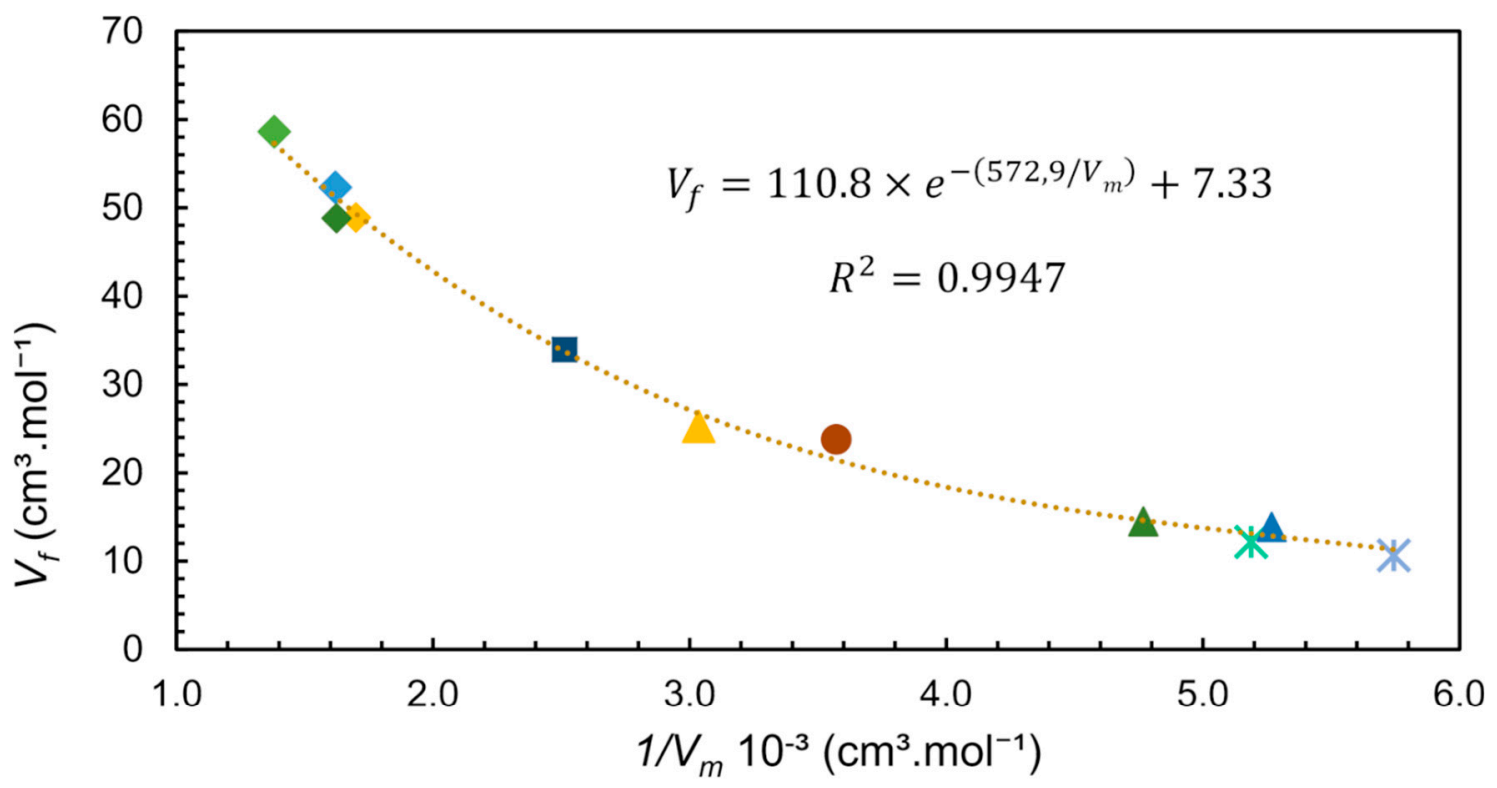

$$
\begin{aligned}
& \bullet\left[\left(\mathrm{C}_{6} \mathrm{H}_{13}\right)_{3} \mathrm{P}\left(\mathrm{C}_{14} \mathrm{H}_{29}\right)\right]\left[\mathrm{NTF}_{2}\right] \bullet\left[\left(\mathrm{C}_{6} \mathrm{H}_{13}\right)_{3} \mathrm{P}\left(\mathrm{C}_{14} \mathrm{H}_{29}\right)\right][\mathrm{DCA}] \bullet\left[\left(\mathrm{C}_{6} \mathrm{H}_{13}\right)_{3} \mathrm{P}\left(\mathrm{C}_{14} \mathrm{H}_{29}\right)\right][\mathrm{Cl}] \\
& \text { - }\left[\left(\mathrm{C}_{6} \mathrm{H}_{13}\right)_{3} \mathrm{P}\left(\mathrm{C}_{14} \mathrm{H}_{29}\right)\right][\mathrm{Ac}] \quad-\left[\mathrm{C}_{10} \mathrm{mim}\right]\left[\mathrm{NTF}_{2}\right] \quad \bullet\left[\mathrm{C}_{2} \text { eim] }\left[\mathrm{NTF}_{2}\right]\right. \\
& *\left[\mathrm{C}_{2} \mathrm{mim}\right]\left[\mathrm{EtSO}_{4}\right] \\
& \triangle\left[\mathrm{C}_{4} \operatorname{mim}\right]\left[\mathrm{PF}_{6}\right] \\
& *\left[\mathrm{C}_{2} \mathrm{mim}\right]\left[\mathrm{MeSO}_{4}\right] \\
& \triangle\left[\mathrm{C}_{4} \mathrm{mim}\right]\left[\mathrm{OcSO}_{4}\right]
\end{aligned}
$$

Figure 13. Free Volume $\left(V_{f}\right)$ dependence of inverse of Molar Volume $\left(1 / V_{m}\right)$ of ILs at $313 \mathrm{~K}$ and 0.1 MPa. The data for trihexyl(tetradecyl)phosphonium-based ILs from references $[87,88],\left[\mathrm{C}_{4} \mathrm{mim}^{+}\right.$-based ILs from [89] and the remaining ILs from [90].

The ILs constituted by the trihexyltetradecylphosphonium $\left[\left(\mathrm{C}_{6} \mathrm{H}_{13}\right)_{3} \mathrm{P}\left(\mathrm{C}_{14} \mathrm{H}_{29}\right)\right]^{+}$family have a large free volume compared to ImIL (Figure 13). These cations have very high molecular volume and molecular mass and are less packed, allowing mobility and providing "available space" to accommodate anions. For this particular cation $\left(\left[\left(\mathrm{C}_{6} \mathrm{H}_{13}\right)_{3} \mathrm{P}\left(\mathrm{C}_{14} \mathrm{H}_{29}\right)\right]^{+}\right)$it is observed that the combination with anions $[\mathrm{DCA}]^{-},[\mathrm{Cl}]^{-}$and $[\mathrm{Ac}]^{-}$has similar free volume and practically the same density at the studied conditions, $\sim 0.88 \mathrm{~g} . \mathrm{cm}^{-3}$. However, the anion $\left[\mathrm{NTF}_{2}\right]^{-}$, which has a molecular mass larger than its analogues, leads to higher density $\left(1.06 \mathrm{~g} . \mathrm{cm}^{-3}\right)$ and a lower molar concentration, indicating that molecular mass is the determinant for the free volume. The IL $\left[\mathrm{C}_{2} \mathrm{mim}\right]\left[\mathrm{MeSO}_{4}\right]$ presents one of the highest densities $\left(1.28 \mathrm{~g} . \mathrm{cm}^{-3}\right)$ and the smaller free volume between the studied ILs (Figure 13), indicating that the counterions are quite packed. The free volume can be related to ILs applications/properties such as gas sorption capacity and solubility of compounds. From Figure 13, it is possible to observe a higher free volume for phosphonium ILs than ImILs, suggesting that this free space is the reason for the higher $\mathrm{CO}_{2}$ sorption capacity observed in phosphonium-based ILs using non-basic anion as counterion [81].

At this point, it is possible to state that the molecular structural organization determines the free volume. This free volume can be evaluated as a free volume fraction $\left(F_{f v}\right)$ of a given IL as in Equation (7).

$$
F_{f v}=V_{f} / V_{m}
$$

Analysing the existing data for different IL families, we constructed a plot correlating $F_{f v}$ versus the inverse of Molar Volume (Figure 14) [87-90]. The values of $F_{f v}$ vary from 0.0610 for $\left[\mathrm{C}_{2} \mathrm{mim}\right]\left[\mathrm{MeSO}_{4}\right]$ to 0.0853 for $\left[\mathrm{C}_{10} \mathrm{mim}\right]\left[\mathrm{NTF}_{2}\right]$, as seen in Figure 14, where $F_{f v}$ is represented as a percentage. Apparently, the points seem scattered showing no correlation between the $F_{f v}$ and the inverse of Molar Volume. However, it is possible to observe that ILs with lower Vm (which corresponds to a higher molar 
concentration) have a tendency to present lower total free volume, probably due to a more even distribution of smaller ions. A closer look into the structure of the ILs shows that in spite of very different $\mathrm{Vm}$, higher values of $F_{f v}$ are more easily reached in ILs with longer linear chains, such as $\left[\mathrm{C}_{10} \mathrm{mim}\right]\left[\mathrm{NTF}_{2}\right]\left(F_{f v}=0.0850\right.$ and $\left.V_{m}=397.9 \mathrm{~cm}^{3} \cdot \mathrm{mol}^{-1}\right)$ and $\left[\left(\mathrm{C}_{6} \mathrm{H}_{13}\right)_{3} \mathrm{P}\left(\mathrm{C}_{14} \mathrm{H}_{29}\right)\right]\left[\mathrm{NTF}_{2}\right]\left(F_{f v}=\right.$ 0.0809 and $V_{m}=723.9 \mathrm{~cm}^{3} \cdot \mathrm{mol}^{-1}$ ).

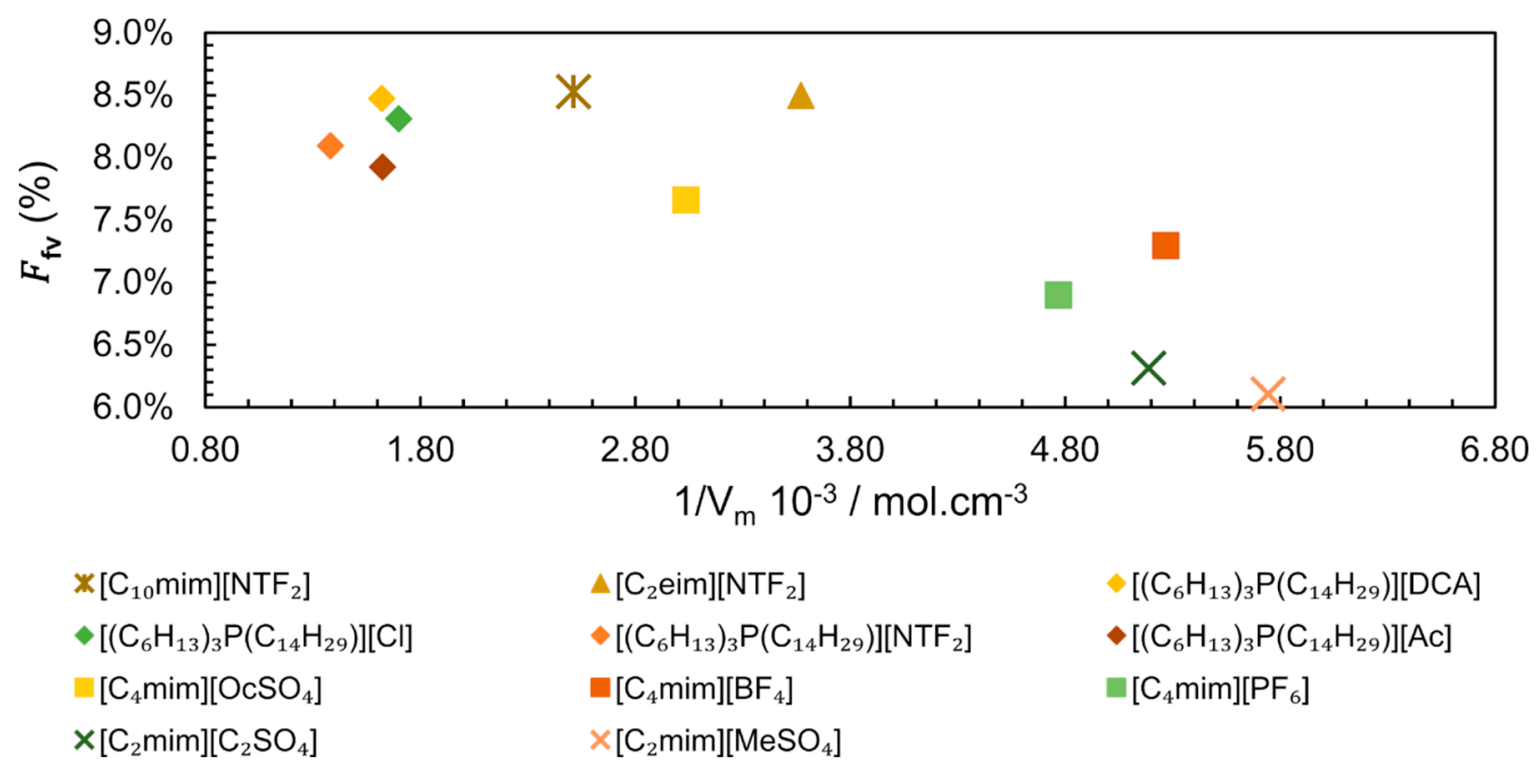

Figure 14. Free volume fraction $\left(F_{f v}\right)$ dependence of inverse of Molar Volume $\left(1 / V_{m}\right)$ of IL at 313 $\mathrm{K}$ and $0.1 \mathrm{MPa}$. The data for trihexyl(tetradecyl)phosphonium-based ILs from references $[87,88]$, $\left[\mathrm{C}_{4} \mathrm{mim}\right]^{+}$-based ILs from [89] and the remaining ILs from [90].

The effect of molar volumes in the application of ILs was demonstrated by Shannon et al. in $\mathrm{CO}_{2}$ capture evaluation [91]. They suggested that the larger the molar volumes of ILs, the higher the $\mathrm{CO}_{2}$ solubility, for non-basic anions. However, the molar volume cannot be the only justification, since $\left[\mathrm{C}_{4} \mathrm{mim}\right]\left[\mathrm{BF}_{4}\right]$ and $\left[\mathrm{C}_{2} \mathrm{mim}\right]\left[\mathrm{C}_{2} \mathrm{SO}_{4}\right]$ have similar molar volumes $\left(189.9\right.$ and $192.8 \mathrm{~cm}^{3} \cdot \mathrm{mol}^{-1}$, receptively), but different $\mathrm{CO}_{2}$ solubility, with a $\mathrm{CO}_{2}$ molar fraction $\left(x_{\mathrm{CO} 2}\right)$ of 0.22 for $\left[\mathrm{C}_{4} \mathrm{mim}\right]\left[\mathrm{BF}_{4}\right]$ $\left(F_{f v}=7.3 \%\right)$ and $x_{\mathrm{CO} 2}=0.11$ for $\left[\mathrm{C}_{2} \mathrm{mim}\right]\left[\mathrm{C}_{2} \mathrm{SO}_{4}\right]\left(F_{f v}=6.3 \%\right)$, at $313 \mathrm{~K}$ and $2.0 \mathrm{MPa}$ [81]. In this case, the solubility of $\mathrm{CO}_{2}$ was higher in the IL ([C $\left.\left.\mathrm{C}_{4} \mathrm{mim}\right]\left[\mathrm{BF}_{4}\right]\right)$ with higher $F_{f v}$. Moreover, ILs with more flexible and/or branched chains demonstrated an increase in the solubility of $\mathrm{CO}_{2}$, which probably can be related to the presence of available holes with the correct size to accommodate $\mathrm{CO}_{2}$ molecules. In other words, the distribution of free volume will influence the solubility of gases and the transport properties of ILs, more than the total free volume [8].

According to the theory of free volume (Equation (8)) developed by Doolittle [92], Cohen and Turnbull [93-96] and adapted by Macedo [97], the diffusion $(D)$ of a molecule/particle in a condensed matter requires two conditions: (i) The occurrence of a cavity greater than a critical size in the vicinity of the diffusing particle; and (ii) This particle having sufficient thermal energy to perform the displacement.

$$
D=D_{0} \times \exp \left(-\frac{\beta \times a^{*}}{V_{f}}-\frac{E^{*}}{k T}\right)
$$

where $V_{f}=a-a *$ is the free volume, $E *$ is the activation energy, $a *$ is the critical size of the molecular volume, $\beta$ = factor to correct for overlapping free volumes (0.5 to 1.0), $D_{0}$, is the Chapman-Enskog self-diffusion coefficient, and $a=$ average volume for a molecule in the system. 
Beichel et al. [3] have fitted experimental viscosity and conductivity of some $\left[\mathrm{C}_{4} \mathrm{mim}\right]^{+}$-based ILs into a similar equation, which ignores the energy requirement for the displacement, Equations (9) and (10).

$$
\begin{gathered}
\eta=A_{0} \sqrt{T} \times \exp ^{\left(\frac{V^{*}}{V_{l}-V^{*}}\right)} \\
\sigma=\frac{A_{0}}{\sqrt{T}} \times \exp ^{\left(-\frac{V^{*}}{V_{l^{-}-V^{*}}}\right)}
\end{gathered}
$$

where $\sigma$ (conductivity), $\eta$ (viscosity), $V_{l}$ (volume of liquid, obtained through $\rho$ data) and temperature are the entered values in the equation while $A_{0}$ and $V^{*}$ are the adjustable fitting parameters (Table 2). $V^{*}$ represents the critical volume necessary for one molecule to perform the displacement. Through the analysis of the data presented in Table 2, it is possible to observe that the critical volumes $\left(V^{*}\right)$ obtained with the conductivity $(\sigma)$ or the viscosity $(\eta)$ data are similar, but always slightly larger than the sum of the molecular volume of both ions ( $\left.V_{\text {Ion Pair }}\right)$. These results once again demonstrate that there is a dependence on the liquid transport properties of the free volume. However, the model cannot adjust solvents whose molecular structure allows strong interactions by hydrogen bonds, as aqueous solutions, indicating that other transport mechanisms may be predominant in these liquids [98].

Table 2. Fit parameters $A_{0}$ and $V^{*}$ for viscosity $(\eta)$ and conductivity $(\sigma)$ of $\left[\mathrm{C}_{4} \mathrm{mim}\right][\mathrm{X}]$, according to

\begin{tabular}{|c|c|c|c|c|c|c|}
\hline Entry & {$[\mathrm{X}]^{-}$} & $V_{\text {IonPair }}\left(\AA^{3}\right)^{[\mathrm{a}]}$ & $A_{0}{ }^{[\mathbf{b}]}\left(10^{-7} \mathbf{P a} \cdot \mathbf{s} \cdot \mathbf{K}^{-0.5}\right)$ & $V^{*}\left(\AA^{3}\right)^{[b]}$ & $A_{0}{ }^{[\mathrm{c}]}\left(10^{4} \mathrm{mS} \cdot \mathrm{cm}^{-1} \cdot \mathbf{K}^{-0.5}\right)$ & $V^{*}\left(\AA^{3}\right)^{[c]}$ \\
\hline 1 & {$[\mathrm{Cl}]$} & 238 & 2.50 & 253 & 69.8 & 251 \\
\hline 2 & {$\left[\mathrm{BF}_{4}\right]$} & 276 & 9.88 & 281 & 9.8 & 274 \\
\hline 3 & {$\left[\mathrm{PF}_{6}\right]$} & 308 & 10.56 & 315 & 9.7 & 308 \\
\hline 4 & [OTF] & 323 & 6.13 & 333 & 8.0 & 324 \\
\hline 5 & {$\left[\mathrm{NTF}_{2}\right]$} & 430 & 7.16 & 432 & 6.4 & 423 \\
\hline 6 & {$\left[\mathrm{~B}(\mathrm{hfip})_{4}\right]$} & 753 & 15.44 & 879 & 0.8 & 839 \\
\hline
\end{tabular}
Equations (9) and (10). Data from reference [3].

${ }^{\text {[a] }}$ The value of $V_{\text {IonPair }}$ the authors took from crystallographic data, if available in the literature, or scaled it from similar structures [3]. ${ }^{[\mathrm{b}]}$ Obtained from $\eta$. ${ }^{[\mathrm{c}]}$ Obtained from $\sigma$.

\subsubsection{Experimental Techniques for Free Volume Determination}

Positron Annihilation Lifetime Spectroscopy (PALS) is the most effective experimental method for quantifying the local free volume (hole volume), $V_{h}$ [3]. The technique involves introducing positrons into a sample where they either annihilate on contact with electrons or form metastable bound states, known as positroniums $(P s)$. The lifetime of the trapped positron is sensitively dependent on the size and even the configurational structure of the vacancy [99-101]. Beichel et al. related the $V_{h}$ measured with PALS with the ratio $V_{\text {ion }}\left(A^{-}\right) / V_{\text {ion }}\left(C^{+}\right)$for $\left[C_{4} \text { mim] }\right]^{+}$-based ILs, Figure 15 [3]. The analysis was performed at a temperature $T_{k}$, which denotes the "knee" temperature, above $T_{k}$ the lifetime does not further mirror the true hole size. For larger holes, positron lifetime saturates, and this sets the limit for size dependence $[99,100]$. Yu et al. observed that $T_{k}$ is close to or even coincides with $T_{m}$ of the corresponding crystalline structure for $\left[\mathrm{C}_{4} \mathrm{mim}\right]\left[\mathrm{NTF}_{2}\right],\left[\mathrm{C}_{4} \mathrm{mim}\right]\left[\mathrm{PF}_{6}\right]$ and $\left[\mathrm{C}_{4} \mathrm{mim}\right][\mathrm{Cl}][101]$. 


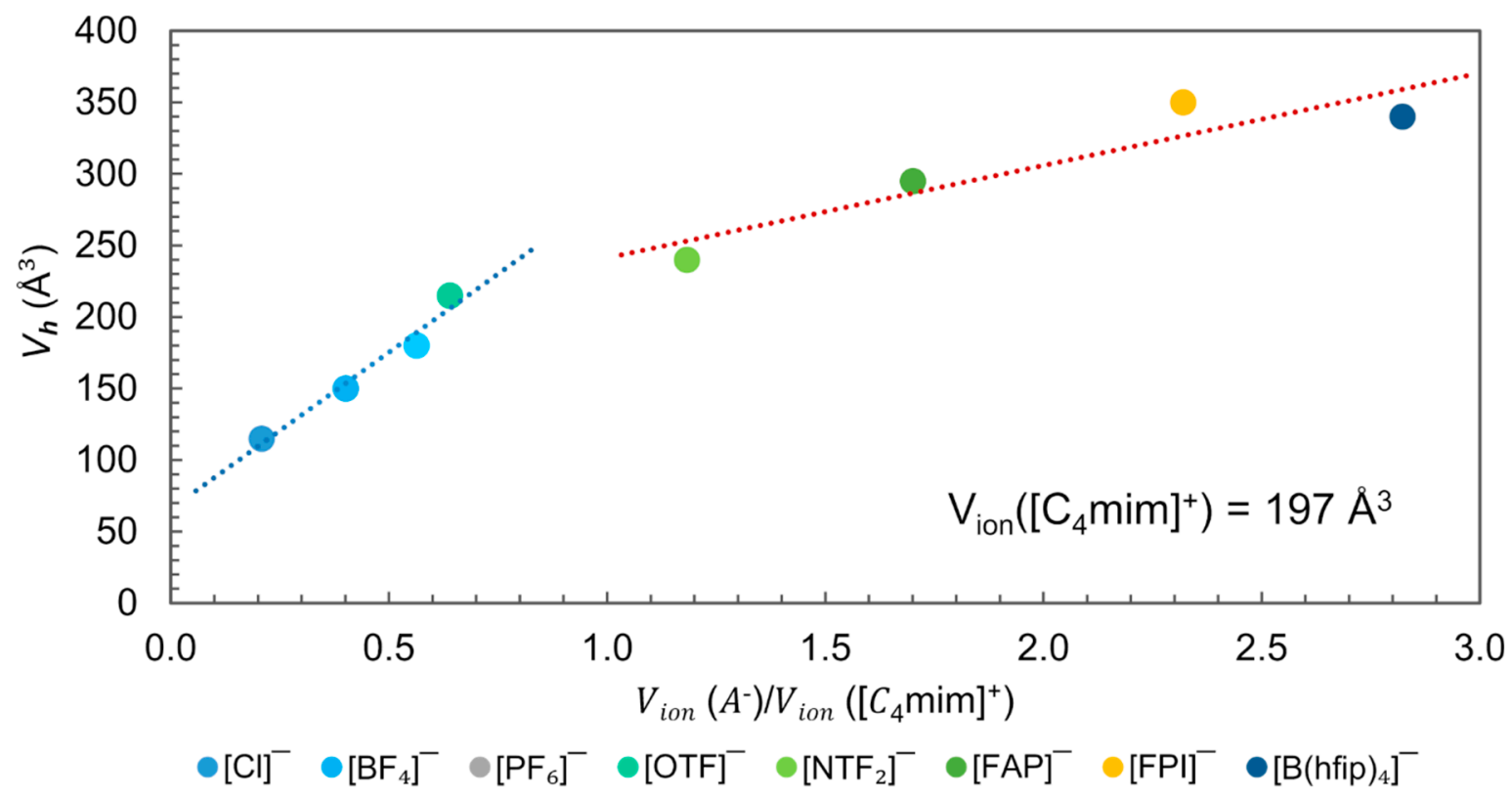

Figure 15. Plot of the hole volume $\left(V_{h}\right)$ versus Anion-Cation volume ratio $V_{\text {ion }}\left(A^{-}\right) / V_{\text {ion }}\left(C^{+}\right)$for the $\left[\mathrm{C}_{4} \mathrm{mim}\right]^{+}$-based ILs at $T_{k}$. Data from reference $[3,88]$.

In Figure 15, two distinct $V_{h}$ dependencies of the ion size are observed. One for those ILs where the anion-cation volume ratio $\frac{V_{\text {ion }}\left(A^{-}\right)}{V_{\text {ion }}\left(\mathrm{C}^{+}\right)}<1.0$, i.e., the anion has a smaller molecular volume than cation $\left(\left[\mathrm{C}_{4} \mathrm{mim}\right]^{+}=197 \AA^{3}\right)$, and another for anion-cation volume ratio $>1.0$, when the anion is bigger than the cation. Since for all ILs represented in this figure, $V_{h}$ is smaller than the $V_{\text {ion pair }}$, and according to the free volume theory, the size of cavities is fundamental for ion displacement, the observed dependence suggests that the displacement of ions in these ILs might be governed by the cation in the first region and by the anion in the second. In the first region, the $V_{h}$ is smaller than $V_{i o n}\left(C^{+}\right)$and is greater than the $V_{\text {ion }}\left(A^{-}\right)$when $\mathrm{X}=[\mathrm{Cl}]^{-},\left[\mathrm{BF}_{4}\right]^{-},\left[\mathrm{PF}_{6}\right]^{-}$. However, in the second region, when $\mathrm{X}=[\mathrm{FAP}]^{-},[\mathrm{FPI}]^{-}$, [B(hfip) $\left.)_{4}\right]^{-}$, the $V_{h}$ is greater than the $V_{\text {ion }}\left(C^{+}\right)$and smaller than $V_{\text {ion }}\left(A^{-}\right)$. In the ILs with $\mathrm{X}=[\mathrm{OTF}]^{-}$ and $\left[\mathrm{NTF}_{2}\right]^{-}, V_{h}$ exceeds the size of both ions $\left(V_{\text {ion }}\left(A^{-}\right)\right.$and $\left.V_{\text {ion }}\left(C^{+}\right)\right)$.

Despite these differences in the relative size of imidazolium cations and anions and the corresponding $V_{h}$ of the ILs, imidazolium cations generally exhibit larger self-diffusion $(D)$ than anions in pure ILs [33]. The explanation obtained by MD simulations shows that the displacement of the imidazolium cation is anisotropic, with the motion normal to the imidazolium ring plane being the most hindered and the motion along the alkyl chain being the most facilitated $[102,103]$. The magnitude of anion displacement is very similar to cation when the negative ion is moving perpendicular to the imidazolium ring plane or along the direction of the 1-alkyl chain. Thus, the large displacement of cations in ImILs in comparison to anions is mainly due to less hindered dynamics along the direction of the carbon $\mathrm{C} 2$ of the imidazolium ring plane. Considering this information, it should be noted that the size of the holes could be smaller than the cation molecular volume. However, only the butyl chain part has a volume (approximately $120 \AA$ ) able to move into this neighbouring space, which suggests an initial step for the cation diffusion mechanism $[3,82,101]$.

The Heisenberg spin exchange-dipole-dipole (HSE-DD) separation method on electron paramagnetic resonance (EPR) spectrum was used to measure the translational diffusion coefficients of the ${ }^{14} \mathrm{~N}$-labeled perdeuterated 2,2,6,6-tetramethyl-4-oxopiperidine-1-oxyl $\left({ }^{14} \mathrm{~N}\right.$-pDTEMPONE) nitroxide spin probe as a function of temperature in two ImILs series, $\left[\mathrm{C}_{n} \text { mim }\right]^{+}(\mathrm{n}=2,4,6,8$ and 10) with $\left[\mathrm{BF}_{4}\right]^{-}$and $\left[\mathrm{NTF}_{2}\right]^{-}$anions [104]. The obtained translational diffusion coefficients of the tracer molecule $\left({ }^{14} \mathrm{~N}\right.$-pDTEMPONE) and IL ions were analysed in terms of the Cohen-Turnbull free volume theory (Equation (8)). The free volume obtained for the nitroxides was compared to the 
free volume obtained from the self-diffusion of the cations and anions. They noted that even in the cases when the self-diffusion coefficients of the cation and anion were noticeably different, the critical free volumes for the diffusion are the same. In addition, the self-diffusion coefficients of cations $\left(D^{+}\right)$ and anions $\left(D^{-}\right)$at different temperatures were adjusted to Equation $(11)[93,95]$. The adjustment parameters for each IL studied are found in Table 3.

$$
D=A_{D} \sqrt{T} \times \exp ^{\left(-\frac{\gamma V^{*}}{V_{f}^{\prime}}\right)}
$$

where $D$ is the self-diffusion, $\gamma V^{*}$ is the minimum (critical) volume for the diffusion, $V_{f}^{\prime}$ is the free volume per solvent molecule and $A_{D}$ is the adjusting fitting parameter. The authors [104] obtained the values of $V_{f}^{\prime}$ through Equation (12) previously proposed in the literature by Beiche et al. [3] and Yu et al. [82].

$$
V_{f}^{\prime}=\frac{M_{w}}{\rho \times N a}-V_{\text {ionpair }}
$$

where $M_{w}$ is the molar mass, $\rho$ is the density, $\mathrm{Na}$ Avogadro number and $V_{\text {Ion Pair }}$ is the volume of the ion pair (volume of cation plus anion).

Table 3. Fit parameters, $A_{D}$ and $\gamma \mathrm{V}^{*}$, for the diffusion coefficients of cations, $\mathrm{D}^{+}$, and anions, $\mathrm{D}^{-}$, in ILs

\begin{tabular}{|c|c|c|c|c|c|c|}
\hline Entry & ILs & $V_{f}^{\prime} / \AA^{3}$ & $A_{D^{+}} / \AA^{2} \cdot \mathbf{n s}^{-1}$ & $\gamma \mathbf{V}^{*[\mathrm{a}]} / \AA^{3}$ & $A_{D^{-}} / \AA^{2} \cdot \mathbf{n s}^{-1}$ & $\gamma \mathbf{V} *[\mathrm{~b}] / \AA^{3}$ \\
\hline 1 & {$\left[\mathrm{C}_{2} \mathrm{mim}\right]\left[\mathrm{BF}_{4}\right]$} & 41.8 & $264 \pm 20$ & $245.9 \pm 3.4$ & $272 \pm 21$ & $253.3 \pm 3.5$ \\
\hline 2 & {$\left[\mathrm{C}_{4} \mathrm{mim}\right]\left[\mathrm{BF}_{4}\right]$} & 39.1 & $371 \pm 35$ & $302.4 \pm 4.2$ & $579 \pm 47$ & $321.1 \pm 3.6$ \\
\hline 3 & {$\left[\mathrm{C}_{6} \mathrm{mim}\right]\left[\mathrm{BF}_{4}\right]$} & 39.4 & $214 \pm 14$ & $313.2 \pm 3.2$ & $153.1 \pm 7.2$ & $295.4 \pm 2.2$ \\
\hline 4 & {$\left[\mathrm{C}_{8} \mathrm{mim}\right]\left[\mathrm{BF}_{4}\right]$} & 40.6 & $68.9 \pm 0.9$ & $294.4 \pm 0.6$ & $85.4 \pm 1.6$ & $296.1 \pm 0.9$ \\
\hline 5 & {$\left[\mathrm{C}_{2} \mathrm{mim}\right]\left[\mathrm{NTF}_{2}\right]$} & 58.0 & $94.6 \pm 3.6$ & $296.6 \pm 2.6$ & $74.9 \pm 2.4$ & $315.4 \pm 2.2$ \\
\hline 6 & {$\left[\mathrm{C}_{4} \mathrm{mim}\right]\left[\mathrm{NTF}_{2}\right]$} & 59.6 & $103.5 \pm 4.8$ & $352.3 \pm 3.2$ & $97.6 \pm 4.1$ & $364.3 \pm 3.0$ \\
\hline 7 & {$\left[\mathrm{C}_{6} \mathrm{mim}\right]\left[\mathrm{NTF}_{2}\right]$} & 60.7 & $83.3 \pm 2.1$ & $370.4 \pm 1.8$ & $75.8 \pm 2.1$ & $373.3 \pm 2.0$ \\
\hline 8 & {$\left[\mathrm{C}_{8} \mathrm{mim}\right]\left[\mathrm{NTF}_{2}\right]$} & 61.2 & $57.2 \pm 0.5$ & $370.6 \pm 0.7$ & $57.1 \pm 0.5$ & $373.3 \pm 0.6$ \\
\hline
\end{tabular}
according to the Equation (12), and the determined $V_{f}^{\prime}$ at $313 \mathrm{~K}$ and 1 bar, data from reference [104].

The similarity of the critical free volumes $(\gamma \mathrm{V} *)$ obtained for the cation and anion (Table 3) suggests that the diffusion mechanism of the anion and the cation are coordinated. This conclusion is clearly illustrated in Figure 16b, where the ratio between the critical volumes of anion by the cation $\left(\gamma \mathrm{V} *\left(\mathrm{~A}^{-}\right) / \gamma \mathrm{V} *\left(\mathrm{C}^{+}\right)\right)$for different ImILs is close to $1.0 \pm 0.06$.

When multiplying $V_{f}^{\prime} \times \mathrm{Na}, V_{f}$ is obtained $\left(\mathrm{cm}^{3} \cdot \mathrm{mol}^{-1}\right)$, using Equations (11) and (12) and the parameters indicated in Table 3, the $V_{f}$ for $\left[\mathrm{C}_{4} \mathrm{mim}\right]\left[\mathrm{BF}_{4}\right]$ at $313 \mathrm{~K}$ is equal to $24 \mathrm{~cm}^{3} \cdot \mathrm{mol}^{-1}$. Different value has been previously described using the method SL-EoS for the same conditions [89], where $V_{f}$ $=14 \mathrm{~cm}^{3} \cdot \mathrm{mol}^{-1}$ was found. However, using the overlap free volumes correction factor in the Equation (11) equal to 0.5 , similar values of $V_{f}$ could be obtained by both methods [104]. The $V_{f}^{\prime}$ determined by the authors vary linearly with temperature and present similar values for the same anion family. Additionally, the $V_{f}^{\prime}$ can be correlated with $\mathrm{D}^{+}$(Figure 16a). The diffusion of cation $\left[\mathrm{C}_{2} \mathrm{mim}\right]^{+}$is $50 \%$ faster when combined with anion $\left[\mathrm{NTF}_{2}\right]^{-}$than with $\left[\mathrm{BF}_{4}\right]^{-}$and the free volume in $\left[\mathrm{C}_{2} \mathrm{mim}\right]\left[\mathrm{BF}_{4}\right]$ is $50 \%$ smaller than in $\left[\mathrm{C}_{2} \mathrm{mim}\right]\left[\mathrm{NTF}_{2}\right]$. 


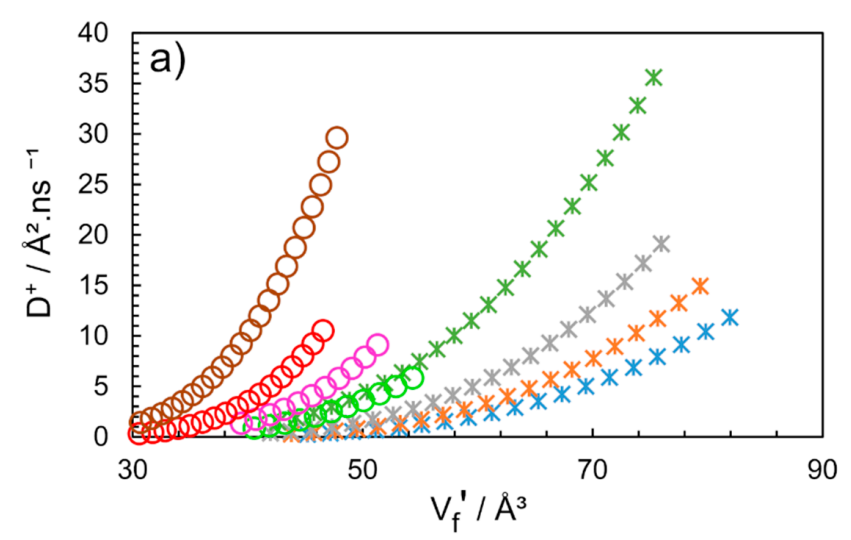

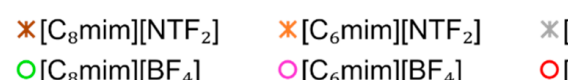

$\begin{array}{lll}*\left[\mathrm{C}_{8} \mathrm{mim}\right]\left[\mathrm{NTF}_{2}\right] & *\left[\mathrm{C}_{6} \mathrm{mim}\right]\left[\mathrm{NTF}_{2}\right] & *\left[\mathrm{C}_{4} \mathrm{mim}_{[}\left[\mathrm{NTF}_{2}\right]\right. \\ \circ\left[\mathrm{C}_{8} \mathrm{mim}\right]\left[\mathrm{BF}_{4}\right] & \circ\left[\mathrm{C}_{6} \mathrm{mim}_{[}\right]\left[\mathrm{BF}_{4}\right] & O\left[\mathrm{C}_{4} \mathrm{mim}_{[}\right]\left[\mathrm{BF}_{4}\right]\end{array}$

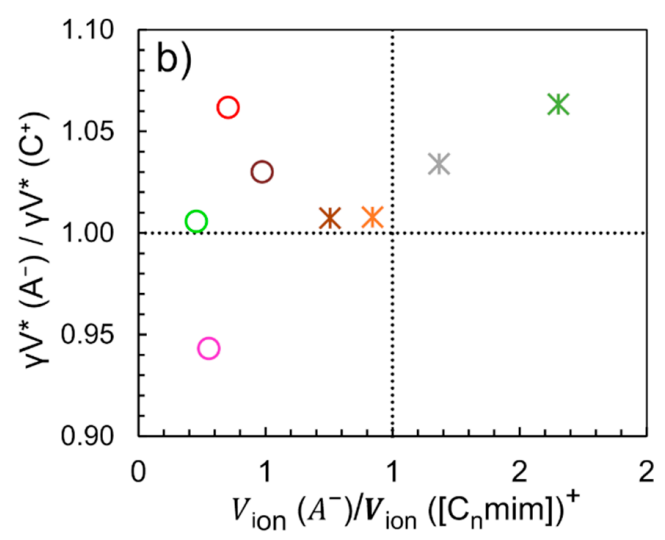

$*\left[\mathrm{C}_{2}\right.$ mim] $\left[\mathrm{NTF}_{2}\right]$

$\mathrm{O}\left[\mathrm{C}_{2} \operatorname{mim}\right]\left[\mathrm{BF}_{4}\right]$

Figure 16. (a) Cation self-diffusion $\left(D^{+}\right)$dependence of free volume per solvent molecule $\left(V_{f}^{\prime}\right)$ and (b) Ratio of critical volume $\left(\gamma V^{*}\right)$ of the counterions as a function of the ratio of molecular volume of counterions $\left(V_{\text {ion }}\left(\mathrm{A}^{-}\right) / V_{\text {ion }}\left[\mathrm{C}_{\mathrm{n}} \mathrm{mim}\right]^{+}\right)$. Graphics constructed from the data published by Merunka and Peric [104], with additional information sent by the authors.

Therefore, at this point, we can conclude that the volume of the anion is responsible for determining the size of the holes and their distribution in the body of the liquid, and that increasing the number of holes and/or its size will facilitate the molecular transport process. In addition, it is noteworthy to point out that by determining the self-diffusion coefficient $\left(D^{+}\right.$and $\left.D^{-}\right)$, is possible to predict the approximate free volume. These $D^{+}$and $D^{-}$can be directly obtained by NMR by pulsed-field gradient experiments such as diffusion-ordered spectroscopy (DOSY) $[105,106]$. The technique represents a powerful method in which the cations and anions self-diffusion coefficients can be measured separately and straightforwardly.

Another technique used to study the local structure of ILs was ${ }^{129} \mathrm{Xe}$ NMR spectroscopy. The Xenon atom can occupy cavities in liquids with enough space to accommodate it, $[84,107-110]$ and the chemical shift $(\delta)$ of free ${ }^{129} \mathrm{Xe} \mathrm{gas,} \mathrm{which} \mathrm{is} \mathrm{close} \mathrm{to} 0 \mathrm{ppm}$, can increase up to several hundred ppm for strongly confined environments. Brooks and co-authors [84] have shown a strong correlation between $\delta$ and $V_{h}\left(V_{h}\right.$ obtained from PALS, $10^{-9} \mathrm{~s}$ timescale), proving the possibility to use ${ }^{129} \mathrm{Xe}$ NMR spectroscopy $\left(10^{-3} \mathrm{~s}\right.$ timescale) to study free volume in ILs despite the vastly different timescales involved in the two techniques $[84,111]$.

In order to check for a possible correlation between free volume and ${ }^{129} \mathrm{Xe}$ chemical shift, we compiled the data of ${ }^{129} \mathrm{Xe}$ chemical shift for several ImILs, reported by Morgado et al. [108], and related them with the free volume obtained using the equation presented before, the results are presented in Figure 17. It can be concluded that the main ${ }^{129} \mathrm{Xe}$ chemical shift differences observed between the described ILs are due to the nature of the anion. The ILs can be grouped according to the type of anion and it is possible to observe five separate trends (dashed lines) between free volume and ${ }^{129} \mathrm{Xe}$ chemical shift, depending on the distinct nature of anions, $\left[\mathrm{NTF}_{2}\right]^{-}$(black), $\left[\mathrm{PF}_{6}\right]^{-}$(yellow), $[\mathrm{Cl}]^{-}$(red), $[\mathrm{I}]^{-}$(purple), and halogenated anions with $\left[\mathrm{C}_{6} \mathrm{mim}\right]^{+}$cation (blue). Narrower holes in ILs containing halogen anions produce larger ${ }^{129} \mathrm{Xe}$ deshielding (>190 ppm) because the average charge distribution around $\mathrm{Xe}$ is more positive [110]. Accordingly, the increase in the alkyl chain of $\left[\mathrm{C}_{\mathrm{n}} \mathrm{mim}\right]\left[\mathrm{NTF}_{2}\right]$ and $\left[\mathrm{C}_{\mathrm{n}} \mathrm{mim}\right]\left[\mathrm{PF}_{6}\right]$, moves the ${ }^{129} \mathrm{Xe}$ chemical shift to the low field (deshielding). The reverse effect is observed, the ${ }^{129} \mathrm{Xe} \delta$ moving to a high field (shielding) with increasing alkyl chain, for the $\left[\mathrm{C}_{n} \mathrm{mim}\right][\mathrm{Cl}]$ and $\left[C_{n}\right.$ mim $][I]$ series. The observed change in chemical shift indicates that the increase in free volume arises within the apolar region of the IL and is likely to consist of an increased number of smaller voids within the liquid structure [107]. 


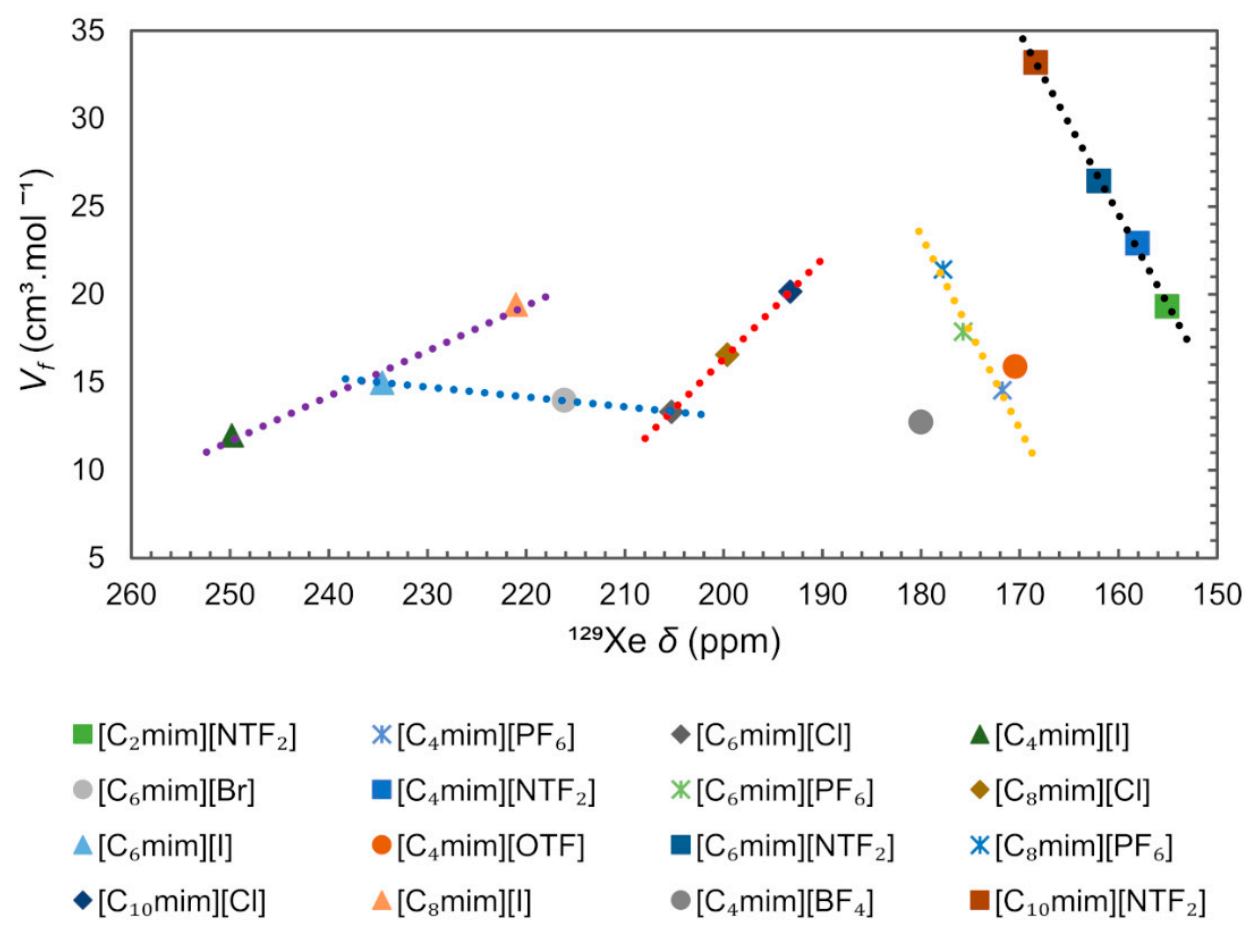

Figure 17. ${ }^{129} \mathrm{Xe}$ chemical shift $(\delta)$ correlated with free volume $\left(V_{f}\right)$ of ImIL. Dashed lines are only intended to make it easier to identify trends. The $\delta$ were taken from reference [108]. The $M$ values used to calculate the $V_{f}$ were obtained through the density values for the liquid corresponding to $313 \mathrm{~K}$ and 0.1 MPa, from the ILthermo database [112].

In conclusion, with this analysis, it was possible to reinforce the relation between molar volume $(V m)$, free volume $(V f)$ and transport properties (such as viscosity, density, diffusivity and conductivity) in ILs systems. As a final remark, considering the high number of studies and applications related to gas solubility in ionic liquid systems, since the size of holes is correlated with the ability of ILs to diffuse, the study of the free volume should be a key property in applications related to gas solubility in these systems.

\section{Water Effect}

When assessing the correlation between structure and physicochemical properties, it is impossible not to consider the effect of the presence of water, since it is an inevitable "contaminant" in real conditions for most organic solvents, including ILs. Two major sources contribute to the presence of water in ILs: it can arise from the IL synthetic route or by absorption due to the hygroscopic character of many ILs. Water is very difficult to remove not only from hygroscopic ILs but also from hydrophobic ILs. As an example, a series of hydrophobic and hydrophilic ILs were exposed to two different moist environments ( 43 and $81 \%$ humidity), and after just five minutes hydrophobic ILs, e.g., $\left[\mathrm{C}_{4} \mathrm{mim}\right]\left[\mathrm{NTF}_{2}\right]$, absorbed a non-negligible water amount, 0.63 and $1.13 \mathrm{~mol} \%$, in 43 and $81 \%$ humidity environments, respectively [113].

Insight into the water effect is particularly relevant when aiming to use ILs for widespread applications. At the industrial level, this is one more factor to control, which can be correlated to an increase in the process cost and/or change in operational conditions.

An example of a negative effect of water is in the field of ILs applied to acidic gases $\left(\mathrm{CO}_{2}\right.$ and $\mathrm{SO}_{2}$ ) capture. Some ILs have shown to experience a reduction in the absorption ability with increasing water content $[114,115]$. However, this hypothesis cannot be generalized since it is IL-dependent, with some ILs-families showing the opposite effect. 
The presence of water in ILs is not necessarily a nuisance, and the use as a co-solvent can be helpful to tune some desirable properties to a specific application. The partial water miscibility in some ILs has created an extensive field of application for liquid-liquid separation. Water is practically immiscible in $\left[\mathrm{C}_{8} \mathrm{mim}\right]\left[\mathrm{BF}_{4}\right]$ at room temperature, but the miscibility increases considerably at higher temperatures. Dyson et al. [116] took advantage of this particularity to separate the catalyst from the products in the 2-butyne-1,4-diol hydrogenation reaction. The reaction was conducted in a water/[ $\left.\mathrm{C}_{8} \mathrm{mim}\right]\left[\mathrm{BF}_{4}\right]$ monophasic system at $353 \mathrm{~K}$, with the catalyst and substrates in the same phase. After completion of the hydrogenation reaction, the system was cooled to $283 \mathrm{~K}$ where phase separation takes place between the IL and water, with the products in the aqueous phase and the catalyst remaining in the IL phase.

Recently, Yu and Jain [117] reported an elegant strategy for the photochemical conversion of $\mathrm{CO}_{2}$ and $\mathrm{H}_{2} \mathrm{O}$ (artificial photosynthesis) to hydrocarbons $\left(\mathrm{C}_{1}-\mathrm{C}_{3}\right)$ in an aqueous IL medium. They used gold nanoparticles ( $\mathrm{Au} \mathrm{NPs}$ ) drop coated in a cotton cloth as catalyst, that was submerged in a $\left[\mathrm{C}_{2} \mathrm{mim}\right]\left[\mathrm{BF}_{4}\right]$ aqueous solution, in an air-tight vessel that was saturated with $\mathrm{CO}_{2}$. The system was then irradiated with green light (incident light beam directed to the substrate containing the nanoparticles) to drive the synthesis of $\mathrm{C}_{1}-\mathrm{C}_{3}$ hydrocarbons from the reduction of $\mathrm{CO}_{2}$ and oxidation of water. The excitation of $\mathrm{Au}$ NPs yields energetic electron-hole $\left(e^{-}-h^{+}\right)$known to activate the reduction of $\mathrm{CO}_{2}$. While water is used as the source of $\mathrm{H}^{+}$, the IL is postulated to have a dual role: promotes e- transfer at the interface of the photoexcited $\mathrm{Au} \mathrm{NP}$ and the adsorbed $\mathrm{CO}_{2}$, as well stabilizes the charged radical intermediate formed $\left(\mathrm{CO}_{2}^{-}\right)$, increasing its lifetime, making the intermediate more available to proceed with multistep reduction and C-C coupling reaction. The IL promoted reactivity boost precludes the need for an applied potential or an external $h^{+}$scavenger for $e^{-}-h^{+}$separation.

The presence of even small amounts of water alters the organizational structure which results in major changes in the IL physicochemical properties, such as viscosity $(\eta)$, density $(\rho)$, diffusion $(D)$, conductivity $(\sigma)$, as well as inducing, in some cases, the formation of nanodomains [118] and nanoclusters [119]. The implications of water content in ILs physicochemical properties have been the subject of several studies, concerning interactions, dynamics, transport properties and microstructure, which have been compiled in a very scarce number of reviews, usually focused on one physicochemical property or an application [120-125]. These implications can be divided into three main sub-subjects: water in the bulk, at the interface and in confinement, with most of the reports on the first topic.

In the bulk water, the electrical conductivity generally increases with increasing water concentration, until it reaches a maximum value at considerable high IL dilution $\left(\sim 0.9 \mathrm{x}_{\mathrm{w}}\right)$, followed by a decrease to values similar to "pure water", Figure 18 [61,126]. This behaviour is divergent from aqueous salts solutions, e.g., $\mathrm{NaCl}$ and $\mathrm{NaOH}$, which show an almost linear electrical conductivity decrease with the increase in water content. The increase in electrical conductivity with the increase in water content can be particularly explained by two factors: the decrease in the mixture viscosity allows higher ion mobility; the other is the segregation of water molecules into clusters that allow the ions to move freely. The conductivity decrease observed in the water-rich domain results from the dispersion of the charge carriers in the media. 


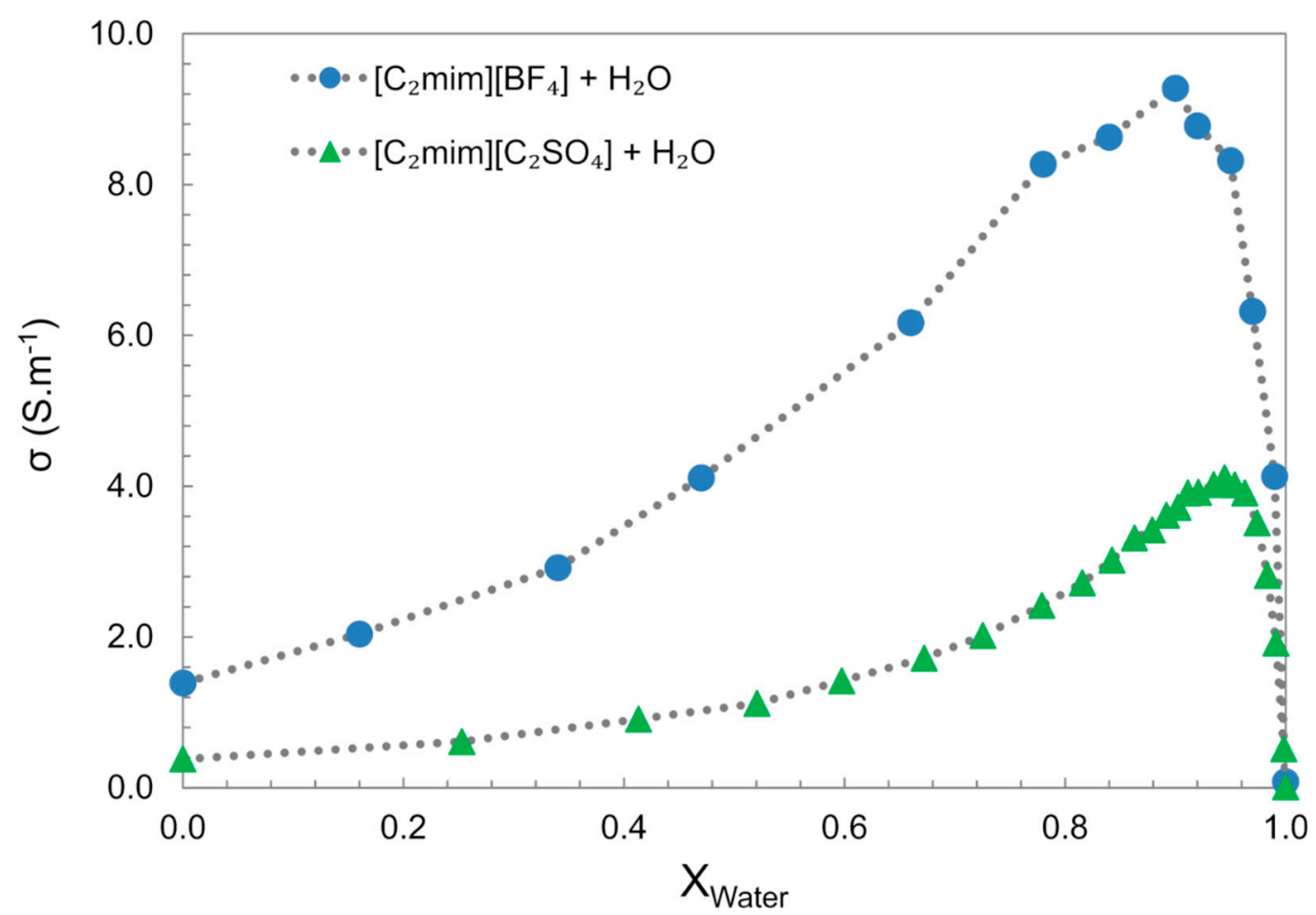

Figure 18. Electrical conductivity $(\sigma)$ of $\left[\mathrm{C}_{2} \mathrm{mim}\right]\left[\mathrm{C}_{2} \mathrm{SO}_{4}\right]+$ water and $\left[\mathrm{C}_{2} \mathrm{mim}\right]\left[\mathrm{BF}_{4}\right]+$ water at $298 \mathrm{~K}$. Data from references [61,126].

Viscosity is very sensitive to impurities in the system, with ILs showing tremendous viscosity changes even in the presence of small amounts of water. In most cases, water addition induces a decrease in the viscosity of the system. As an example, for $\left[\mathrm{C}_{2} \mathrm{mim}\right]\left[\mathrm{C}_{2} \mathrm{SO}_{4}\right]$, the addition of water induces a decrease in the viscosity showing a greater impact at lower temperatures as depicted in Figure $19[59,60,127]$.

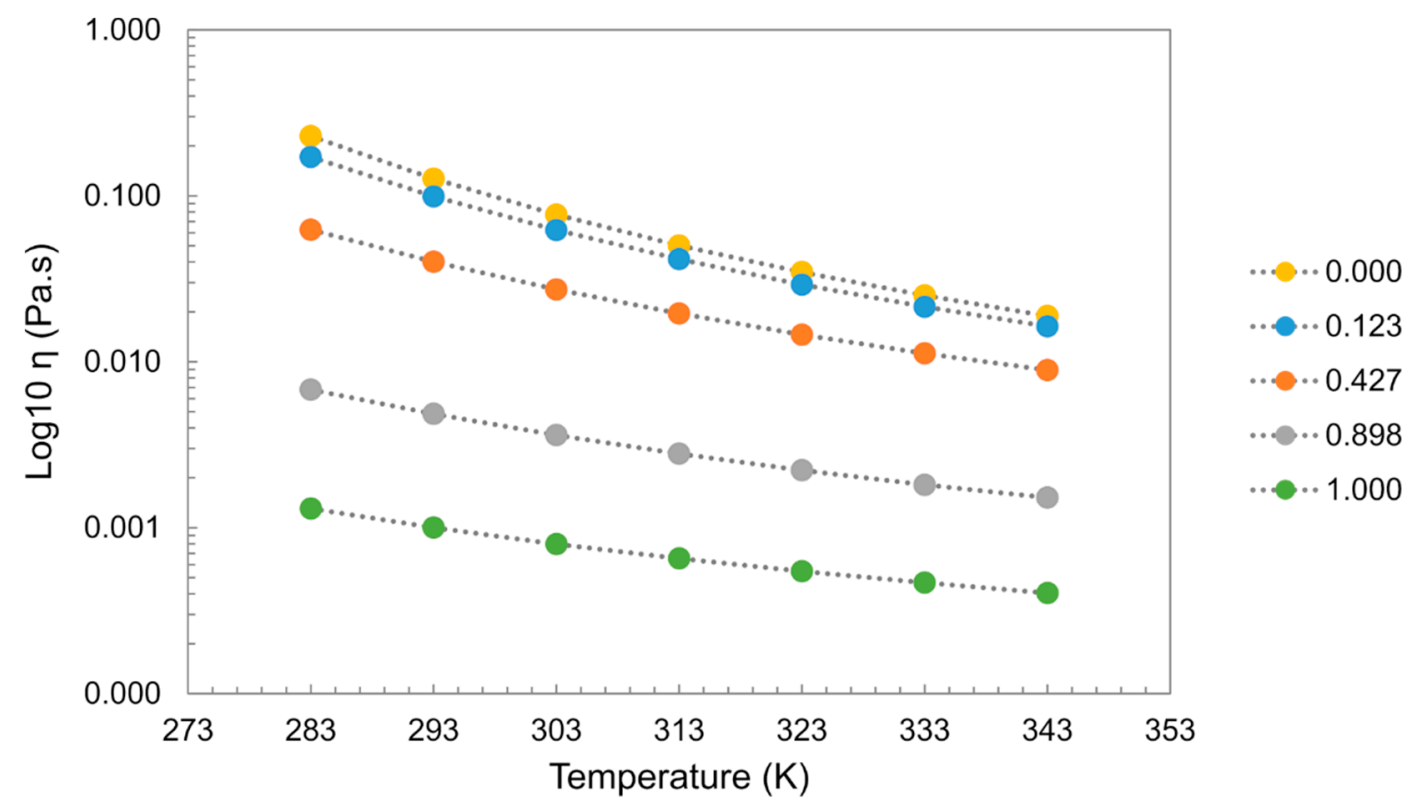

Figure 19. Mixture of $\left[\mathrm{C}_{2}\right.$ mim $]\left[\mathrm{C}_{2} \mathrm{SO}_{4}\right]+\mathrm{H}_{2} \mathrm{O}$. Viscosity $(\eta)$ dependence of temperature $(\mathrm{T})$ and water molar fraction $\left(X_{w}\right)$. Data from references $[59,60,127]$. 
However, there are some exceptions and $\left[\mathrm{C}_{4} \mathrm{mim}\right][\mathrm{Ac}]$ viscosity shows a water content viscosity dependency. Initially, a small water amount (up to $0.02 \mathrm{wt} \%$ ) induces an increase in the viscosity, which decreases with the increase in water addition [128]. By MD simulations, the authors attributed this anomalous behaviour to a water-induced structural change in the IL, with the formation of chain-like

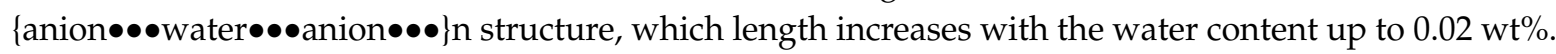
In terms of interactions, there is a hydrogen bond (HB) weakening between ion pairs but the overall balance shows an increase in the global $\mathrm{HB}$ due to water/anion interactions. This phenomenon was not observed for $\left[\mathrm{C}_{4} \mathrm{mim}\right]\left[\mathrm{BF}_{4}\right]$ and $\left[\mathrm{C}_{4} \mathrm{mim}\right]\left[\mathrm{NTF}_{2}\right]$, which by comparative structural analysis between $\left[\mathrm{C}_{4} \mathrm{mim}\right][\mathrm{Ac}]$ and $\left[\mathrm{C}_{4} \mathrm{mim}\right]\left[\mathrm{BF}_{4}\right]$ showed the latter forming a more spherical-type complex, which has higher mobility than the chain structure.

Several experimental methods have been applied to study the structure and dynamics of both neat IL and its mixtures with molecular solvents, particularly for phase-behaviour of water-IL mixtures, from DFT calculations [129-131] and molecular dynamics (MD) simulations [132-134], to spectroscopic techniques like NMR [32,106,135-138], Small-Angle Neutron Scattering (SANS) [139,140], infrared and RAMAN spectroscopy [141-145].

MD simulation has been one of the most widely used and has assumed an essential role in understanding the molecular interactions in ILs, particularly the anomalous phenomena observed in the macroscopic properties both for neat and IL-molecular solvent mixtures. Since the early work by the Lynden-Bell group [146,147] and also the Maginn group [148,149] several theoretical studies have been reported for ILs, both in neat and as molecular solvents mixtures, see for instance reviews [32,120,121,132,150,151] and book chapter [152] and references therein. It is important to highlight that most of the work has been focused on imidazolium-based ILs, with preponderance for $\left[\mathrm{BF}_{4}\right]^{-}$and $\left[\mathrm{PF}_{6}\right]^{-}$anions.

One of the earliest studies for IL-water mixtures by Hanke and Lynden-Bell, compared a hydrophilic $\left(\left[\mathrm{C}_{1} \mathrm{mim}\right] \mathrm{Cl}\right.$ and a hydrophobic $\left(\left[\mathrm{C}_{1} \mathrm{mim}\right]\left[\mathrm{PF}_{6}\right]\right)$ IL. They showed that at low water concentrations the water molecules are isolated or in small clusters [146]. Above $75 \%$ water molar ratio, there is a combination of percolating water, small clusters and isolated water. The main differences between the systems were on the signal of the excess volume, and the molecular motion behaviour (both rotational and translational), however the motion for both ILs becomes faster with the increasing amount of water. By Far-infrared (FIR) spectroscopy, Dominguez-Vidal et al. [143] showed for $\left[\mathrm{C}_{2} \mathrm{mim}\right]\left[\mathrm{BF}_{4}\right]$, $\left[\mathrm{C}_{4} \mathrm{mim}\right]\left[\mathrm{BF}_{4}\right]$ and $\left[\mathrm{C}_{4} \mathrm{mim}\right]\left[\mathrm{PF}_{6}\right]$ water mixtures, at different concentrations, that water molecules bind more strongly to $\left[\mathrm{BF}_{4}\right]^{-}$-based ILs (hydrophilic) than to $\left[\mathrm{PF}_{6}\right]^{-}$(hydrophobic). The interaction between monomeric water and the anions is absent in $\left[\mathrm{C}_{4} \mathrm{mim}\right]\left[\mathrm{PF}_{6}\right]$ aqueous solution IR spectra, indicating that the water $/\left[\mathrm{PF}_{6}\right]^{-}$interaction is very weak, which is in agreement with DFT calculations that showed that $\left[\mathrm{PF}_{6}\right]^{-}$anions could not form stable complexes with water, opposite to $\left[\mathrm{BF}_{4}\right]^{-}$[153].

Bernardes et al. [154] studied $\left[\mathrm{C}_{2}\right.$ mim] $]\left[\mathrm{C}_{2} \mathrm{SO}_{4}\right]+\mathrm{H}_{2} \mathrm{O}$ system and identified four distinct solution regimes (Figure 20):

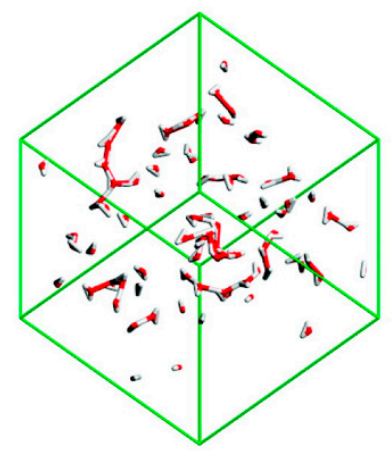

a)

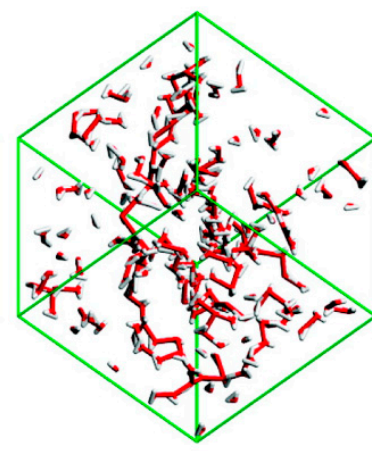

b)

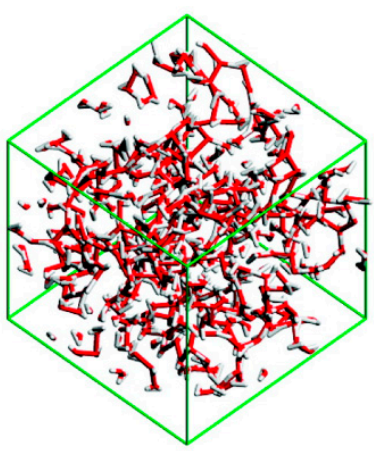

c)

Figure 20. Snapshot images of the water clusters in simulation boxes with (a) $x_{\mathrm{H}_{2} \mathrm{O}}=0.5$, (b) $x_{\mathrm{H}_{2} \mathrm{O}}=0.8$, and (c) $x_{\mathrm{H}_{2} \mathrm{O}}=0.92$. Fully reproduced image from reference [154]. 
For $x_{\mathrm{H}_{2} \mathrm{O}} \leq 0.5$, water molecules are either isolated or in small chain-like clusters;

For $0.5<x_{\mathrm{H}_{2} \mathrm{O}}<0.8$, the water molecules are surrounded by two or less water molecules, suggesting the formation of linear chains. These chains grow and start to entangle the IL polar network;

For $0.8<x_{\mathrm{H}_{2} \mathrm{O}}<$ between 0.8 and 0.95 , the water molecules transition from a chain-like aggregate to a 3D web network, forming with the IL two distinct continuous networks;

$x_{\mathrm{H}_{2} \mathrm{O}}<0.95$, the polar network of the IL starts to break into smaller aggregates and loses its continuous nature. Water molecules begin to experience levels of connectivity similar to that found for pure water.

Trinidad Méndez-Morales et al. [155] performed extensive MD simulations to investigate the structure and some dynamic properties of aqueous mixtures of the hydrophobic family $\left[\mathrm{C}_{\mathrm{n}} \mathrm{mim}\right]\left[\mathrm{PF}_{6}\right]$ and hydrophilic $\left[C_{n}\right.$ mim $][\mathrm{Cl}]$ and $\left[C_{n} \operatorname{mim}\right][\mathrm{Br}](n=2,4,6$ or 8$)$. The authors stated that water tends to cluster in the IL cavities inside the IL polar domains, in which the structuring role of water in the system strongly depends on the hydrophobicity degree of both the cation and the anion, but most strongly from the latter, showing a higher degree of water clustering with the increase in the hydrophobic character of the system $[155,156]$. These water clusters were labelled as "water-pocket" or "confined water" (non-bulk water) into the IL framework. At low water content, most of the macroscopic properties are virtually unaffected, with a slight increase in the self-diffusion and a decrease in the viscosity.

Extensive experiments have been carried out to probe the existence of water pockets. Small-angle neutron scattering (SANS) measurements enable the analysis of the distribution of deuterated water between being molecularly dissolved and microphase separated, upon mixture with ILs.

Abe et al. $[157,158]$ used a complementary methodology of SANS and Small-angle X-ray scattering (SAXS) to study the water-rich regions of $\left[\mathrm{C}_{4} \mathrm{mim}\right]\left[\mathrm{NO}_{3}\right],[\mathrm{DEME}]\left[\mathrm{BF}_{4}\right]$ and $[\mathrm{DEME}]\left[\mathrm{NO}_{3}\right]$ $\left(\mathrm{DEME}=\mathrm{N}, \mathrm{N}\right.$-diethyl- $\mathrm{N}$-methyl- $\mathrm{N}$-(2-methoxyethyl) ammonium) aqueous solutions, $70-90 \mathrm{~mol} \% \mathrm{D}_{2} \mathrm{O}$. For the imidazolium-based IL, they identified the presence of water pockets, with an average size of 20 $\AA$, which were not present in $[\mathrm{DEME}]\left[\mathrm{BF}_{4}\right]$ and $[\mathrm{DEME}]\left[\mathrm{NO}_{3}\right]$, suggesting that cation interactions can be responsible in the control of water pocket formation.

Focusing on the hydrophilic IL $\left[\mathrm{C}_{4} \mathrm{mim}\right]\left[\mathrm{BF}_{4}\right]$, Gao and Wagner [119] investigated the microstructure of the IL rich region of IL/deuterated water mixture by SANS. The authors claimed the existence of three water content domains (Figure 21). Up to 2:1 water:IL mol ratio $\left(x_{w}=0.66\right)$, the water molecules are lodged in the IL polar network, interacting with cations and anions by hydrogen bonds, without any significant change in the microstructure of the IL. Further addition of water $\mathrm{x}_{\mathrm{W}} \sim 0.7$ results in the formation of clusters, whose size increases with the addition of $\mathrm{D}_{2} \mathrm{O}$, forming a partition between water in the dissolved state and a microphase separated state. Above $\sim 80 \% \mathrm{~mol}$, a phase inversion occurs, forming IL aggregates.

The properties of water confined in $\left[\mathrm{C}_{4} \mathrm{mim}\right]\left[\mathrm{BF}_{4}\right]$ have also been investigated by NMR. Saihara and co-authors [118] followed up the SAXS and SANS studies reported by the same research group (vide Abe et al. described above [157]), using partially deuterated water (HOD, a 1:1 mixture of $\mathrm{H}_{2} \mathrm{O}$ and $\mathrm{D}_{2} \mathrm{O}$ ) as a probe to explore the state of the water molecules inside the IL framework in a water/IL mixture $\left(\mathrm{IL}=\left[\mathrm{C}_{4} \mathrm{mim}\right]\left[\mathrm{BF}_{4}\right]\right.$ and $\left.[\mathrm{DEME}]\left[\mathrm{BF}_{4}\right]\right)$. The authors acquired ${ }^{1} \mathrm{H}$ NMR spectra of IL + partially deuterated water mixtures (50 mol\% water) (Figure 22), which showed that the water signals split into two distinct peaks, corresponding to $\mathrm{HOD}$ and $\mathrm{H}_{2} \mathrm{O}$. In solution, the ${ }^{1} \mathrm{H}$ NMR spectrum of a mixture of $\mathrm{H}_{2} \mathrm{O}: \mathrm{D}_{2} \mathrm{O}(1: 1)$ shows only one peak due to the fast $\mathrm{H} / \mathrm{D}$ exchange, hence the presence of IL decreases the exchange rate among the water molecules in the IL to a very slow exchange regime. The authors attributed this slowing down to the water experiencing different environments because of water molecules being confined inside IL nanodomains ("water pocket"). 


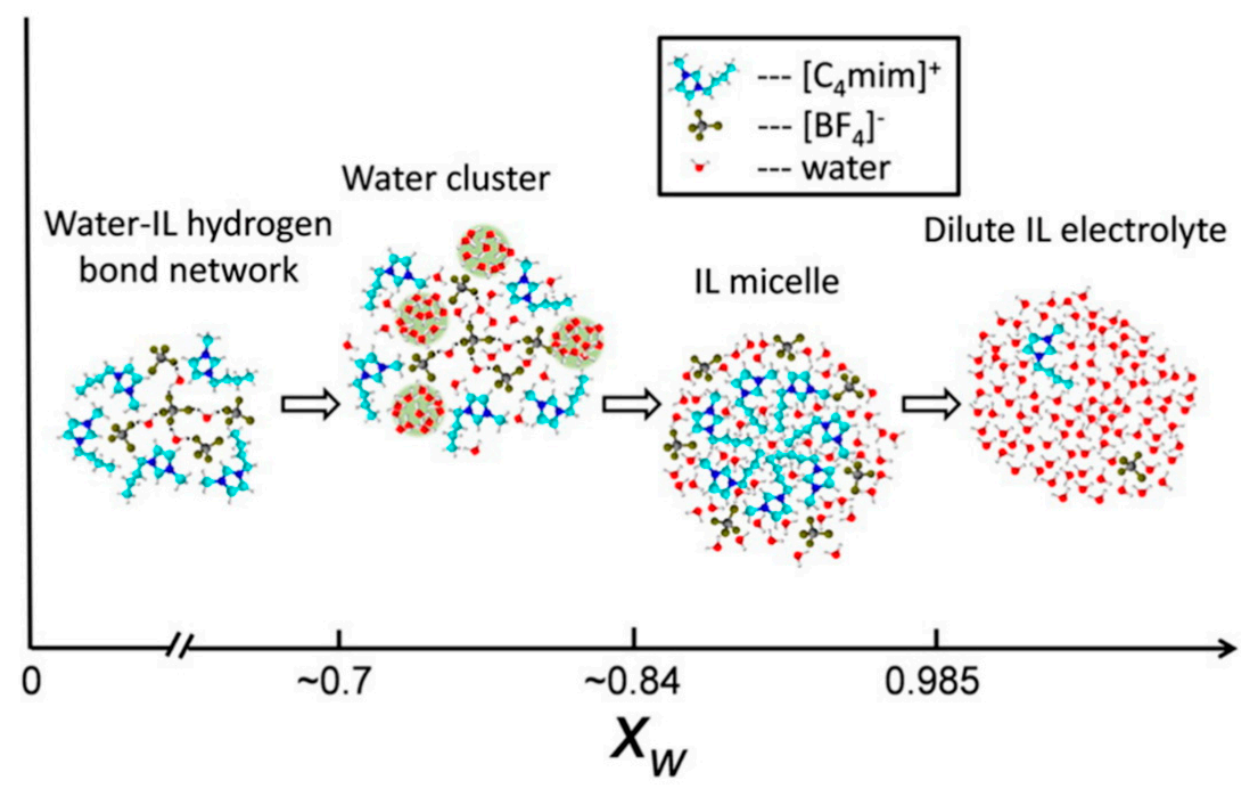

Figure 21. Schematic illustration of structures in mixtures of $\left[\mathrm{C}_{4} \mathrm{mim}\right]\left[\mathrm{BF}_{4}\right]$ and $\mathrm{D}_{2} \mathrm{O}$ determined by small-angle neutron scattering (SANS), fully replicated image from reference [119].
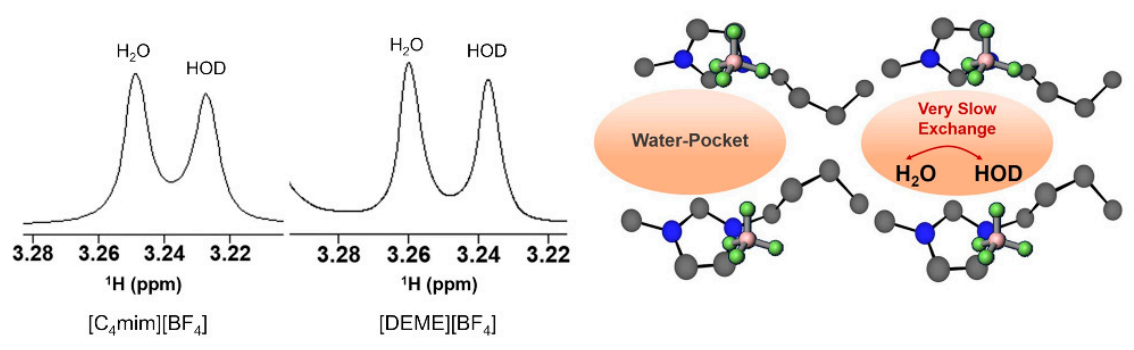

Figure 22. ${ }^{1} \mathrm{H}$ NMR spectra of $50 \mathrm{~mol} \%$ water mixtures of $\left[\mathrm{C}_{4} \mathrm{mim}\right]\left[\mathrm{BF}_{4}\right]$ and $[\mathrm{DEME}]\left[\mathrm{BF}_{4}\right]$. Schematic representation of the "two waters" in $\left[\mathrm{C}_{4} \mathrm{mim}\right]\left[\mathrm{BF}_{4}\right]-50 \mathrm{~mol} \%$ water, from reference [118].

For [DEME] $\left[\mathrm{BF}_{4}\right]$ the authors observed the same behaviour in the ${ }^{1} \mathrm{H}$ NMR spectra, even further changing the partially deuterated water composition in the mixture to $20-90 \% \mathrm{~mol}$, the split signals are observed from the lowest water content up to $80 \%$ mol. [DEME] $\left[\mathrm{BF}_{4}\right]$ has previously been analysed by SANS/SAXS $[157,158]$ with no evidence of water pocket presence, which contradicts the affirmation by Saihara et al. that $\mathrm{HOD} / \mathrm{H}_{2} \mathrm{O}$ peak splitting is an indicator for the existence of "water pockets". This inconsistency was recently pointed out by Bystrov et al. [138], who also added that the presence of split signal from low water content up to $80 \%$ mol contradicts the previous work that stated the presence of water pockets between $70-90 \%$ mol fraction. Additionally, the SANS data show that the water pockets should have a considerable size (average $30 \AA$ ), which corresponds to almost 1000 water molecules, that would be organized in a 3D framework. To obey the slow exchange regime condition, $2 \pi \Delta v t_{e x c} \gg 1$ (where $\Delta v$ is the linewidth variation between the peaks $(\mathrm{Hz})$ and $t_{e x c}$ is the exchange time) the exchange time should be higher than $200 \mathrm{~ms}$, which would be improbable in a 3D structure inside the pocket (pure water exchange time is $\sim 1 \mathrm{~ms}$ ).

In a recent paper by Abe et al. [139], the cation effect in the formation of a water pocket was clarified comparing $\left[\mathrm{C}_{4} \mathrm{mim}\right]\left[\mathrm{NO}_{3}\right]$ with $[\mathrm{DEME}]\left[\mathrm{NO}_{3}\right]$ water mixtures. SANS shows only evidence of "water pockets" formation in the imidazole system. Previous $\left[\mathrm{C}_{4} \mathrm{mim}\right]\left[\mathrm{BF}_{4}\right]$-water $\mathrm{MD}$ simulations showed that molecular interactions between the cation and water molecules have a repulsive nature, which the authors suggested to be the driving force to exclude the water molecules, favouring the existence of "water pockets" (Figure 23). For the [DEME] ${ }^{+}$cation, its structure has an ether group, which would interact with water molecules, that migrate between cation and anion, making it very 
unlikely to form pockets. These data are in agreement with the inconsistencies noted by Bystrov and co-authors [138] on the conclusions by Saihara and co-authors [118]. Hence, the signal splitting of the $\mathrm{HOD} / \mathrm{H}_{2} \mathrm{O}{ }^{1} \mathrm{H}$ NMR chemical shift could explain water pockets, however, it should not exist in [DEME]-IL system. SANS show no water pocket formation and cannot explain the slow-exchange between the different waters.

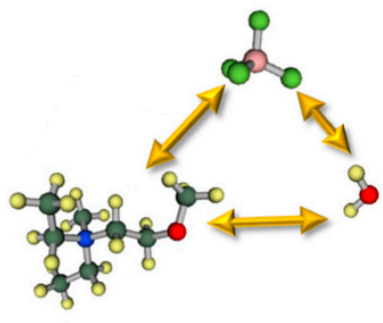

[DEME $^{+}$

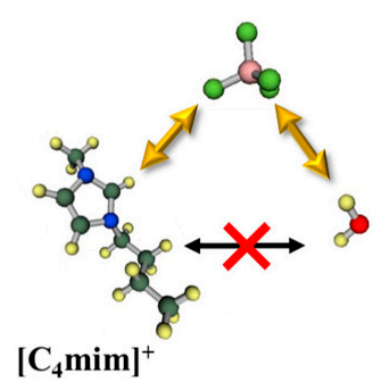

$\left[\mathrm{C}_{4} \mathrm{mim}\right]^{+}$

Figure 23. Molecular interactions of $[D E M E]\left[\mathrm{BF}_{4}\right]-\mathrm{H}_{2} \mathrm{O}$ and $\left[\mathrm{C}_{4} \operatorname{mim}\right]\left[\mathrm{BF}_{4}\right]-\mathrm{H}_{2} \mathrm{O}$. Image fully reproduced from reference [139].

The self-diffusion coefficients can be used to probe the phase behaviour in ILs, both neat and for mixtures. Cascão et al. [106] studied $\left[\mathrm{C}_{4} \mathrm{mim}\right]\left[\mathrm{BF}_{4}\right]+\mathrm{H}_{2} \mathrm{O}$ system by multinuclear NMR approach, to probe in detail the translational and rotational motion of the cation and anion at different water content. The authors identified a critical water composition of $10 \%$ mol water, where the cation and anion share the same self-diffusion coefficients (and therefore share the same hydrodynamic radius) which indicates the presence of a special kind of aggregation or long-lived ion pair/water cluster. Water at this composition has a higher effect on the rotational diffusion of the anion, showing a sharp decrease to values similar to diluted IL. These data suggested that water could be incorporated in the IL nanostructure, allowing water molecules to position close to the cation, competing with the anion to establish interactions with the cation. This leads to the disruption of some cation/anion interactions increasing both the rotational and translational dynamics of the anion.

By MD simulations, Moreno and co-authors [159] studied $\left[\mathrm{C}_{4} \mathrm{mim}\right]\left[\mathrm{BF}_{4}\right]$ and its mixtures with water, concluding that the relative distance of the anion is closer to cations' $\mathrm{H} 2$ (between the two nitrogens of the imidazolium ring) and water molecules, and further away from $\left[\mathrm{C}_{4} \mathrm{mim}\right]^{+}$aliphatic chain. The authors also concluded that by increasing the water concentration, the anions are more dispersed in the aqueous medium than the cations, with the stability of the ionic pair beginning to be affected at $x_{\mathrm{w}}=0.20$.

Bystrov et al. [138] also studied the self-diffusion by pulsed-field gradient-stimulated echo (PFGSTE) NMR and relaxation rates in a set of imidazolium-based ILs $\left(\left[\mathrm{C}_{4} \mathrm{mim}\right][\mathrm{X}],[\mathrm{X}]=\left[\mathrm{BF}_{4}\right]^{-}\right.$, $\left[\mathrm{NO}_{3}\right]^{-},[\mathrm{OTF}]^{-},[\mathrm{Cl}]^{-},[\mathrm{Br}]^{-}$and $[\mathrm{I}]^{-}$) and their aqueous mixtures. The combination of the experimental NMR data with MD simulation studies led the authors to disprove the water pocket model proposed by Saihara, considering as alternative a model where the water molecules are dispersed ("spread") along with the hydrophilic domains of the IL, which could be applied up to $80-90 \%$ water concentration. This model was created based on the well-established heterogeneity of neat ILs, that presents the distribution of polar and non-polar domains, in which the water molecules are dispersed in crevices surrounding the hydrophilic regions of the cations or, mainly, near the anions (Figure 24). This model is very similar to that proposed by Rollet et al. [160] for $\left[\mathrm{C}_{4} \mathrm{mim}\right]\left[\mathrm{NTF}_{2}\right]$ aqueous mixtures based also in PFGSTE NMR, in which the water molecules form thin "streams"|"creeks" as the water concentration increases, with partial segregation between more IL and less IL enriched phases.

As seen by the examples discussed above, the question of how the addition of water correlates to the structural modifications is very complex and instigates a heated scientific debate. Even very recently, two papers, Verma et al. [133] using MD simulations with ab-initio force fields, and Yoshimura et al. [142] using NMR and Raman spectroscopy, formulated a new model for $\left[\mathrm{C}_{4} \mathrm{mim}\right]\left[\mathrm{BF}_{4}\right] /$ water systems at low water content. Both works maintained the idea that at low water content the water is 
"trapped" inside the IL network, with small water clusters characterized by water molecules with three or four hydrogen bonds per molecule, indicating that local structure approaches bulk water like coordination environment.

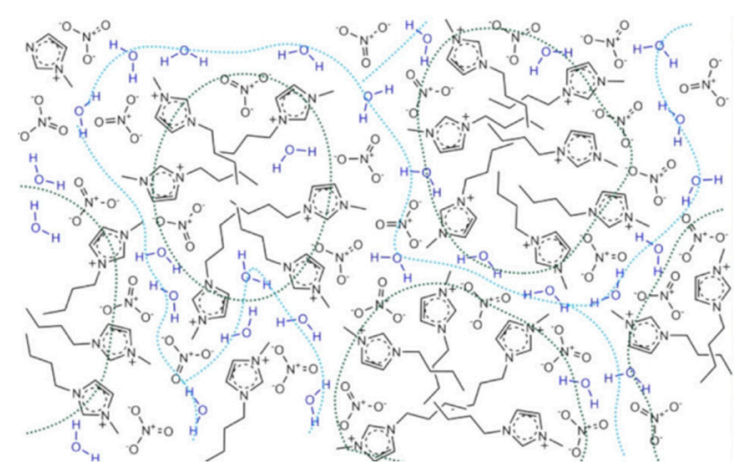

Figure 24. Model proposed by Bystrov et al. [138] of a mixture of IL and water ( $\left.x_{\mathrm{w}} \approx 50 \% \mathrm{~mol}\right)$ The black dotted lines indicate hydrophobic fragments, and the blue ones show the "facilitated" diffusion paths of water molecules. Image edited from [138].

While the amount of experimental data gathered is remarkable, the interpretation has been at least very subjective as seen by the different available models. Although the concept of designing a global model for IL-water mixtures towards the tuning of physicochemical properties for a given application would be a major achievement, this seems a herculean task even focusing on only an IL family.

\section{Conclusions}

Almost 30 years of research on ILs was presented from the perspective of transport properties and their relationship with structure, organization, size and volume.

The local nanostructural organization and the physicochemical properties of ILs are directly related. The intermolecular interactions present in the system are determined by the ion structure and can have a sophisticated organization that is ultimately the result of the balance of the many types of interaction possible between the ions (hydrogen bonds, Van der Waals, etc.). These will determine the interionic distances and structural heterogeneity, and consequently, the existence of aggregates, ion pairs and the free volume.

The phenomenon of ion-pair formation in ILs was addressed and the different definitions of ion-pairs were reviewed. Despite the different definitions that mainly differ in the lifetime and dynamics/identity of the interacting counter ions, it was shown that the transport properties are strongly influenced by the rate of association/disruption of these close interacting cation and anion species.

The importance of the molecular volume (volume of ions) as the main determinant of IL transport properties (viscosity, conductivity, diffusivity) was highlighted and its relation to the free volume was described. It is possible to predict the density, viscosity and conductivity of families of ILs as a function of the molecular volume and the anion type. The volume of the ions and their nature determine the size of the free volume and the way it is distributed inside the liquid (hole volume, $V_{h}$ ).

Several methodologies to estimate IL free volume were reviewed. The free volume can be estimated from the Sanchez-Lacombe equation of state, through the pressure-temperature density dependence. It can also be obtained using the density and molecular volume of the IL (obtained through crystallographic or scaled data). Experimental techniques such as Positron Annihilation Lifetime Spectroscopy can be used to measure/inform the average volume of holes, but is not able to measure the quantity (distribution) of holes and consequently the free volume.

The Cohen and Turnbull equations have been used successfully to correlate transport properties to the free volume of ILs. This has been known for almost five decades for non-functionalized organic solvents. 
In summary, from the literature reviewed here and our own findings, we can highlight the following points:

1. The free volume $\left(V_{f}\right)$ of ionic liquids increases with temperature (isobaric expansion) and decreases with pressure (isothermal compression);

2. The molar volume $(\mathrm{Vm})$ of ILs is associated with the free volume;

3. The free volume is distributed in holes/voids;

4. The size of holes is correlated with the ability of ILs to diffuse and to solubilize gases;

5. The nature of the cation-anion interaction will determine how hole volume $\left(V_{h}\right)$, free volume $\left(V_{f}\right)$ and the ion pair volume $\left(V_{\text {fionpair }}\right)$ will influence the transport properties of liquids.

The water effect in ILs was lightly reviewed in this paper, selecting examples that address the peculiar interactions present in aqueous ILs. Overall, the effect of water in ILs can be summarized into four main regions:

1. Low water content (water in IL; $\mathrm{x}_{\mathrm{H}_{2} \mathrm{O}}<0.1$ ) regime; the water molecules are dispersed in the IL nanostructure, filling the structural holes present in the ILs 3D network, without disrupting it;

2. Intermediate regime $\left(0.2<\mathrm{x}_{\mathrm{H}_{2} \mathrm{O}}<0.8\right)$. Increasing the IL dilution, water starts to aggregate, forming clusters. While the formation of clusters has been accepted by the majority of studies, the shape, size and morphology are still subject to discussion, in which the formation of water "pockets" and creek like structures (water dispersion in IL) are the two main hypotheses, connecting polar domains of the IL;

3. High water regime (IL in water; $0.8<\mathrm{x}_{\mathrm{H}_{2} \mathrm{O}}<0.9$ ). The clusters are partially or totally destroyed, with the ions experiencing a solvent-mediated ion pair, leading to increased spatial associations between ions and, thus, having a strong effect on translational and rotational dynamics of ion species in mixtures;

4. Diluted solutions $\left(\mathrm{x}_{\mathrm{H}_{2} \mathrm{O}}>0.95\right)$. Above this water content, there is an infinite dilution of ILs in water, with the ions fully hydrated, forming a loose ion pair, with physicochemical properties similar to pure water.

5. While the topics of this review have been addressed separately, they cannot be dissociated from one another. In the case of aqueous IL solutions, the heterogeneity and the clustering of water not only affects the physicochemical properties and dynamics but can also be rationalized as a function of the structural organization.

Overall, IL properties were shown to depend on the molecular scale details of structure and dynamics, which are reflected in the intermolecular interactions and can be traced back to aggregate formation, ion-pairing and free volume.

Author Contributions: Conceptualization \& Writing-Original Draft Preparation, W.S.; Writing-Review \& Editing, M.Z.; A.S.F.; M.C.C.; E.J.C.; Supervision, M.C.C. and E.J.C.; Project Administration \& Funding Acquisition, M.C.C. and E.J.C. All authors have read and agreed to the published version of the manuscript.

Funding: This research was funded by Conselho Nacional de Desenvolvimento Científico e Tecnológico (CNPq), grant number 201863/2014-6; FEDER funds through the COMPETE 2020 Program and Fundação para a Ciência e Tecnologia (FCT), Portugal, under projects UIDB/04378/2020 for Applied Molecular Biosciences Unit-UCIBIO and UIDB/50025/2020-2023 for the Institute of Nanostructures, Nanomodeling and Nanofabrication, POCI-01-0145-FEDER-007688, and PTDC/QUI-QFI/31508/2017. The NMR spectrometers at FCT NOVA are part of Rede Nacional de RMN (PTNMR), supported by FCT-(ROTEIRO/0031/2013-PINFRA/22161/2016) co-financed by FEDER through COMPETE 2020, POCI, and PORL and FCT through PIDDAC). The APC was funded by UIDB/04378/2020.

Acknowledgments: W.S. gratefully acknowledges CNPq-Brazil for the PhD grant. M.C.C. gratefully acknowledges PTNMR for the researcher contract. The authors acknowledge Luis Paulo Rebelo and José Esperança for helpful discussions concerning free volume theory.

Conflicts of Interest: The authors declare no conflict of interest. 


\section{Abbreviations}

\section{Symbols}

$\alpha_{p}$

$\delta$

$\eta$

$\rho$

$\sigma$

D

$F_{f v}$

I

$K_{T}$

$M_{w}$

$\mathrm{M}$

$N_{A}$

$T_{C}$

$T_{g}$

$T_{m}$

$V_{h}$

$V_{\text {IonPair }}$

$V_{c}$

$V_{\text {counterion }}$

$V_{i}$

$V_{f}$

$V_{\text {ion }} A^{-}$

$V_{\text {ion }} \mathrm{C}^{+}$

$V_{l}$

$V m$

$V_{o c c}$

$V_{w}$

$x$

General Abbreviations

APIL

API

COSMO-RS

DFT

$E_{\mathrm{HB}}$

$\mathrm{HB}$

EoS

EPR

$\mathrm{Eq}$

FIR

HSE-DD

IC

IL

ImIL

IP

MD

NP

PALS

PGSE

PIL

PCM

Ps isobaric expansivity

chemical shift

viscosity

density

conductivity

self-diffusion

free volume fraction

ionicity

isothermal compressibility

molecular weight

molar concentration

Avogadro number

crystallization temperature

glass transition

melting point

volume of holes

molecular volume of the ion pair

volume of crystal

volume of the counterion

volume interstitial

free volume

volume molecular of anion

volume molecular of cation

volume of liquid

volume molar

volume occupied

Van der Waals volume

molar fraction

Aprotic ionic liquid

Active Pharmaceutical Ingredients

Conductor-like Screening Model for Real Solvents

Density Functional Theory

hydrogen-bonding interaction energy

hydrogen bond

equation of state

electron paramagnetic resonance

equation

Far-infrared

Heisenberg spin exchange-dipole-dipole

ionic cage

ionic liquid

imidazolium-based ionic liquid

ion pair

molecular dynamics

nanoparticles

Positron Annihilation Lifetime Spectroscopy

pulse-field-gradient spin-echo

Protic ionic liquid

polarizable continuum model

positroniums 


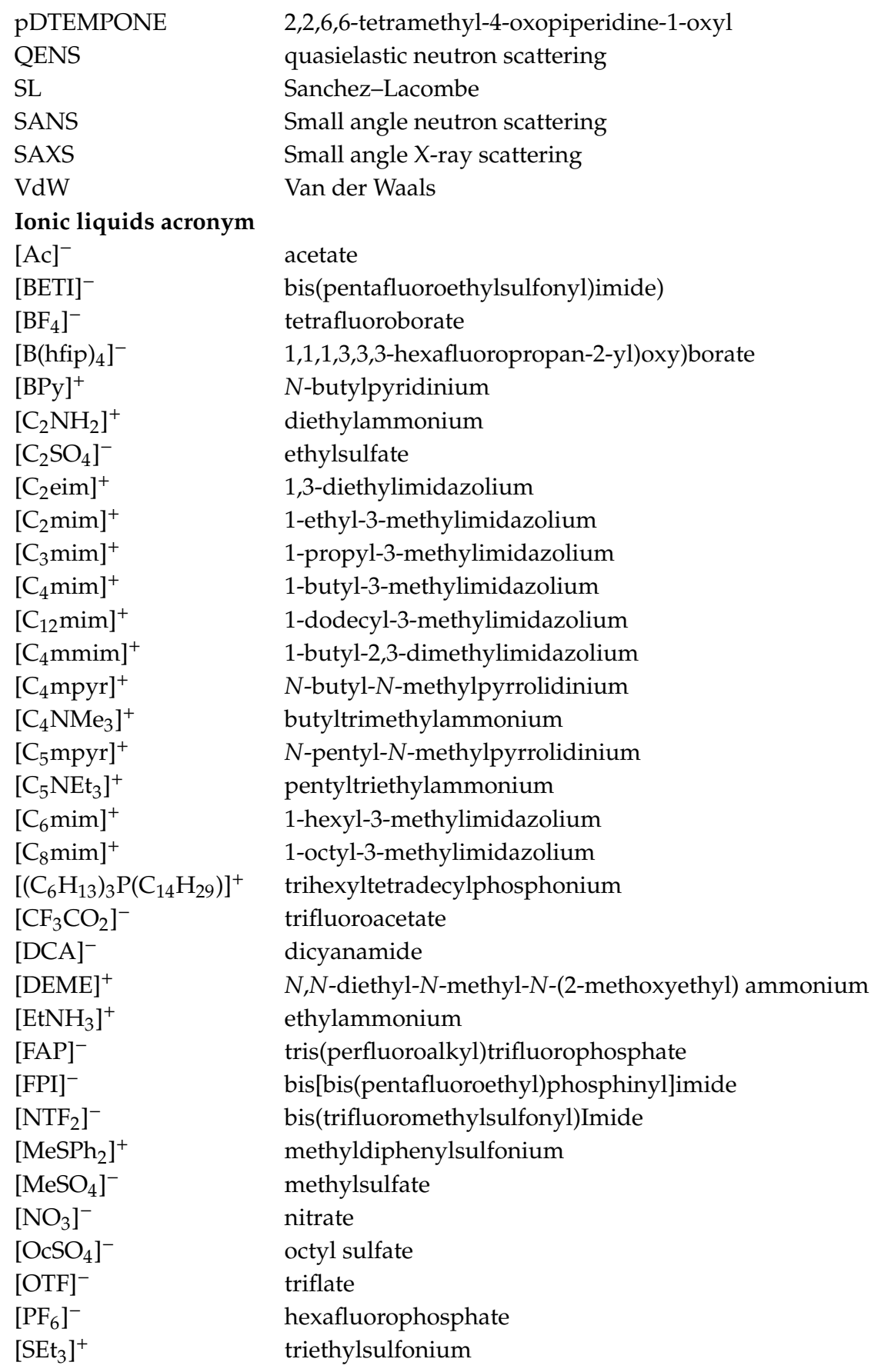

\section{References}

1. Plechkova, N.V.; Seddon, K.R. Applications of ionic liquids in the chemical industry. Chem. Soc. Rev. 2008, 37, 123-150. [CrossRef] [PubMed]

2. Kohno, Y.; Ohno, H. Ionic liquid/water mixtures: From hostility to conciliation. Chem. Commun. 2012, 48, 7119-7130. [CrossRef] [PubMed]

3. Beichel, W.; Yu, Y.; Dlubek, G.; Krause-Rehberg, R.; Pionteck, J.; Pfefferkorn, D.; Bulut, S.; Bejan, D.; Friedrich, C.; Krossing, I. Free volume in ionic liquids: A connection of experimentally accessible observables from PALS and PVT experiments with the molecular structure from XRD data. Phys. Chem. Chem. Phys. 2013, 15, 8821. [CrossRef]

4. Hallett, J.P.; Welton, T. Room-Temperature Ionic Liquids: Solvents for Synthesis and Catalysis. 2. Chem. Rev. 2011, 111, 3508-3576. [CrossRef] [PubMed]

5. Sheldon, R. Catalytic reactions in ionic liquids. Chem. Commun. 2011, 2399-2407. [CrossRef] 
6. Zhang, X.; Zhang, X.; Dong, H.; Zhao, Z.; Zhang, S.; Huang, Y. Carbon capture with ionic liquids: Overview and progress. Energy Environ. Sci. 2012, 5, 6668. [CrossRef]

7. Bernard, F.L.; Duczinski, R.B.; Rojas, M.F.; Fialho, M.C.C.; Carreño, L.Á.; Chaban, V.V.; Vecchia, F.D.; Einloft, S. Cellulose based poly(ionic liquids): Tuning cation-anion interaction to improve carbon dioxide sorption. Fuel 2018, 211, 76-86. [CrossRef]

8. Corvo, M.C.; Sardinha, J.; Casimiro, T.; Marin, G.; Seferin, M.; Einloft, S.; Menezes, S.C.; Dupont, J.; Cabrita, E.J. A Rational Approach to CO2 Capture by Imidazolium Ionic Liquids: Tuning CO2 Solubility by Cation Alkyl Branching. ChemSusChem 2015, 8, 1935-1946. [CrossRef]

9. MacFarlane, D.R.; Tachikawa, N.; Forsyth, M.; Pringle, J.M.; Howlett, P.C.; Elliott, G.D.; Davis, J.H.; Watanabe, M.; Simon, P.; Angell, C.A. Energy applications of ionic liquids. Energy Environ. Sci. 2014, 7, 232-250. [CrossRef]

10. Brandt, A.; Gräsvik, J.; Hallett, J.P.; Welton, T. Deconstruction of lignocellulosic biomass with ionic liquids. Green Chem. 2013, 15, 550. [CrossRef]

11. Passos, H.; Freire, M.G.; Coutinho, J.A.P. Ionic liquid solutions as extractive solvents for value-added compounds from biomass. Green Chem. 2014, 16, 4786-4815. [CrossRef]

12. Ferraz, R.; Branco, L.C.; Prudêncio, C.; Noronha, J.P.; Petrovski, Ž. Ionic Liquids as Active Pharmaceutical Ingredients. ChemMedChem 2011, 6, 975-985. [CrossRef] [PubMed]

13. Marrucho, I.M.; Branco, L.C.; Rebelo, L.P.N. Ionic Liquids in Pharmaceutical Applications. Annu. Rev. Chem. Biomol. Eng. 2014, 5, 527-546. [CrossRef]

14. Lopes, J.N.C.; Rebelo, L.P.N. Ionic liquids and reactive azeotropes: The continuity of the aprotic and protic classes. Phys. Chem. Chem. Phys. 2010, 12, 1948. [CrossRef] [PubMed]

15. Greaves, T.L.; Drummond, C.J. Protic Ionic Liquids: Properties and Applications. Chem. Rev. 2008, 108, 206-237. [CrossRef]

16. Walden, P. Molecular weights and electrical conductivity of several fused salts. Bull. Acad. Imper. Sci. St. Petersburg 1914, 1800, 405-422.

17. Gabriel, S.; Weiner, J. Ueber einige Abkömmlinge des Propylamins. Ber. Dtsch. Chem. Ges. 1888, 21, 2669-2679. (In German) [CrossRef]

18. Wilkes, J.S.; Levisky, J.A.; Wilson, R.A.; Hussey, C.L. Dialkylimidazolium chloroaluminate melts: A new class of room-temperature ionic liquids for electrochemistry, spectroscopy and synthesis. Inorg. Chem. 1982, 21, 1263-1264. [CrossRef]

19. Wilkes, J.S.; Zaworotko, M.J. Air and water stable 1-ethyl-3-methylimidazolium based ionic liquids. J. Chem. Soc. Chem. Commun. 1992, 965. [CrossRef]

20. Morton, M.D.; Hamer, C.K. Ionic liquids-The beginning of the end or the end of the beginning?-A look at the life of ionic liquids through patent claims. Sep. Purif. Technol. 2018, 196, 3-9. [CrossRef]

21. Visser, A.E.; Swatloski, R.P.; Reichert, W.M.; Davis, J.H., Jr.; Rogers, R.D.; Mayton, R.; Sheff, S.; Wierzbicki, A. Task-specific ionic liquids for the extraction of metal ions from aqueous solutions. Chem. Commun. 2001, 135-136. [CrossRef]

22. Davis, J.H. Task-specific ionic liquids. Chem. Lett. 2004, 33, 1072-1077. [CrossRef]

23. Hough, W.L.; Smiglak, M.; Rodríguez, H.; Swatloski, R.P.; Spear, S.K.; Daly, D.T.; Pernak, J.; Grisel, J.E.; Carliss, R.D.; Soutullo, M.D.; et al. The third evolution of ionic liquids: Active pharmaceutical ingredients. New J. Chem. 2007, 31, 1429. [CrossRef]

24. Le, T.; Epa, V.C.; Burden, F.R.; Winkler, D.A. Quantitative Structure-Property Relationship Modeling of Diverse Materials Properties. Chem. Rev. 2012, 112, 2889-2919. [CrossRef] [PubMed]

25. Hayes, R.; Warr, G.G.; Atkin, R. Structure and Nanostructure in Ionic Liquids. Chem. Rev. 2015, 115, 6357-6426. [CrossRef]

26. Amarasekara, A.S. Acidic Ionic Liquids. Chem. Rev. 2016, 116, 6133-6183. [CrossRef]

27. Greaves, T.L.; Drummond, C.J. Protic Ionic Liquids: Evolving Structure-Property Relationships and Expanding Applications. Chem. Rev. 2015, 115, 11379-11448. [CrossRef]

28. Sepehri, B. A review on created QSPR models for predicting ionic liquids properties and their reliability from chemometric point of view. J. Mol. Liq. 2020, 297, 112013. [CrossRef]

29. Hosseini, S.M.; Mulero, A.; Alavianmehr, M.M. Predictive methods and semi-classical Equations of State for pure ionic liquids: A review. J. Chem. Thermodyn. 2019, 130, 47-94. [CrossRef] 
30. Coutinho, J.A.P.; Carvalho, P.J.; Oliveira, N.M.C. Predictive methods for the estimation of thermophysical properties of ionic liquids. RSC Adv. 2012, 2, 7322. [CrossRef]

31. Saielli, G. Bulk Structure Elucidation: Computational Spectroscopy of Ionic Liquids for Bulk Structure Elucidation. Adv. Theory Simul. 2018, 1, 1870026. [CrossRef]

32. Dong, K.; Liu, X.; Dong, H.; Zhang, X.; Zhang, S. Multiscale Studies on Ionic Liquids. Chem. Rev. 2017, 117, 6636-6695. [CrossRef] [PubMed]

33. Tokuda, H.; Hayamizu, K.; Ishii, K.; Susan, M.A.B.H.; Watanabe, M. Physicochemical Properties and Structures of Room Temperature Ionic Liquids. 1. Variation of Anionic Species. J. Phys. Chem. B 2004, 108, 16593-16600. [CrossRef]

34. Tokuda, H.; Hayamizu, K.; Ishii, K.; Susan, M.A.B.H.; Watanabe, M. Physicochemical Properties and Structures of Room Temperature Ionic Liquids. 2. Variation of Alkyl Chain Length in Imidazolium Cation. J. Phys. Chem. B 2005, 109, 6103-6110. [CrossRef]

35. Tokuda, H.; Ishii, K.; Susan, M.A.B.H.; Tsuzuki, S.; Hayamizu, K.; Watanabe, M. Physicochemical Properties and Structures of Room-Temperature Ionic Liquids. 3. Variation of Cationic Structures. J. Phys. Chem. B 2006, 110, 2833-2839. [CrossRef] [PubMed]

36. Tokuda, H.; Tsuzuki, S.; Susan, M.A.B.H.; Hayamizu, K.; Watanabe, M. How Ionic Are Room-Temperature Ionic Liquids? An Indicator of the Physicochemical Properties. J. Phys. Chem. B 2006, 110, 19593-19600. [CrossRef] [PubMed]

37. Jin, H.; O'Hare, B.; Dong, J.; Arzhantsev, S.; Baker, G.A.; Wishart, J.F.; Benesi, A.J.; Maroncelli, M. Physical Properties of Ionic Liquids Consisting of the 1-Butyl-3-Methylimidazolium Cation with Various Anions and the Bis(trifluoromethylsulfonyl)imide Anion with Various Cations. J. Phys. Chem. B 2008, 112, 81-92. [CrossRef]

38. Chen, H.; Chen, X.; Deng, J.; Zheng, J. Isotropic ordering of ions in ionic liquids on the sub-nanometer scale. Chem. Sci. 2018, 9, 1464-1472. [CrossRef]

39. Dong, K.; Song, Y.; Liu, X.; Cheng, W.; Yao, X.; Zhang, S. Understanding Structures and Hydrogen Bonds of Ionic Liquids at the Electronic Level. J. Phys. Chem. B 2012, 116, 1007-1017. [CrossRef]

40. Wang, Y.-L.; Li, B.; Sarman, S.; Mocci, F.; Lu, Z.-Y.; Yuan, J.; Laaksonen, A.; Fayer, M.D. Microstructural and Dynamical Heterogeneities in Ionic Liquids. Chem. Rev. 2020, 120, 5798-5877. [CrossRef]

41. Urahata, S.M.; Ribeiro, M.C.C. Structure of ionic liquids of 1-alkyl-3-methylimidazolium cations: A systematic computer simulation study. J. Chem. Phys. 2004, 120, 1855-1863. [CrossRef] [PubMed]

42. Wang, Y.; Voth, G.A. Unique spatial heterogeneity in ionic liquids. J. Am. Chem. Soc. 2005, 127, 12192-12193. [CrossRef]

43. Wang, Y.; Jiang, W.; Voth, G.A. Spatial heterogeneity in ionic liquids. In ACS Symposium Series; American Chemical Society: Washington, DC, USA, 2007; Volume 975, pp. 272-307.

44. Wang, Y.; Voth, G.A. Molecular dynamics simulations of polyglutamine aggregation using solvent-free multiscale coarse-grained models. J. Phys. Chem. B 2010, 114, 8735-8743. [CrossRef] [PubMed]

45. Canongia Lopes, J.N.A.; Pádua, A.A.H. Nanostructural Organization in Ionic Liquids. J. Phys. Chem. B 2006, 110, 3330-3335. [CrossRef] [PubMed]

46. Dibrov, S.M.; Kochi, J.K. Crystallographic view of fluidic structures for room-temperature ionic liquids: 1-butyl-3-methylimidazolium hexafluorophosphate. Acta Crystallogr. Sect. C Cryst. Struct. Commun. 2006, 62, 19-21. [CrossRef] [PubMed]

47. Fuller, J.; Carlin, R.T.; De Long, H.C.; Haworth, D. Structure of 1-ethyl-3-methylimidazolium hexafluorophosphate: Model for room temperature molten salts. J. Chem. Soc. Chem. Commun. 1994, 299. [CrossRef]

48. Triolo, A.; Russina, O.; Fazio, B.; Triolo, R.; Di Cola, E. Morphology of 1-alkyl-3-methylimidazolium hexafluorophosphate room temperature ionic liquids. Chem. Phys. Lett. 2008, 457, 362-365. [CrossRef]

49. Triolo, A.; Russina, O.; Bleif, H.-J.; Di Cola, E. Nanoscale Segregation in Room Temperature Ionic Liquids. J. Phys. Chem. B 2007, 111, 4641-4644. [CrossRef]

50. Hardacre, C.; Holbrey, J.D.; Mullan, C.L.; Youngs, T.G.A.; Bowron, D.T. Small angle neutron scattering from 1-alkyl-3-methylimidazolium hexafluorophosphate ionic liquids ([Cnmim][PF6], n=4, 6, and 8). J. Chem. Phys. 2010, 133, 074510. [CrossRef]

51. Gordon, C.M.; Holbrey, J.D.; Kennedy, A.R.; Seddon, K.R. Ionic liquid crystals: Hexafluorophosphate salts. J. Mater. Chem. 1998, 8, 2627-2636. [CrossRef] 
52. Dupont, J. From Molten Salts to Ionic Liquids: A “Nano” Journey. Acc. Chem. Res. 2011, 44, $1223-1231$. [CrossRef] [PubMed]

53. Zanatta, M.; dos Santos, F.P.; Biehl, C.; Marin, G.; Ebeling, G.; Netz, P.A.; Dupont, J. Organocatalytic Imidazolium Ionic Liquids H/D Exchange Catalysts. J. Org. Chem. 2017, 82, 2622-2629. [CrossRef] [PubMed]

54. Schulz, P.S.; Müller, N.; Bösmann, A.; Wasserscheid, P. Effective Chirality Transfer in Ionic Liquids through Ion-Pairing Effects. Angew. Chem. Int. Ed. 2007, 46, 1293-1295. [CrossRef] [PubMed]

55. Zanatta, M.; Simon, N.M.; dos Santos, F.P.; Corvo, M.C.; Cabrita, E.J.; Dupont, J. Correspondence on "Preorganization and Cooperation for Highly Efficient and Reversible Capture of Low-Concentration $\mathrm{CO}_{2}$ by Ionic Liquids. " Angew. Chem. Int. Ed. 2019, 58, 382-385. [CrossRef] [PubMed]

56. Simon, N.M.; Zanatta, M.; dos Santos, F.P.; Corvo, M.C.; Cabrita, E.J.; Dupont, J. Carbon Dioxide Capture by Aqueous Ionic Liquid Solutions. ChemSusChem 2017, 10. [CrossRef] [PubMed]

57. Anderson, J.L.; Armstrong, D.W. High-Stability Ionic Liquids. A New Class of Stationary Phases for Gas Chromatography. Anal. Chem. 2003, 75, 4851-4858. [CrossRef] [PubMed]

58. Jin, X.; Yu, H.; Ma, Y. Reversed-phase ion-pair chromatography of hydroxyl functionalized imidazolium ionic liquid cations and its application in analysis of environmental water and measurement of hydrophobicity constants. Microchem. J. 2019, 145, 988-995. [CrossRef]

59. Bhattacharjee, A.; Varanda, C.; Freire, M.G.; Matted, S.; Santos, L.M.N.B.F.; Marrucho, I.M.; Coutinho, J.A.P. Density and Viscosity Data for Binary Mixtures of 1-Alkyl-3-methylimidazolium Alkylsulfates + Water. J. Chem. Eng. Data 2012, 57, 3473-3482. [CrossRef]

60. Gaciño, F.M.; Regueira, T.; Lugo, L.; Comuñas, M.J.P.; Fernández, J. Influence of Molecular Structure on Densities and Viscosities of Several Ionic Liquids. J. Chem. Eng. Data 2011, 56, 4984-4999. [CrossRef]

61. Jarosik, A.; Krajewski, S.R.; Lewandowski, A.; Radzimski, P. Conductivity of ionic liquids in mixtures. J. Mol. Liq. 2006, 123, 43-50. [CrossRef]

62. Borun, A. Conductance and ionic association of selected imidazolium ionic liquids in various solvents: A review. J. Mol. Liq. 2019, 276, 214-224. [CrossRef]

63. Marcus, Y.; Hefter, G. Ion Pairing. Chem. Rev. 2006, 106, 4585-4621. [CrossRef]

64. Hollóczki, O.; Malberg, F.; Welton, T.; Kirchner, B. On the origin of ionicity in ionic liquids. Ion pairing versus charge transfer. Phys. Chem. Chem. Phys. 2014, 16, 16880-16890. [CrossRef] [PubMed]

65. MacFarlane, D.R.; Forsyth, M.; Izgorodina, E.I.; Abbott, A.P.; Annat, G.; Fraser, K. On the concept of ionicity in ionic liquids. Phys. Chem. Chem. Phys. 2009, 11, 4962. [CrossRef]

66. Ueno, K.; Tokuda, H.; Watanabe, M. Ionicity in ionic liquids: Correlation with ionic structure and physicochemical properties. Phys. Chem. Chem. Phys. 2010, 12, 1649. [CrossRef]

67. Cláudio, A.F.M.; Swift, L.; Hallett, J.P.; Welton, T.; Coutinho, J.A.P.; Freire, M.G. Extended scale for the hydrogen-bond basicity of ionic liquids. Phys. Chem. Chem. Phys. 2014, 16, 6593. [CrossRef]

68. Ab Rani, M.A.; Brant, A.; Crowhurst, L.; Dolan, A.; Lui, M.; Hassan, N.H.; Hallett, J.P.; Hunt, P.A.; Niedermeyer, H.; Perez-Arlandis, J.M.; et al. Understanding the polarity of ionic liquids. Phys. Chem. Chem. Phys. 2011, 13, 16831. [CrossRef] [PubMed]

69. Kirchner, B.; Malberg, F.; Firaha, D.S.; Hollóczki, O. Ion pairing in ionic liquids. J. Phys. Condens. Matter 2015, 27. [CrossRef] [PubMed]

70. Del Pópolo, M.G.; Voth, G.A. On the Structure and Dynamics of Ionic Liquids. J. Phys. Chem. B 2004, 108, 1744-1752. [CrossRef]

71. Zhao, W.; Leroy, F.; Heggen, B.; Zahn, S.; Kirchner, B.; Balasubramanian, S.; Müller-Plathe, F. Are There Stable Ion-Pairs in Room-Temperature Ionic Liquids? Molecular Dynamics Simulations of 1-n-Butyl-3-methylimidazolium Hexafluorophosphate. J. Am. Chem. Soc. 2009, 131, 15825-15833. [CrossRef]

72. Zhang, Y.; Maginn, E.J. Direct Correlation between Ionic Liquid Transport Properties and Ion Pair Lifetimes: A Molecular Dynamics Study. J. Phys. Chem. Lett. 2015, 6, 700-705. [CrossRef] [PubMed]

73. Fumino, K.; Stange, P.; Fossog, V.; Hempelmann, R.; Ludwig, R. Equilibrium of contact and solvent-separated ion pairs in mixtures of protic ionic liquids and molecular solvents controlled by polarity. Angew. Chem. Int. Ed. 2013, 52, 12439-12442. [CrossRef]

74. Stassen, H.K.; Ludwig, R.; Wulf, A.; Dupont, J. Imidazolium salt ion Pairs in solution. Chem. Eur. J. 2015, 21, 8324-8335. [CrossRef]

75. Gabl, S.; Steinhauser, O.; Weingärtner, H. From Short-Range to Long-Range Intermolecular NOEs in Ionic Liquids: Frequency Does Matter. Angew. Chem. Int. Ed. 2013, 52, 9242-9246. [CrossRef] [PubMed] 
76. Corvo, M.C.; Sardinha, J.; Menezes, S.C.; Einloft, S.; Seferin, M.; Dupont, J.; Casimiro, T.; Cabrita, E.J. Solvation of carbon dioxide in [c4mim][bf4] and [c4mim][pf6] ionic liquids revealed by high-pressure NMR spectroscopy. Angew. Chem. Int. Ed. 2013, 52, 13024-13027. [CrossRef] [PubMed]

77. Martin, P.-A.; Salager, E.; Forsyth, M.; O’Dell, L.A.; Deschamps, M. On the measurement of intermolecular heteronuclear cross relaxation rates in ionic liquids. Phys. Chem. Chem. Phys. 2018, 20, 13357-13364. [CrossRef]

78. Hu, X.; Lin, Q.; Gao, J.; Wu, Y.; Zhang, Z. Anion-cation and ion-solvent interaction of some typical ionic liquids in solvents with different dielectric constant. Chem. Phys. Lett. 2011, 516, 35-39. [CrossRef]

79. Slattery, J.M.; Daguenet, C.; Dyson, P.J.; Schubert, T.J.S.; Krossing, I. How to Predict the Physical Properties of Ionic Liquids: A Volume-Based Approach. Angew. Chem. Int. Ed. 2007, 46, 5384-5388. [CrossRef]

80. Ye, C.; Shreeve, J.M. Rapid and Accurate Estimation of Densities of Room-Temperature Ionic Liquids and Salts. J. Phys. Chem. A 2007, 111, 1456-1461. [CrossRef]

81. Lei, Z.; Dai, C.; Chen, B. Gas Solubility in Ionic Liquids. Chem. Rev. 2014, 114, 1289-1326. [CrossRef]

82. Yu, Y.; Bejan, D.; Krause-Rehberg, R. Free volume investigation of imidazolium ionic liquids from positron lifetime spectroscopy. Fluid Phase Equilib. 2014, 363, 48-54. [CrossRef]

83. Beichel, W.; Eiden, P.; Krossing, I. Establishing Consistent van der Waals Volumes of Polyatomic Ions from Crystal Structures. ChemPhysChem 2013, 14, 3221-3226. [CrossRef]

84. Brooks, N.J.; Castiglione, F.; Doherty, C.M.; Dolan, A.; Hill, A.J.; Hunt, P.A.; Matthews, R.P.; Mauri, M.; Mele, A.; Simonutti, R.; et al. Linking the structures, free volumes, and properties of ionic liquid mixtures. Chem. Sci. 2017, 8, 6359-6374. [CrossRef]

85. Guerrieri, Y.; Valverde, K.; Nunes Costa, G.M.; Embiruu, M. A Survey of Equations of State for Polymers. In Polymerization; InTech: Rijeka, Croatia, 2012; Volume i, pp. 357-402.

86. Sanchez, I.C.; Lacombe, R.H. Statistical Thermodynamics of Polymer Solutions. Macromolecules 1978, 11, 1145-1156. [CrossRef]

87. Esperança, J.M.S.S.; Guedes, H.J.R.; Blesic, M.; Rebelo, L.P.N. Densities and Derived Thermodynamic Properties of Ionic Liquids. 3. Phosphonium-Based Ionic Liquids over an Extended Pressure Range. J. Chem. Eng. Data 2006, 51, 237-242. [CrossRef]

88. Gonçalves, F.A.M.M.; Costa, C.S.M.F.; Ferreira, C.E.; Bernardo, J.C.S.; Johnson, I.; Fonseca, I.M.A.; Ferreira, A.G.M. Pressure-volume-temperature measurements of phosphonium-based ionic liquids and analysis with simple equations of state. J. Chem. Thermodyn. 2011, 43, 914-929. [CrossRef]

89. Machida, H.; Sato, Y.; Smith, R.L. Pressure-volume-temperature (PVT) measurements of ionic liquids $([\mathrm{bmim}+][\mathrm{PF} 6-],[\mathrm{bmim}+][\mathrm{BF} 4-],[\mathrm{bmim}+][\mathrm{OcSO} 4-])$ and analysis with the Sanchez-Lacombe equation of state. Fluid Phase Equilib. 2008, 264, 147-155. [CrossRef]

90. Tomé, L.I.N.; Gardas, R.L.; Carvalho, P.J.; Pastoriza-Gallego, M.J.; Piñeiro, M.M.; Coutinho, J.A.P. Measurements and Correlation of High-Pressure Densities of Phosphonium Based Ionic Liquids. J. Chem. Eng. Data 2011, 56, 2205-2217. [CrossRef]

91. Shannon, M.S.; Tedstone, J.M.; Danielsen, S.P.O.; Hindman, M.S.; Irvin, A.C.; Bara, J.E. Free Volume as the Basis of Gas Solubility and Selectivity in Imidazolium-Based Ionic Liquids. Ind. Eng. Chem. Res. 2012, 51, 5565-5576. [CrossRef]

92. Doolittle, A.K. Studies in Newtonian Flow. II. The Dependence of the Viscosity of Liquids on Free-Space. J. Appl. Phys. 1951, 22, 1471-1475. [CrossRef]

93. Cohen, M.H.; Turnbull, D. Molecular Transport in Liquids and Glasses. J. Chem. Phys. 1959, 31, 1164-1169. [CrossRef]

94. Turnbull, D.; Cohen, M.H. On the Free-Volume Model of the Liquid-Glass Transition. J. Chem. Phys. 1970, 52, 3038-3041. [CrossRef]

95. Turnbull, D.; Cohen, M.H. Free-volume model of the amorphous phase: Glass transition. J. Chem. Phys. 1961, 34, 120-125. [CrossRef]

96. Cohen, M.H.; Grest, G.S. Liquid-glass transition, a free-volume approach. Phys. Rev. B 1979, 20, 1077-1098. [CrossRef]

97. Macedo, P.B.; Litovitz, T.A. On the Relative Roles of Free Volume and Activation Energy in the Viscosity of Liquids. J. Chem. Phys. 1965, 42, 245-256. [CrossRef]

98. Miller, A.A. "Free Volume" and the Viscosity of Liquid Water. J. Chem. Phys. 1963, 38, 1568-1571. [CrossRef] 
99. Viswanathan, B. Microscopic, Spectroscopic, and Physical Techniques. In Encyclopedia of Materials: Science and Technology; Elsevier: Amsterdam, The Netherlands, 2001; pp. 5661-5666. ISBN 9780080431529.

100. Ismail, A.F.; Khulbe, K.C.; Matsuura, T. RO Membrane Characterization. In Reverse Osmosis; Elsevier: Amsterdam, The Netherlands, 2019; pp. 57-90. ISBN 9780128114681.

101. Yu, Y.; Beichel, W.; Dlubek, G.; Krause-Rehberg, R.; Paluch, M.; Pionteck, J.; Pfefferkorn, D.; Bulut, S.; Friedrich, C.; Pogodina, N.; et al. Free volume and phase transitions of 1-butyl-3-methylimidazolium based ionic liquids from positron lifetime spectroscopy. Phys. Chem. Chem. Phys. 2012, 14, 6856. [CrossRef] [PubMed]

102. Urahata, S.M.; Ribeiro, M.C.C. Single particle dynamics in ionic liquids of 1-alkyl-3-methylimidazolium cations. J. Chem. Phys. 2005, 122, 024511. [CrossRef]

103. Liu, H.; Maginn, E. A molecular dynamics investigation of the structural and dynamic properties of the ionic liquid 1-n-butyl-3-methylimidazolium bis(trifluoromethanesulfonyl)imide. J. Chem. Phys. 2011, 135, 124507. [CrossRef]

104. Merunka, D.; Peric, M. An analysis of radical diffusion in ionic liquids in terms of free volume theory. J. Chem. Phys. 2020, 152, 024502. [CrossRef]

105. Zanatta, M.; Antunes, V.U.; Tormena, C.F.; Dupont, J.; Dos Santos, F.P. Dealing with supramolecular structure for ionic liquids: A DOSY NMR approach. Phys. Chem. Chem. Phys. 2019, 21, 2567-2571. [CrossRef]

106. Cascão, J.; Silva, W.; Ferreira, A.S.D.; Cabrita, E.J. Ion pair and solvation dynamics of [Bmim][BF4] + water system. Magn. Reson. Chem. 2018, 56, 127-139. [CrossRef]

107. Weber, C.C.; Brooks, N.J.; Castiglione, F.; Mauri, M.; Simonutti, R.; Mele, A.; Welton, T. On the structural origin of free volume in 1-alkyl-3-methylimidazolium ionic liquid mixtures: A SAXS and 129 Xe NMR study. Phys. Chem. Chem. Phys. 2019, 21, 5999-6010. [CrossRef]

108. Morgado, P.; Shimizu, K.; Esperança, J.M.S.S.; Reis, P.M.; Rebelo, L.P.N.; Canongia Lopes, J.N.; Filipe, E.J.M. Using 129 Xe NMR to Probe the Structure of Ionic Liquids. J. Phys. Chem. Lett. 2013, 4, 2758-2762. [CrossRef]

109. Castiglione, F.; Simonutti, R.; Mauri, M.; Mele, A. Cage-Like Local Structure of Ionic Liquids Revealed by a 129 Xe Chemical Shift. J. Phys. Chem. Lett. 2013, 4, 1608-1612. [CrossRef] [PubMed]

110. Saielli, G.; Bagno, A.; Castiglione, F.; Simonutti, R.; Mauri, M.; Mele, A. Understanding Cage Effects in Imidazolium Ionic Liquids by 129 Xe NMR: MD Simulations and Relativistic DFT Calculations. J. Phys. Chem. B 2014, 118, 13963-13968. [CrossRef]

111. Bryant, R.G. The NMR time scale. J. Chem. Educ. 1983, 60, 933. [CrossRef]

112. Dong, Q.; Muzny, C.D.; Kazakov, A.; Diky, V.; Magee, J.W.; Widegren, J.A.; Chirico, R.D.; Marsh, K.N.; Frenkel, M. ILThermo: A Free-Access Web Database for Thermodynamic Properties of Ionic Liquids $†$. J. Chem. Eng. Data 2007, 52, 1151-1159. [CrossRef]

113. Di Francesco, F.; Calisi, N.; Creatini, M.; Melai, B.; Salvo, P.; Chiappe, C. Water sorption by anhydrous ionic liquids. Green Chem. 2011, 13, 1712. [CrossRef]

114. Stevanovic, S.; Podgoršek, A.; Pádua, A.A.H.; Costa Gomes, M.F. Effect of Water on the Carbon Dioxide Absorption by 1-Alkyl-3-methylimidazolium Acetate Ionic Liquids. J. Phys. Chem. B 2012, 116, 14416-14425. [CrossRef] [PubMed]

115. Zakrzewska, M.E.; Nunes da Ponte, M. Influence of Water on the Carbon Dioxide Solubility in [OTf]- and [eFAP]-Based Ionic Liquids. J. Chem. Eng. Data 2018, 63, 907-912. [CrossRef]

116. Dyson, P.J.; Ellis, D.J.; Welton, T. A temperature-controlled reversible ionic liquid-water two phase-Single phase protocol for hydrogenation catalysis. Can. J. Chem. 2001, 79, 705-708. [CrossRef]

117. Yu, S.; Jain, P.K. Plasmonic photosynthesis of C1-C3 hydrocarbons from carbon dioxide assisted by an ionic liquid. Nat. Commun. 2019, 10, 2022. [CrossRef]

118. Saihara, K.; Yoshimura, Y.; Ohta, S.; Shimizu, A. Properties of Water Confined in Ionic Liquids. Sci. Rep. 2015, 5, 10619. [CrossRef] [PubMed]

119. Gao, J.; Wagner, N.J. Water Nanocluster Formation in the Ionic Liquid 1-Butyl-3-methylimidazolium Tetrafluoroborate ([C 4 mim][BF 4 ])-D 2 O Mixtures. Langmuir 2016, 32, 5078-5084. [CrossRef]

120. Ma, C.; Laaksonen, A.; Liu, C.; Lu, X.; Ji, X. The peculiar effect of water on ionic liquids and deep eutectic solvents. Chem. Soc. Rev. 2018, 47, 8685-8720. [CrossRef] [PubMed]

121. Foroutan, M.; Fatemi, S.M.; Esmaeilian, F. A review of the structure and dynamics of nanoconfined water and ionic liquids via molecular dynamics simulation. Eur. Phys. J. E 2017, 40, 19. [CrossRef]

122. Podgoršek, A.; Jacquemin, J.; Pádua, A.A.H.; Costa Gomes, M.F. Mixing Enthalpy for Binary Mixtures Containing Ionic Liquids. Chem. Rev. 2016, 116, 6075-6106. [CrossRef] 
123. Mahmood Fatemi, S.; Foroutan, M. Recent findings about ionic liquids mixtures obtained by molecular dynamics simulation. J. Nanostruct. Chem. 2015, 5, 243-253. [CrossRef]

124. Troncoso, J. Isobaric Heat Capacity of Ionic Liquids in Aqueous Solutions. A Review. J. Chem. Eng. Data 2019, 64, 4611-4618. [CrossRef]

125. Tariq, M.; Freire, M.G.; Saramago, B.; Coutinho, J.A.P.; Lopes, J.N.C.; Rebelo, L.P.N. Surface tension of ionic liquids and ionic liquid solutions. Chem. Soc. Rev. 2012, 41, 829-868. [CrossRef] [PubMed]

126. Rilo, E.; Vila, J.; García-Garabal, S.; Varela, L.M.; Cabeza, O. Electrical Conductivity of Seven Binary Systems Containing 1-Ethyl-3-methyl Imidazolium Alkyl Sulfate Ionic Liquids with Water or Ethanol at Four Temperatures. J. Phys. Chem. B 2013, 117, 1411-1418. [CrossRef] [PubMed]

127. Lemmon, E.W.; McLinden, M.O.; Friend, D.G. Thermophysical Properties of Fluid Systems. In NIST Chemistry Webbook; NIST Standard Reference Database No. 69; Linstrom, P.J., Mallard, W.G., Eds.; National Institute of Standards and Technology: Gaithersburg, MD, USA, 1998.

128. Zhou, J.; Liu, X.; Zhang, S.; Zhang, X.; Yu, G. Effect of small amount of water on the dynamics properties and microstructures of ionic liquids. AIChE J. 2017, 63, 2248-2256. [CrossRef]

129. Saielli, G. Computational NMR Spectroscopy of Ionic Liquids: [C4C1im]Cl/Water Mixtures. Molecules 2020, 25, 2085. [CrossRef]

130. Voss, J.M.; Marsh, B.M.; Zhou, J.; Garand, E. Interaction between ionic liquid cation and water: Infrared predissociation study of $[\mathrm{bmim}]+\cdot\left(\mathrm{H}_{2} \mathrm{O}\right) \mathrm{n}$ clusters. Phys. Chem. Chem. Phys. 2016, 18, 18905-18913. [CrossRef] [PubMed]

131. Cammarata, L.; Kazarian, S.G.; Salter, P.A.; Welton, T. Molecular states of water in room temperature ionic liquids. Phys. Chem. Chem. Phys. 2001, 3, 5192-5200. [CrossRef]

132. Varela, L.M.; Méndez-Morales, T.; Carrete, J.; Gómez-González, V.; Docampo-Álvarez, B.; Gallego, L.J.; Cabeza, O.; Russina, O. Solvation of molecular cosolvents and inorganic salts in ionic liquids: A review of molecular dynamics simulations. J. Mol. Liq. 2015, 210, 178-188. [CrossRef]

133. Verma, A.; Stoppelman, J.P.; McDaniel, J.G. Tuning Water Networks via Ionic Liquid/Water Mixtures. Int. J. Mol. Sci. 2020, 21, 403. [CrossRef]

134. Kobayashi, T.; Kemna, A.; Fyta, M.; Braunschweig, B.; Smiatek, J. Aqueous Mixtures of Room-Temperature Ionic Liquids: Entropy-Driven Accumulation of Water Molecules at Interfaces. J. Phys. Chem. C 2019, 123, 13795-13803. [CrossRef]

135. Kaneko, K.; Saihara, K.; Masuda, Y.; Yoshimura, Y.; Shimizu, A. Dynamic properties of water molecules in ionic liquid/water mixture with various alkyl chain length. J. Mol. Liq. 2018, 264, 337-342. [CrossRef]

136. Nanda, R.; Damodaran, K. A review of NMR methods used in the study of the structure and dynamics of ionic liquids. Magn. Reson. Chem. 2018, 56, 62-72. [CrossRef] [PubMed]

137. Murgia, S.; Monduzzi, M.; Lopez, F.; Palazzo, G. Mesoscopic Structure in Mixtures of Water and 1-Butyl-3-methyl imidazolium tetrafluoborate: A Multinuclear NMR Study. J. Solut. Chem. 2013, 42, 1111-1122. [CrossRef]

138. Bystrov, S.S.; Matveev, V.V.; Egorov, A.V.; Chernyshev, Y.S.; Konovalov, V.A.; Balevičius, V.; Chizhik, V.I. Translational Diffusion in a Set of Imidazolium-Based Ionic Liquids [bmim] + A-And Their Mixtures with Water. J. Phys. Chem. B 2019, 123, 9187-9197. [CrossRef] [PubMed]

139. Abe, H.; Takekiyo, T.; Yoshimura, Y.; Shimizu, A. Static and dynamic properties of nano-confined water in room-temperature ionic liquids. J. Mol. Liq. 2019, 290, 111216. [CrossRef]

140. Almásy, L.; Turmine, M.; Perera, A. Structure of Aqueous Solutions of Ionic Liquid 1-Butyl-3methylimidazolium Tetrafluoroborate by Small-Angle Neutron Scattering. J. Phys. Chem. B 2008, 112, 2382-2387. [CrossRef]

141. Jeon, Y.; Sung, J.; Seo, C.; Lim, H.; Cheong, H.; Kang, M.; Moon, B.; Ouchi, Y.; Kim, D. Structures of Ionic Liquids with Different Anions Studied by Infrared Vibration Spectroscopy. J. Phys. Chem. B 2008, 112, 4735-4740. [CrossRef]

142. Yoshimura, Y.; Mori, T.; Kaneko, K.; Nogami, K.; Takekiyo, T.; Masuda, Y.; Shimizu, A. Confirmation of local water structure confined in ionic liquids using H/D exchange. J. Mol. Liq. 2019, 286. [CrossRef]

143. Dominguez-Vidal, A.; Kaun, N.; Ayora-Cañada, M.J.; Lendl, B. Probing Intermolecular Interactions in Water/Ionic Liquid Mixtures by Far-infrared Spectroscopy. J. Phys. Chem. B 2007, 111, 4446-4452. [CrossRef] [PubMed]

144. Kausteklis, J.; Talaikis, M.; Aleksa, V.; Balevičius, V. Raman spectroscopy study of water confinement in ionic liquid 1-butyl-3-methylimidzolium nitrate. J. Mol. Liq. 2018, 271, 747-755. [CrossRef] 
145. Wang, T.-H.; Wu, M.-S.; Chang, H.-C. Characterization of Local Structures of Confined Imidazolium Ionic Liquids in PVdF-co-HFP Matrices by High Pressure Infrared Spectroscopy. Nanomaterials 2020, 10, 1973. [CrossRef]

146. Hanke, C.G.; Lynden-Bell, R.M. A Simulation Study of Water-Dialkylimidazolium Ionic Liquid Mixtures. J. Phys. Chem. B 2003, 107, 10873-10878. [CrossRef]

147. Hanke, C.G.; Price, S.L.; Lynden-Bell, R.M. Intermolecular potentials for simulations of liquid imidazolium salts. Mol. Phys. 2001, 99, 801-809. [CrossRef]

148. Shah, J.K.; Maginn, E.J. Monte Carlo Simulations of Gas Solubility in the Ionic Liquid 1-n-Butyl-3methylimidazolium Hexafluorophosphate. J. Phys. Chem. B 2005, 109, 10395-10405. [CrossRef] [PubMed]

149. Morrow, T.I.; Maginn, E.J. Molecular Dynamics Study of the Ionic Liquid 1-n-Butyl-3-methylimidazolium Hexafluorophosphate. J. Phys. Chem. B 2002, 106, 12807-12813. [CrossRef]

150. Koishi, T. Molecular Dynamics Study of the Effect of Water on Hydrophilic and Hydrophobic Ionic Liquids. J. Phys. Chem. B 2018, 122, 12342-12350. [CrossRef]

151. Dhakal, P.; Shah, J.K. Recent advances in molecular simulations of ionic liquid-ionic liquid mixtures. Curr. Opin. Green Sustain. Chem. 2019, 18, 90-97. [CrossRef]

152. Kirchner, B. Ionic Liquids from Theoretical Investigations. In Ionic Liquids; Kirchner, B., Ed.; Springer: Berlin/Heidelberg, Germany, 2008; pp. 213-262. ISBN 978-3-642-01780-3.

153. Wang, Y.; Li, H.; Han, S. A Theoretical Investigation of the Interactions between Water Molecules and Ionic Liquids. J. Phys. Chem. B 2006, 110, 24646-24651. [CrossRef]

154. Bernardes, C.E.S.; Minas da Piedade, M.E.; Canongia Lopes, J.N. The Structure of Aqueous Solutions of a Hydrophilic Ionic Liquid: The Full Concentration Range of 1-Ethyl-3-methylimidazolium Ethylsulfate and Water. J. Phys. Chem. B 2011, 115, 2067-2074. [CrossRef]

155. Méndez-Morales, T.; Carrete, J.; Cabeza, O.; Gallego, L.J.; Varela, L.M. Molecular Dynamics Simulation of the Structure and Dynamics of Water-1-Alkyl-3-methylimidazolium Ionic Liquid Mixtures. J. Phys. Chem. B 2011, 115, 6995-7008. [CrossRef]

156. Abe, H.; Takekiyo, T.; Yoshimura, Y.; Saihara, K.; Shimizu, A. Anomalous Freezing of Nano-Confined Water in Room-Temperature Ionic Liquid 1-Butyl-3-Methylimidazolium Nitrate. ChemPhysChem 2016, 17, 1136-1142. [CrossRef]

157. Abe, H.; Takekiyo, T.; Shigemi, M.; Yoshimura, Y.; Tsuge, S.; Hanasaki, T.; Ohishi, K.; Takata, S.; Suzuki, J. Direct Evidence of Confined Water in Room-Temperature Ionic Liquids by Complementary Use of Small-Angle X-ray and Neutron Scattering. J. Phys. Chem. Lett. 2014, 5, 1175-1180. [CrossRef] [PubMed]

158. Abe, H.; Takekiyo, T.; Shigemi, M.; Yoshimura, Y.; Tsuge, S.; Hanasaki, T.; Ohishi, K.; Takata, S.; Suzuki, J. Size-tunable Confined Water in a Room Temperature Ionic Liquid. In Proceedings of the 2nd International Symposium on Science at J-PARC - Unlocking the Mysteries of Life, Matter and the Universe, Tsukuba, Japan, 12-15 July 2014. [CrossRef]

159. Moreno, M.; Castiglione, F.; Mele, A.; Pasqui, C.; Raos, G. Interaction of Water with the Model Ionic Liquid [bmim][BF 4 ]: Molecular Dynamics Simulations and Comparison with NMR Data. J. Phys. Chem. B 2008, 112, 7826-7836. [CrossRef] [PubMed]

160. Rollet, A.-L.; Porion, P.; Vaultier, M.; Billard, I.; Deschamps, M.; Bessada, C.; Jouvensal, L. Anomalous Diffusion of Water in [BMIM][TFSI] Room-Temperature Ionic Liquid. J. Phys. Chem. B 2007, 111, 11888-11891. [CrossRef] [PubMed]

Publisher's Note: MDPI stays neutral with regard to jurisdictional claims in published maps and institutional affiliations.

(C) 2020 by the authors. Licensee MDPI, Basel, Switzerland. This article is an open access article distributed under the terms and conditions of the Creative Commons Attribution (CC BY) license (http://creativecommons.org/licenses/by/4.0/). 